\title{
Morphology of the spermatheca in the Cydnidae (Hemiptera: Heteroptera): Bearing of its diversity on classification and phylogeny
}

\author{
DominiQUe PLUOT-SIGWALT ${ }^{1}$ and JERZY A. LIS ${ }^{2}$ \\ ${ }^{1}$ Biologie et Évolution des Insectes, École Pratique des Hautes Études et Muséum National d'Histoire Naturelle, 45 rue Buffon, \\ F-75005 Paris, France; e-mail: dps@mnhn.fr \\ ${ }^{2}$ Department of Biosystematics, Division of Invertebrate Zoology, University of Opole, Oleska 22, PL-45-052 Opole, Poland; \\ e-mail: cydnus@uni.opole.pl
}

Key words. Heteroptera, Pentatomomorpha, Pentatomoidea, Cydnidae, Amaurocorinae stat. n., vaginal structures, spermatheca, parietovaginal gland, ring sclerite, fecundation canal, morphology, classification, phylogeny

\begin{abstract}
Cuticular parts of the spermatheca and associated vaginal structures (chiefly the ring sclerites of the parietovaginal glands) have been examined and compared in 190 cydnid species representing 65 genera and all five subfamilies currently recognized in the family (Amnestinae, Cephalocteinae, Cydninae, Garsauriinae, Sehirinae). Four species belonging to genera formerly included within the Cydnidae (Dismegistus, Parastrachia, Thaumastella, Thyreocoris) were also examined. Morphology of the three main parts of the spermatheca [seminal receptacle (distal bulb), intermediate part (pump apparatus), spermathecal duct] is described. Four main types of spermathecae can be recognized from the distal receptacle and the intermediate part: the amaurocorine type (in Sehirinae: Amaurocorini), amnestine type (in Amnestinae), garsauriine type (in Garsauriinae), and "cydnoid" type (in Cephalocteinae + Cydninae: Cydnini, Geotomini + Sehirinae: Sehirini). No synapomorphy of these types was found which suggests that the currently conceived Cydnidae are not monophyletic. Moreover, out of these four types only the "cydnoid" is typically pentatomoidean due to the presence of an intermediate part usually well delimited by two flanges and having always an unsclerotized flexible zone as well as two internal cuticular structures (septum and fretum) partly obstructing the lumen. The simple tubular amaurocorine type is unusual and aberrant within all Pentatomoidea. The amnestine and garsauriine types display some similarities with taxa outside the Pentatomoidea, especially with some lygaeoid or coreoid spermathecae, mainly in the structure of the intermediate part not delimited proximally (absence of flanges) and devoid of the flexible zone. Within the "cydnoid" type, six spermathecal facies can be characterized principally according to the shape of both the apical reservoir along with the intermediate part, and the differentiations of the spermathecal duct. It has been impossible to find any synapomorphy for all species and for the six facies belonging to the "cydnoid" type of spermatheca. We suggest that the Cydnidae as defined presently are probably a polyphyletic group; moreover its main "cydnoid" branch, called by us Cydnidae sensu stricto (Cephalocteinae + Cydninae + Sehirinae: Sehirini) seems to be relatively recent among the Pentatomoidea. Nishadana and Nishocoris are transferred from Garsauriinae back to Cydninae: Cydnini and the tribe Amaurocorini (Sehirinae) is upgraded to a separate subfamily Amaurocorinae stat. nov. Moreover, we regard the Geotomini and the Sehirini both as non-monophyletic and we indicate that by appending them sensu lato (Geotomini "s. 1.", Sehirini "s. 1.")
\end{abstract}

\section{Contents}

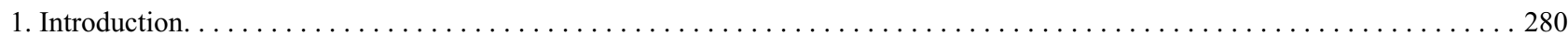

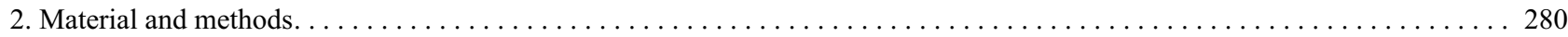

3. General structure of the cydnid spermatheca. Definition and terminology $\ldots \ldots \ldots \ldots \ldots \ldots \ldots \ldots \ldots \ldots \ldots \ldots \ldots \ldots \ldots$

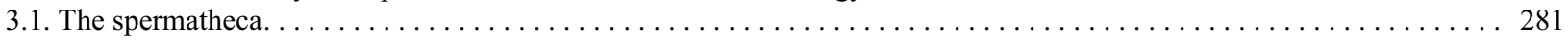

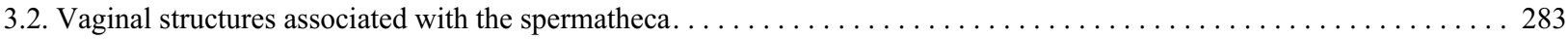

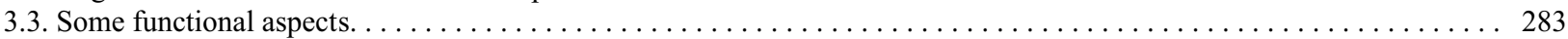

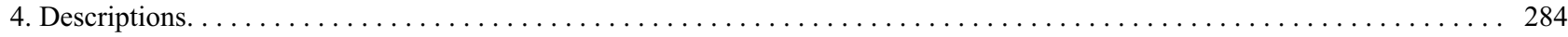

4.1. Amnestinae Hart. . . . . . . . . . . . . . . . . . . . . . . . . . . . . . . . . . . . . . . . . . . . . . . . . . . 284

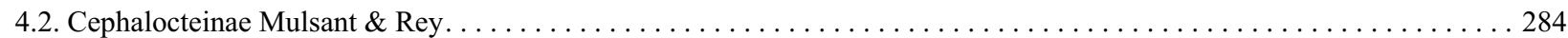

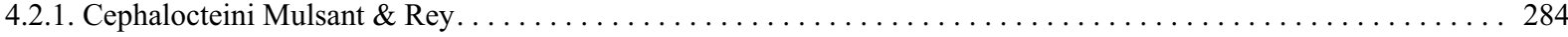

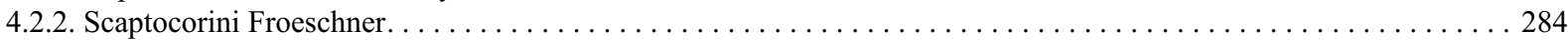

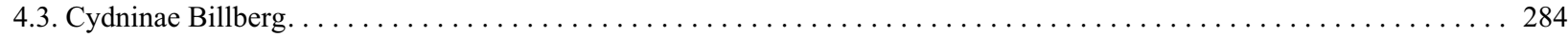

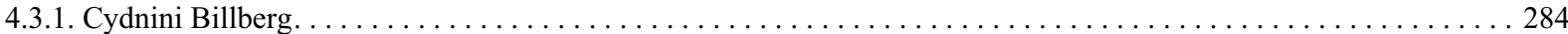

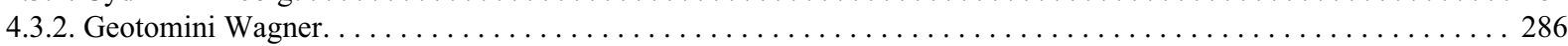

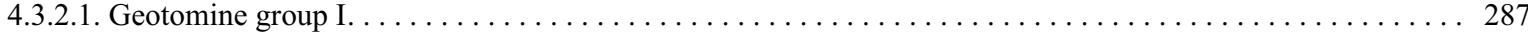

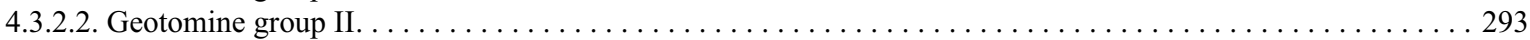

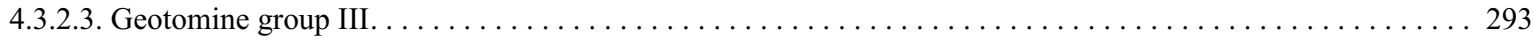

4.4. Garsauriinae Froeschner. . . . . . . . . . . . . . . . . . . . . . . . . . . . . . . . . . . . . . . . . . . . . . 294

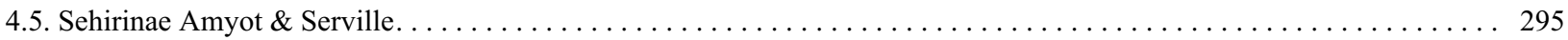

4.5.1. Amaurocorini Wagner. .................................................. 295

4.5.2. Sehirini Amyot \& Serville. . . . . . . . . . . . . . . . . . . . . . . . . . . . . . . . . . . . . . . 296

4.6. Genera formerly included within Cydnidae: Dismegistus, Parastrachia, Thaumastella, Thyreocoris. .......... 298 


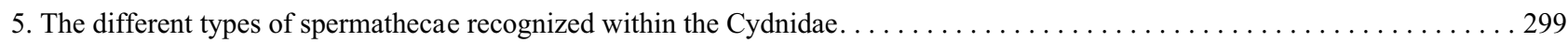

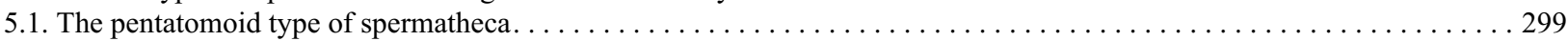

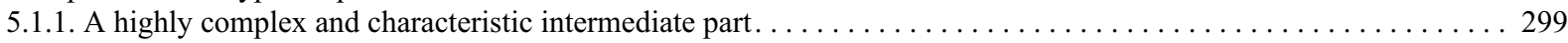

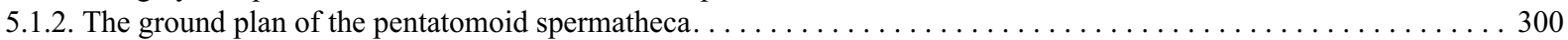

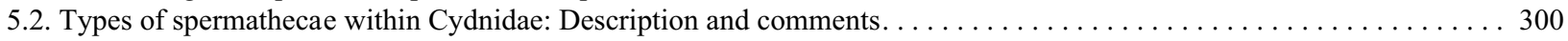

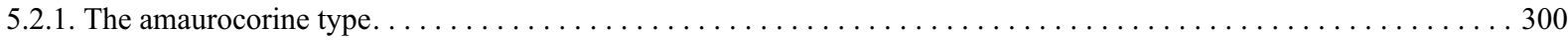

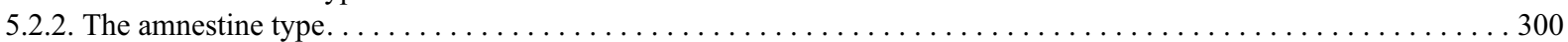

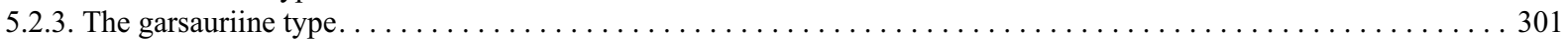

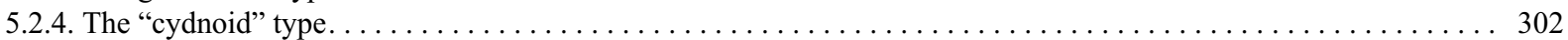

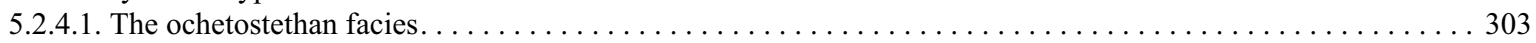

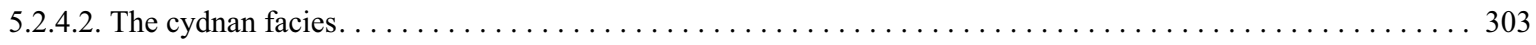

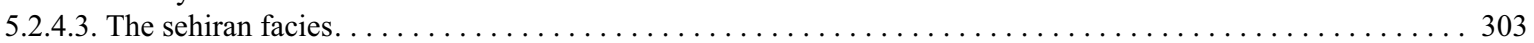

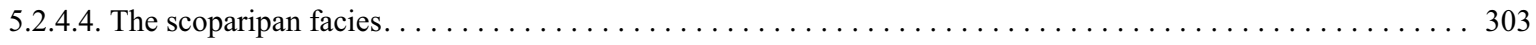

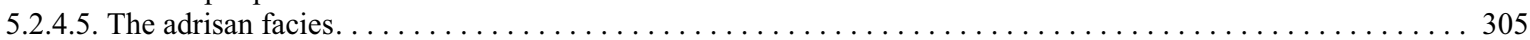

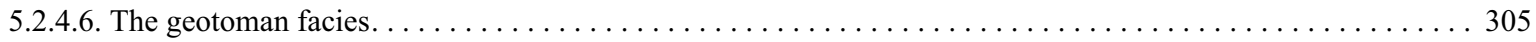

5.3. Spermathecal structures in Dismegistus, Parastrachia, Thaumastella and Thyreocoris............... 305

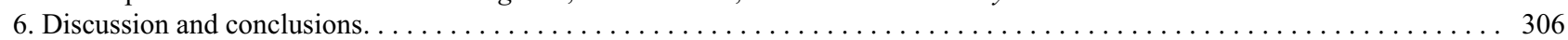

6.1. Potential phylogenetic importance of the cydnid spermathecae in Cydnidae. . . . . . . . . . . . . . . . 306

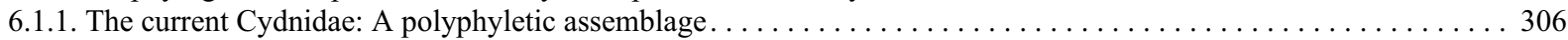

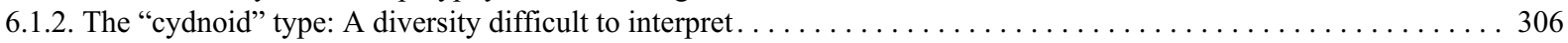

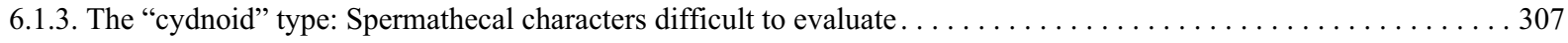

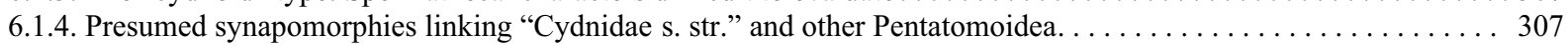

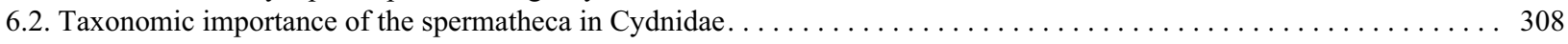

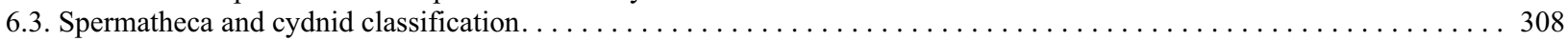

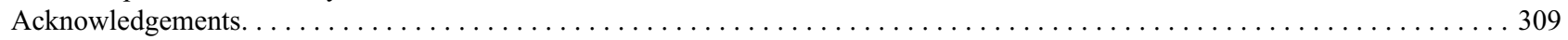

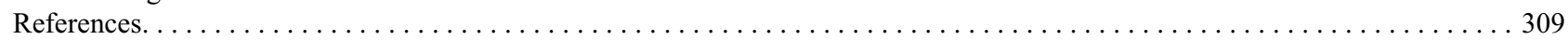

\section{INTRODUCTION}

In Heteroptera the structure of the spermatheca, often highly complex, shows a great diversity and was found to exhibit many important characters for classification, taxonomy and phylogeny (Pendergrast, 1957).

Little attention has been paid until now to the spermatheca in the Cydnidae, a family often considered a key taxon to understand the relationships and origin of the Pentatomoidea, but still an unsatisfactorily defined group of Pentatomoidea. Though McDonald (1966) stressed the great diversity of the cydnid spermatheca, the characters offered by this part of the female genitalia were not taken into consideration for the suprageneric classification of the family (Froeschner, 1960; Dolling, 1981; Lis, 1994). Nevertheless, comparative data concerning the morphology of spermatheca exist for some species (Pendergrast, 1957; Putchkova, 1959; Polivanova, 1959; Scudder, 1959; Kumar, 1962; McDonald, 1966). Other important data, although more succinct, can be found in alpha-taxonomic papers (Kerzhner, 1976; Schmitz, 1976; Moizuddin \& Ahmad, 1990; Linnavuori, 1993; Kim \& Lee, 1995; Magnien, 1998; Rizzoti-Vlach, 2000; Czaja \& Lis, 2002, 2003). Histological data exist for a single species, namely Aethus indicus (Westwood) studied by Ramamurty \& Medhi (1970).

The intention of the present study is to give a general view of the diversity and complexity of the spermatheca within the family, to compare its structure and construction to those found in other pentatomomorphan spermatheca and to evaluate the importance of the spermatheca in the systematics and phylogeny of Cydnidae.

The paper consists of three main parts. The first one brings precisions about the general structure of the cydnid spermatheca and terminology used; all spermathecal parts considered in the study are listed and illustrated using the geotomine spermatheca as example, because this type exhibits the highest complexity. We also want to point to possible correlations between the spermatheca and other vaginal structures. The second part describes the main spermathecal features in all genera studied. The third part attempts to analyze the remarkable diversity of the spermatheca within Cydnidae; this leads us to re-examine the characteristics of the pentatomoid spermatheca in order to group the different cydnid spermathecae examined into several morphological types. In conclusion, we discuss the significance of the spermatheca for cydnid classification and phylogeny.

\section{MATERIAL AND METHODS}

Representatives of all subfamilies and tribes of Cydnidae were studied: in total 190 species of 65 genera. In addition, four species belonging to genera of uncertain position or formerly included within the Cydnidae (Dismegistus, Parastrachia, Thaumastella, Thyreocoris) were examined. A list of the studied species is given at the beginning of descriptions for each subfamily or tribe. The suprageneric classification of the family follows Froeschner (1960) and Lis (1994).

Spermathecae were studied in dried specimens after $\mathrm{KOH}$ treatment of the abdomen. Observations were made after cleaning and clearing in glycerol or lactophenol; sometimes, membranous or small structures were stained by chlorazol black. Fresh material was also used; in some cases, the information offered by fresh specimens made it possible to interpret details in preparations with greater precision than that offered by dry material.

For the structure of the spermatheca, we follow the terminology proposed by Dupuis (1970), but for more details see also Dupuis $(1955,1963)$ and below (part I) for some recent terms.

Figs $1-3$ show all parts of the spermatheca mentioned in this paper and the terminology used. Figs 67-75 indicate some conventional representation adopted for the drawings. 


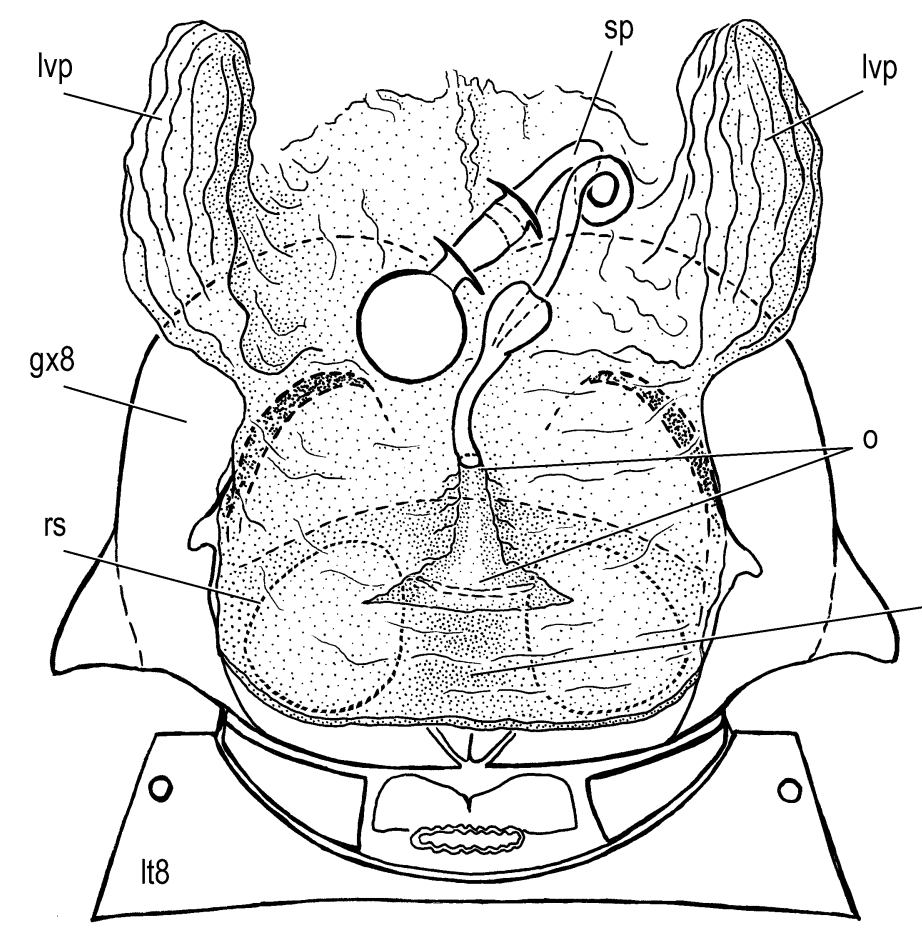

$1 \mathrm{~A}$

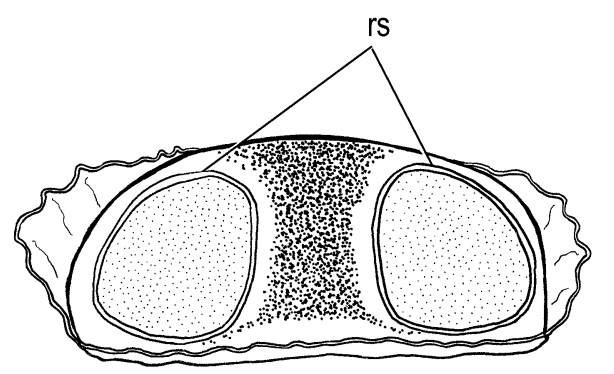

dpvp

$1 \mathrm{~B}$
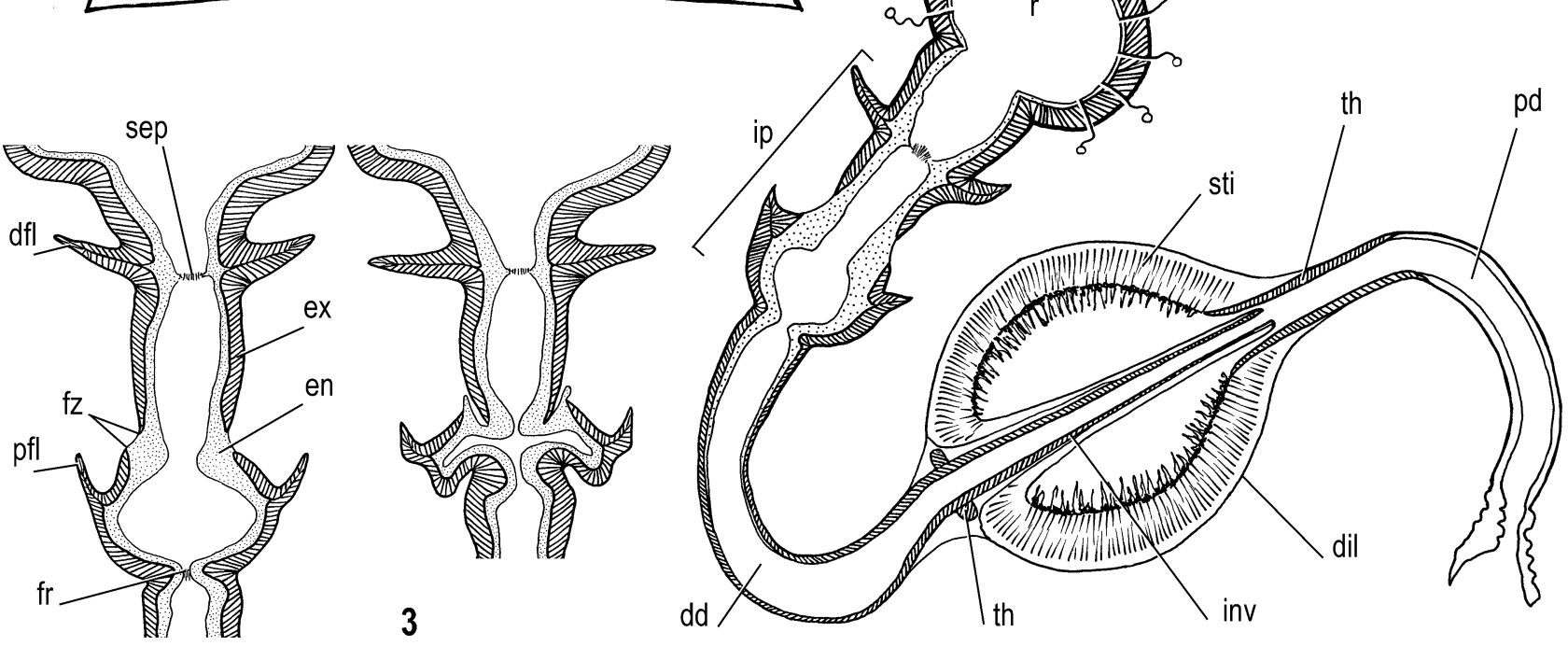

Figs 1-3. Geotomine pattern of the internal female genitalia in Cydnidae: 1A - dorsal view of the vagina (after KOH treatment) showing the respective situation of the spermatheca (sp), the ring sclerites (rs) and the lateral vaginal pouches (lvp); B - view of the ring sclerites on the floor of the posterior vaginal pouch, the dorsal wall being removed; 2 - structure of the spermatheca in a generalized geotomine species; 3 - detail of the intermediate part of the spermatheca (pump apparatus) showing the cuticular deformations due to the combined action of both muscle fibres and flexible zone. Abbreviations: dd - distal part of the spermathecal duct; dfl distal flange; dil - dilation of the spermathecal duct; dpvp - dorso-posterior vaginal pouch; dgc - ductules of the gland cells; en endocuticle; ex - exocuticle; fz - flexible zone; fl - flange; fr - fretum; gx8 - gonocoxite 8; ip - intermediate part of the spermatheca; inv - invaginated part of the spermathecal duct; $1 \mathrm{t} 8$ - laterotergite 8 ; lvp - lateral vaginal pouch; o - spermathecal opening into the vagina; $\mathrm{pd}$ - proximal duct; $\mathrm{pfl}$ - proximal flange; $\mathrm{r}$ - seminal receptacle; $\mathrm{rs}$ - ring sclerites; sep - septum; sp - spermatheca; sti striated intima; th - thickening or sclerotization of the duct.

\section{GENERAL STRUCTURE OF THE CYDNID SPERMATHECA. DEFINITION AND TERMINOLOGY}

In Pentatomoidea, or generally in the pentatomomorphans, the spermatheca (receptaculum seminis) is composed of three differentiated parts (Dupuis, 1955, 1963; Pendergrast, 1957): (1) an apical storage receptacle; (2) a muscular intermediate part acting as a pumping region; (3) an extremely variable spermathecal duct.
In most Cydnidae, the spermatheca is usually built of these three structurally and functionally distinct parts. It arises from a dorso-posterior pouch of the vagina (Fig. 1A) and can be associated with two particular vaginal structures described hereinafter, the parietovaginal glands (ring sclerites) and the fecundation canal.

\subsection{The spermatheca}

(Fig. 2) 
From the apical to the basal part one may recognize the following:

The apical receptacle (distal bulb of several authors) or seminal capsule (capsula seminalis). It is usually sclerotized and pigmented, ovoid or spherical, sometimes elongate, connected by a basal neck-like duct (more or less elongated), sometimes lacking.

The seminal receptacle is completely or partly surrounded by glandular cells (Fig. 77b), the spermathecal gland (glandula apicalis). Each glandular cell has its own efferent cuticular ductule which opens into the lumen of the receptacle.

The intermediate part (pars intermedialis) (spermathecal pump or pump apparatus of several authors) is a modified segment of the spermathecal duct adjacent to the seminal receptacle. This part is surrounded by muscle fibres and functions as a sperm pump. It is usually delimited by two cuticular plate-like flanges (apical and proximal) providing a place for muscle insertion. Flanges may be poorly (forming a small apodeme) or well-developed; sometimes one or both may be absent. In this case, muscle fibres are attached elsewhere, either around the basal edge of the receptacle or at some parts of the spermathecal duct. Sometimes, the position of the missing flange may be indicated by a sclerotized area or annular thickening.

The cuticular wall of the intermediate part is usually homogeneously sclerotized and pigmented, except for the area located about the middle, the cuticular lining of which is, to some degree, unsclerotized and flexible; we named this area, the flexible zone. This short segment, apparently solely composed of endocuticle, having already been observed by Berlese (1899) in Graphosoma, can also be recognized as a flexible zone in other families of Pentatomoidea; see, for instance, the illustrations given by Štys \& Davidová (1979: in Thyreocoris) or Davidová-Vilímová \& Štys (1980: in Plataspidae); see also Fig. 3, how it can be distorted during the action of muscles.

Two internal endocuticular structures partly obstructing the lumen must also be mentioned: a septum (cf. Slater \& Carayon, 1963: in Lygaeidae; Pluot, 1970: in Pyrrhocoridae) and a fretum (from Latin, meaning "strait"; cf. Moulet, 1993: in Coreoidea). Both structures may be simultaneously present in Cydnidae: the former often as a narrow filamentous partition wall about the level of the distal flange; the latter usually as a strong thickening of the internal wall narrowing the lumen, just posteriorly to the proximal flange.

The morphological distinction between the septum and the fretum is difficult in practice (see Moulet, 1993) and therefore it is not attempted here. These two still insufficiently known structures are frequent in Pentatomoidea, but they are often inconspicuous and difficult to observe in most species; thus, they have not been systematically investigated in this paper and will be mentioned (and illustrated) only when well visible.

The spermathecal duct (ductus receptaculi) is a tube varying in length and diameter leading to the vagina. This canal may be simple (rarely) or complex (often), enlarged or not, with or without differentiation (dilation or "bursa"). Several cases should be distinguished in Cydnidae:

i. Simple duct without marked enlarged part. The duct has the same constitution along its entire length (Figs 11, 15), or exhibits two distinct parts, distal and basal (Figs $36,48,50$ ) according to the structure of its wall (cuticular intima sclerotized or not, thin or thick, rigid or soft, smooth or striated).

ii. Duct with an enlarged part (dilation). Here it is necessary to distinguish between two kinds of dilation: the simple dilation and the dilation with invagination exhibiting a very complex structure. In the first case the lumen merely swells, usually at the middle of the duct (Figs 41, $49,57,58,59)$. In the second case, the dilation is accompanied by the invagination of the apical part of the duct within the proximal part (Figs 25-31, 34-35, 37-40, 76-82). We will distinguish the proximal duct, from vagina to dilation, and the distal duct leading to the apical receptacle (Fig. 2). The lumen remains usually more or less the same along the duct, including the invaginated part.

The dilation may also occur at the base of the spermathecal duct. In this case, it is difficult to ascertain the origin of the dilated part: it may be seen as a differentiated part of the spermathecal duct, or as an evagination of the vaginal wall as well (see for instance Fig. 12 and compare with Figs 11, 15).

The shape, size and aspect of the cuticular wall of the dilation vary greatly within the Cydnidae. Strong pigmentation, sclerotizations and differentiation may totally or partially obscure its structure as already noted by Pendergrast (1957). When the duct is invaginated, sclerotization, pigmentation or thickening of the intima may be observed, in particular at the base and apex of the dilation. Nevertheless, the thick intima of the dilation is often composed of two distinct layers: the outer finely striated and translucent; the inner usually pigmented and serrated, projecting into the lumen gill-like cuticular extensions (Fig. 2). These features can be seen in a photograph of a transversal section of the dilation given by Ramamurty \& Medhi (1970). In many cases, the dilation may be observed in external view as a ribbed structure, the wall being regularly fluted or pleated either vertically or diagonally (Figs 9, 10, 28, 33, 42, 44, 46).

iii. Duct with a diverticulum. A diverticulum (tubular or sacciform) may be present - although rarely - at the base of the spermathecal duct (Fig. 4).

The spermathecal opening (orificium receptaculi) and surrounding area. The outlet of the spermathecal duct may be a simple aperture in the dorsal wall of the vagina. More frequently it is surrounded or flanked by particular structures: various thickening, more or less sclerotized areas, sclerites, or complicated folds of the vaginal intima. In some instances, the duct opens into an individualized pouch of which, as said above, it is difficult to recognize if it is a diffentiation of the vagina (i.e. a special dorsal pouch) or a mere dilation of the basal part of the spermathecal duct. In the following sections we briefly refer to these structures merely as "spermathecal opening". 


\subsection{Vaginal structures associated with the spermatheca}

The two following vaginal structures are to some extent functionally related to the spermatheca (see below) and for this reason they must be mentioned. They will not be described thought, only reported as present or absent.

The parietovaginal glands (also called "ringed glands") which can be located in dried specimens owing to their ring sclerites (Fig. 1) are usually paired, one on either side of the spermathecal opening. They are widespread within Pentatomomorpha (see Scudder, 1959; Carayon, 1964) and also present in Saldidae (Carayon, 1964) and in Miridae (Slater, 1950). In Cydnidae, a pair of ring sclerites may be absent, more often present (Scudder, 1959; McDonald, 1966; Schmitz, 1976; Rieger, 1997; Magnien, 1998; Kim \& Lee, 1995). Scudder (1959) wrongly considered that they were missing in Cydninae. In fact, the ring sclerites being often fine, slightly pigmented or unpigmented and inconspicuous can be easily overlooked or not recognized. In addition, in many species they are difficult to observe in dorsal view, lying usually (Geotomini) under the dorso-posterior pouch of the vagina, just below the opening of the spermathecal duct (Fig. 1A). According to Rieger (1997), the ring sclerites in Canthophorus may display intraspecific variation in their form.

In some species, a pair of lateral vaginal pouches (Fig. 1A), each placed opposite to each ring sclerite, is more or less closely connected with the parietovaginal glands. These large, membranous, distensible sac-like pouches act apparently as a reservoir for the adjacent glands. Comparable vaginal pouches associated with parietovaginal glands have been described in some Scutelleridae (Gaffour-Bensebbane, 1994).

A fecundation canal may also be present in some cydnid species, although rarely (Figs 48, 51). This structure is a groove (or a canal) more or less sclerotized in the dorsal wall of the vagina, running from the opening of the spermathecal duct toward the oviduct. This structure is known in several heteropteran families. It is widespread in Gerromorpha, present in all families of the infraorder (Gerridae, Hebridae, Hydrometridae, Macroveliidae, Mesoveliidae, Paraphrynoveliidae, Veliidae) except Hermatobatidae (Andersen, 1982; see also Pendergrast, 1957; Heming-van Battum \& Heming, 1986); it has been also described in some Leptopodomorpha (Leptopodidae, Omaniidae: Scudder, 1959; Cobben, 1970) and in Pentatomomorpha as well (Pyrrhocoridae: Pluot, 1970; Scutelleridae: Gaffour-Bensebbane, 1991a).

\subsection{Some functional aspects}

In Pentatomoidea, the spermatheca appears to be a highly complex organ especially when the spermathecal duct is differentiated into a dilation which includes an invaginated part. This complex organization probably implies a concomitant complexity in function. Unfortunately, the functional signification of the different parts of the spermatheca (and of the genital tract) during copulation, insemination and fecundation is far to be known and understood. We attemp here to summarize the little we know.

It is likely that in many Cydnidae, insemination takes place, during copulation, into the vagina and not directly into the apical receptacle, as for instance in Lygaeidae (Bonhag \& Wick, 1953). Moreover there is a strong evidence that the male transfers sperm at the base of the spermathecal duct, precisely into the spermathecal opening. As said above, the vaginal intima at the point of entry of the spermathecal duct often bears various modifications (folded or sclerotized areas, particular structures more or less convoluted). These modifications suggest that, at least in some species, the vesica (or part of the vesica) penetrates the base of the spermathecal duct for anchoring and locking the phallus during copulation.

The entry and exit of sperm into the apical receptacle are controlled - at least partly - by the intermediate part, an efficient pump equipped with muscle fibres, flexible zone, and valvular mechanism (septum and fretum), although sperm motility is probably also involved in sperm tranfer. The spermathecal pump may also control the opening and closing of the dilation, allowing the way either into the cavity or toward the receptacle.

The function of the various differentiations of the spermathecal duct are more enigmatic. As observed by several authors (Berlese, 1899 in Graphosoma; Malouf, 1933 and Ramamurty, 1969 in Nezara; Ramamurty \& Medhi, 1970 in Aethus), the dilation comprising an invagination is covered by columnar cells forming a secretory epithelium. Berlese (1899) regarded it as an organ of digestion of excess of seminal material. He showed that in the inseminated female it contains an heterogenous material in which spermatozoa are numerous and degenerative. The dilation could be indeed a site where the excess of spermatozoa is received, destroyed and reprocessed. However, Adams (2001) on the basis of electrophoretic analysis in Perillus bioculatus (Pentatomidae: Asopinae) claimed that only ectadenial secreted proteins were transferred into the dilation, spermatozoa themselves being never found in the dilation, only in the spermathecal duct and seminal reservoir.

The paired parietal glands are still insufficiently known. According to the observations made by Carayon (1964) in various heteropteran species, these vaginal glands situated always to both sides of the spermathecal opening, appear to be also concerned with spermatozoa migration after the insemination. In several occasions, the spermophilous nature of the secretion has been noticed and, in some species, the concomitant loss of spermatheca and parietal glands observed as well.

Some interrelations between different parts of the female genital system may exist. At least in some groups (Scutelleridae), morpho-functional correlations seem to exist among spermatheca, parietovaginal glands and fecundation canal (Gaffour-Bensebbane, 1993, 1994). In particular, the possible correlation between the presence of a big dilation-invagination in the spermathecal duct and the reduction (or absence) of ring sclerites (i.e. parietovaginal glands) in the vaginal wall suggested by 
Gaffour-Bensebbane (1993) is interesting and should be confirmed.

\section{DESCRIPTIONS}

Detailed descriptions are not given for each species, only the general structure within one or several genera is presented, along with interspecific variation being noted afterward.

\subsection{Amnestinae Hart}

(Fig. 4)

Species examined: Amnestus pusio (Stål), raunoi Lis. Previous data: McDonald (1966): Amnestus pusio, A. pallidus Zimmer.

Amnestus Dallas (Fig. 4). Entire spermatheca slightly sclerotized and pigmented. Receptacle spherical. Intermediate part indistinct, both flanges being absent; no septum or fretum distinct. A stout, wide, rigid, and three-four time coiled duct follows, with irregular diameter. Spermathecal opening through an evagination of vaginal intima surrounding basal part of duct; cuticular lining partly sclerotized making a kind of ring around evagination. Small membranous sac-like diverticulum connected at this level.

Ring sclerites indistinct, probably absent.

Note. The spermatheca presents the same structure in both species examined agreeing with the description given by McDonald (1966). The later reported the presence of a membranous diverticulum at the base of the duct, and he also pointed out that the intermediate part (pumping region) was not evident. Nevertheless, the prominent base of the receptacle might act as an apical flange; a very thin flexible zone seems to exist at this level (Fig. 67).

\subsection{Cephalocteinae Mulsant \& Rey}

(Figs 5-10)

\subsubsection{Cephalocteini Mulsant \& Rey}

(Fig. 5)

Species examined: Cephalocteus scarabaeoides (F.).

Cephalocteus Dufour (Fig. 5). Entire spermatheca unpigmented and unsclerotized. Receptacle spherical, slightly flattened, thick-walled, connected by a very short neck. Intermediate part delimited by well-developed distal and proximal flanges, wide in diameter; slight constriction present at middle (at level with flexible zone). Duct with very small dilation-invagination about middle of its length; distal duct coiled, narrow, cuticular wall smooth, rigid; proximal duct wider, more or less straight, cuticular wall thick and rather soft, somewhat irregular and wrinkled, making a narrow lumen; its basal part finely striated, not free, firmly linked to vaginal wall. Spermathecal opening into vagina simple.

Ring sclerites present, but inconspicuous, associated with pair of lateral vaginal pouches.

\subsubsection{Scaptocorini Froeschner}

(Figs 7-10)

Species examined: Pseudostibaropus testaceus (Walker) - Scaptocoris australis Lis, minor Berg - Schiodtella secunda Lis, subglabra (Breddin) - Stibaropus pseudominor Lis.

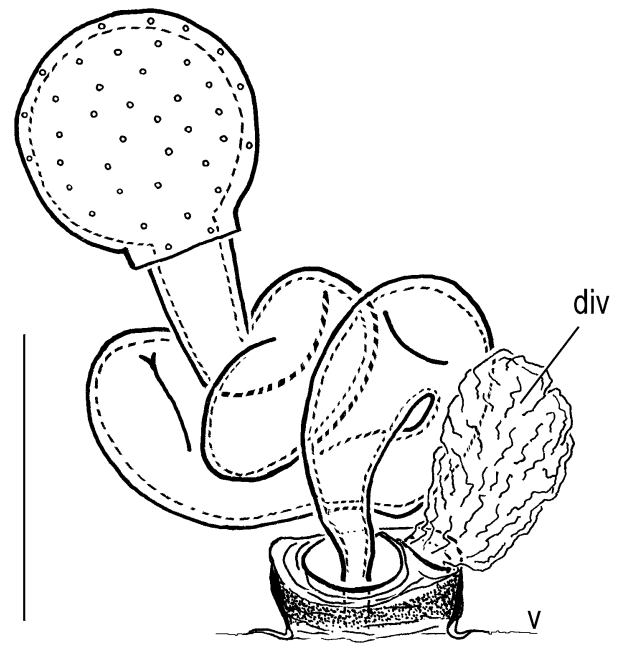

Fig. 4. Spermatheca of Amnestus pusio (Amnestinae); div diverticulum; $\mathrm{v}$ - vagina. Scale bar: $0.1 \mathrm{~mm}$.

Previous data: Kumar (1962): Stibaropus callidus (Schiødte) Moizuddin \& Ahmad (1990): Stibaropus callidus (Schiødte), molginus (Schiødte).

Stibaropus Dallas (Fig. 7). Receptacle slightly pigmented, ovoid, connected by a very short neck. Intermediate part well differentiated (as in Cephalocteus), wide and delimited by two flanges; constriction present (at middle at level with flexible zone). Duct with big spherical dilation-invagination strongly sclerotized, black pigmented, entirely opaque; distal duct short and narrow, thin-walled, transparent; proximal duct also short and unpigmented, slightly wider than distal one, lumen very narrow. Spermathecal opening through thick whorl-like structure differentiated in dorsal wall of vagina.

Ring sclerites present, associated with pair of lateral vaginal pouches.

Pseudostibaropus Lis (Fig. 8), Schiodtella Signoret (Fig. 6). Receptacle spherical, connected by a short neck. Duct with big spherical, dilation-invagination strongly pigmented and opaque.

Scaptocoris Perty (Figs 9, 10). Receptacle spherical slightly flattened, connected by a long slightly bent neck. Intermediate part with two well-developed flanges. Duct with pear-shaped, more or less pigmented, thick-walled dilation-invagination; internal layer of intima regularly fluted obliquely.

\subsection{Cydninae Billberg}

(Figs 11-46)

\subsubsection{Cydnini Billberg}

(Figs 11-24)

Species examined: Chilocoris barbarae Lis, biroi Horváth, incomptus Froeschner, nepalensis Lis, nitidus Mayr, piceus Signoret, ritzemae (Signoret), somalicus Mancini, tenebricola Jeannel - Cydnus aterrimus (Forster), pericarti Lis - Parachilocoris dispar Horváth, japonicus Lis, luzonicus Lis, minutus (Distant).

Previous data: Linnavuori (1993): Chilocoris laevicollis Horváth, somalicus aequatorialis Linnavuori; Cydnus aterrimus 

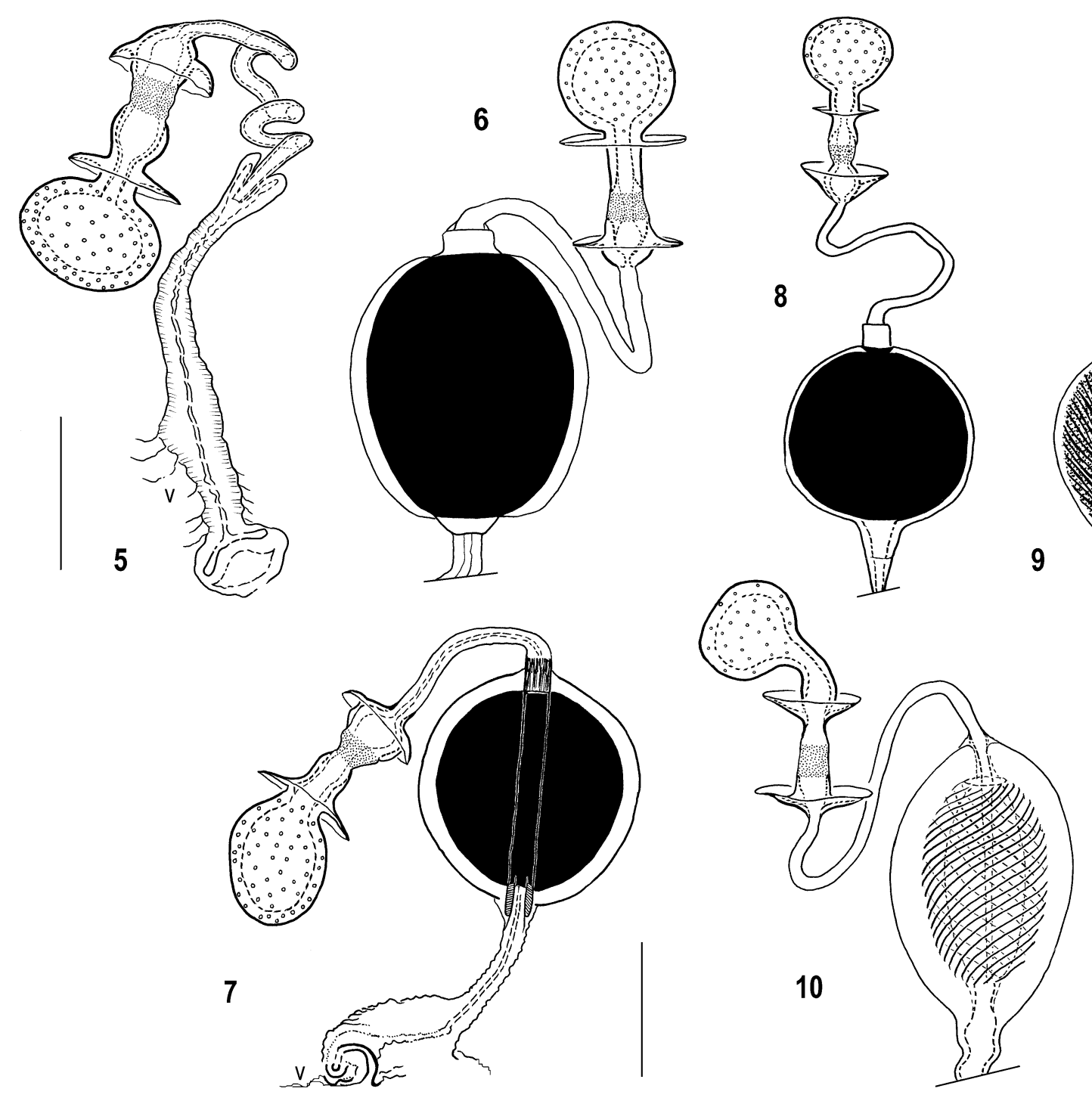

Figs 5-10. Spermathecae in Cephalocteinae: 5 - Cephalocteus scarabaeoides; 6 - Schiodtella secunda; 7 - Stibaropus pseudominor; 8 - Pseudostibaropus testaceus; 9 - Scaptocoris minor; 10 - Scaptocoris australis; v - vagina. Scale bars: $0.2 \mathrm{~mm}$.

(Forster) - Moizuddin \& Ahmad (1990): Cydnus aterrimus (Forster) - Kim \& Lee (1995): Chilocoris confusus Horváth.

Chilocoris Mayr (Figs 11, 12, 16-23). Receptacle spherical, sclerotized and pigmented, without neck. Intermediate part with proximal flange well developed, distal one often variously reduced from species to species, rarely absent, often asymmetrical (more developed on one side) (Figs 16-23); flexible zone taking up nearly whole length of intermediate part; septum indistinct, fretum inconspicuously developed. Duct long or very long and usually coiled; simple or with basal differentiation depending on the species examined. Therefore, two groups can be recognized:

Group 1 (Fig. 11) (barbarae, biroi, incomptus, piceus, ritzemae, somalicus, tenebricola). In most species, the duct is simple, with a thin, hard and smooth cuticular wall, slightly sclerotized; it is regularly winded (at first in one direction, then in the opposite direction). Spermathecal opening simple, situated medially on a particular area of the dorsal wall of the vagina where the intima is folded making concentric circles. From the drawing given by Linnavuori (1993), laevicollis also belongs to this group.

Group 2 (Fig. 12) (nitidus, nepalensis). In the two species, the basal part of the duct turns into a long and wide membranous tubular segment; its cuticular intima, thick and soft, is concentrically folded and unpigmented. Spermathecal opening into the vagina simple, without particular structure. Note: the basal part of the spermathecal duct could be just as well interpreted as a long dorsal pouch of the vagina: compare its intima with that of the vaginal intima in Fig. 11; both appear very similar).

Ring sclerites (more or less distinct) present in all species examined.

Cydnus Fabricius. The two species examined are strongly different and must be described separately.

C. aterrimus (Fig. 14). Receptacle spherical, sclerotized and pigmented, connected by a very short neck. Intermediate part delimited by two well-developed flanges; flexible zone long; septum inconspicuous, fretum 
present. Duct very short, straight, devoid of any differentiation except for a short basal segment more pigmented forming a sclerotized ring; cuticular wall smooth and rigid. Spermathecal opening simple, into a huge dorsal sac-like pouch of vagina; pouch membranous and wrinkled; spermatheca opening ventrally.

Ring sclerites present.

Note. The dorsal pouch of the vagina where the spermathecal duct opens has been drawn by Linnavuori (1993: Fig. 82i) as a basal dilated part of the spermathecal duct. The ring sclerites were not found in $C$. aterrimus by Scudder (1959), who wrongly stated they were absent.

C. pericarti (Fig. 13). Receptacle without neck. Intermediate part lacking truly developed flanges: distal one reduced to a small ridge basally to receptacle, proximal one missing or replaced by an enlargement of duct; conspicuous fretum present at this place in lumen; flexible zone taking up nearly whole length of intermediate part. Duct short, straight with a sclerotized basal ring. Spermathecal opening through a small dorsal pouch of vagina forming numerous large folds and coils there.

Ring sclerites present.

Parachilocoris Horváth (Fig. 15). Spermatheca very similar to that of Chilocoris group 1, except for the following points: intermediate part without distal flange, proximal one well developed; flexible zone not clearly distinct, apparently situated apically just beneath the seminal receptacle. Duct thin-walled, very long, narrow and coiled.

Ring sclerites present, but inconspicuous.

\subsubsection{Geotomini Wagner}

(Figs 25-46)

Species examined: Adrisa flavomarginata (Vollenhoven), magna (Uhler), mayri Signoret, sumatrana Lis - Aethoscytus baloni Lis, multisetosus (Noualhier), secundus Lis - Aethus indicus (Westwood), nepalensis (Westwood), philippinensis Dallas, pseudindicus Lis, tanna (Distant) - Alonips acrostictus (Distant), apicalis (Dallas), mirabilis Lis, taiwanicus Lis Byrsinus australis Lis, flavicornis (F.), nigroscutellatus Montandon, ochraceus (Distant), pallidus (Puton), penicillatus Wagner, pseudosyriacus (Linnavuori), varians (F.) - Choerocydnus coleopteroides Bergroth, foveolatus White - Cydnotomus australis Lis, secundus Lis - Cyrtomenus mirabilis (Perty), teter (Spinola) - Dallasiellus viduus (Stål) - Dearcla punctatissima (Dallas) - Endotylus brevicornis Horváth, pallidus Linnavuori - Eulonips coleopteroides Lis, occidentalis Lis, pilitylus (Signoret) - Fromundiellus latiusculus (Horváth), maurus (Dallas) - Fromundus biimpressus (Horváth), difficilis (Stål), glaber (Signoret), opacellus Lis, parcimonius (Signoret), pygmaeus (Dallas), singularis (Horváth) - Gampsotes parallelus Signoret - Geocnethus boulardi Linnavuori, ornatus Linnavuori, ornatellus Linnavuori, pallipennis (Dallas), plagiatus (Signoret) - Geopeltus tuberculatus Lis Geotomus alexandria (Distant), brunnipennis Wagner, coimbatoricus Lis, convexus Hsiao, elongatus (Herrich-Schaeffer), garsaurioides Lis, gracilipes Signoret, hildegardae Lis, katakadioides Lis, obesus Lis, perpunctatus (Signoret) - Hiverus hirtus Amyot \& Serville - Katakadia caliginosa (Walker) - Lactistes latus Distant, mediator Breddin, minutus Lis, rastellus Schiødte, truncatoserratus Signoret, vericulatus Schiødte - Macroscytus aequalis (Walker), annulipes Horváth, annulipoides Lis, arnhemicus Lis, australis (Erichson), badius (Walker), bipunctatus Lis, bisetosus Lis, borneensis Lis, brun- neus (F.) (Cyprus, Morocco, Zimbabwe, S Rhodesia), dominiqueae Lis, gibbulus (Ellenrieder), japonensis Scott, javanus Mayr, minimus Lis, nigroaeneus (Walker), pfeifferi (Signoret), piceus (Westwood), popovi Lis, privignus Horváth, reflexus Signoret, ruficornis Signoret, transversus (Burmeister) Melanaethus spinolae (Signoret) - Mesocricus cribripennis Horváth - Microporus laticeps (Signoret), lautipennis (Stål), nigrita (F.), pallidipennis (Reuter), vietnamicus Lis - Microscytus schaeferi (Signoret) - Megacydnus signatus Linnavuori - Pangaeus aethiops (F.), docilis (Walker) - Paraethus capicola (Westwood), saprinoides (Gerstaecker) - Peltoscytus solomonensis Lis - Peribyssus scutellaris Puton - Plonisa tartarea (Stål) - Prolactistes australis Lis - Prolobodes gigas (Signoret), giganteus (Burmeister) - Pseudonalips cribratus (Signoret) - Pseudoscoparipes nigritus Lis, nilgiricus Lis, schaeferi Lis - Raunoloma longiceps (Linnavuori) Scoparipes affinis Lis, dissimilis Horváth, stygius (Walker) Scoparipoides ceylonicus Lis, curviductus Lis - Teabooma princeps Distant - Tominotus unisetosus Froeschner.

Previous data: Pendergrast (1957): Macroscytus brunneus (F.) Kumar (1962): Alonips apicalis (Dallas) (as Geotomus) McDonald (1966): Cyrtomenus crassus Walker, Dallasiellus discrepans (Uhler), Pangaeus aethiops (F.) - Schmitz (1976): Microporus pallidipennis (Reuter) (as Aethus) - Linnavuori (1993): Aethoscytus multisetosus (Noualhier), Aethus holothrix Linnavuori, laevioides Lis (as laevis Douglas \& Scott), lindbergi Wagner, perosus Stål, solutus Linnavuori, torridus (Erichson), uageranus Linnavuori, seydiensis Jeannel; Byrsinus albipennis (Costa), azrak Linnavuori, pallidus (Puton), pauculus (Signoret), pilosulus (Klug), pseudosyriacus Linnavuori (all as Putonisca); Endotylus brevicornis Horváth, pallidus Linnavuori; Fromundus bicornis (Linnavuori), difficilis (Stål), glaber (Signoret), hirtipes (Palisot de Beauvois), montanus (Linnavuori), parcimonius (Signoret), pygmaeus (Dallas) (all as Geotomus), singularis (Horváth) (as Alamprella); Geocnethus boulardi Linnavuori, ifensis Linnavuori, incognitus Linnavuori, laticeps Linnavuori, maboke Linnavuori, nitidus (Signoret), obalanus Linnavuori, ornatus Linnavuori, ornatellus Linnavuori, pallipennis (Dallas), plagiatus (Signoret), proximus (Signoret), sibitiensis Linnavuori; Geotomus palustris Linnavuori, remedellii Mancini; Lactistes puncticollis Linnavuori, vericulatus Schiødte; Macroscytus brunneus (F.), excavatus Signoret; Megacydnus signatus Linnavuori; Microporus lautipennis (Stål) (as Putonisca); Microscytus schaeferi (Signoret); Paraethus capicola (Westwood), saprinoides (Gerstaecker), splendidus (Linnavuori) (all as Aethus); Pseudonalips cribratus (Signoret); Raunoloma longiceps (Linnavuori) (as Aloma); Shillukia polita Linnavuori Moizuddin \& Ahmad (1990): Aethus islamabadensis Moizuddin \& Ahmad, Alonips acrostictus (Distant) [as Geotomus pygmaeus (Dallas)], microevaporatorius (Moizuddin \& Ahmad) (as Geotomus), Byrsinus pallidus (Puton) (as Aethus bipunctatus Moizuddin \& Ahmad), pilosulus (Klug) (as Aethus karachiensis Moizuddin \& Ahmad), Fromundus pygmaeus (Dallas) (as Geotomus macroevaporatorius Moizuddin \& Ahmad), Geotomus perpunctatus (Signoret) (as G. nigratus Moizuddin \& Ahmad), Lactistes latus (Distant) (as L. rastellus Schiødte), rastellus Schiødte (as L. vicinus Signoret), Macroscytus brunneus (F.) (as M. subaeneus (Dallas)) - Kim \& Lee (1995): Adrisa magna (Uhler), Aethus nigrita (Fabricius), Fromundus palliditarsus (Scott) (as Geotomus), Macroscytus japonensis Scott - Czaja \& Lis (2002, 2003): Coleocydnus inexpectatus Czaja \& Lis, multisetosus Czaja \& Lis, punctatus Czaja \& Lis, ruvenzoricus Czaja \& Lis, similis Lis \& Czaja. 


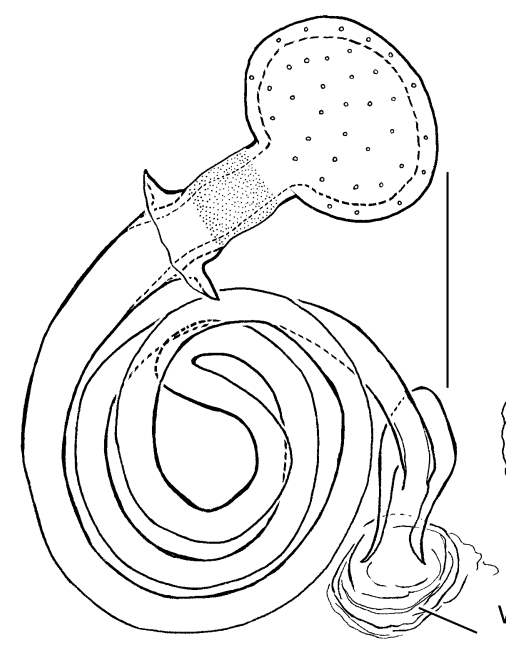

11

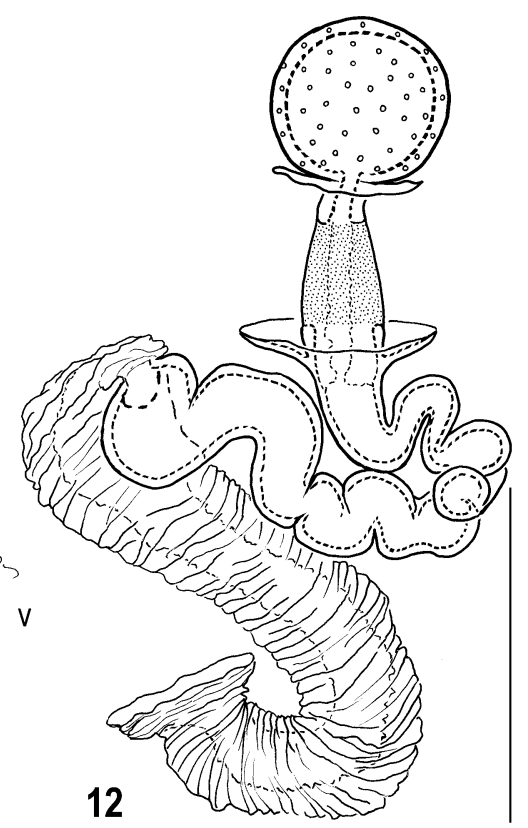

12
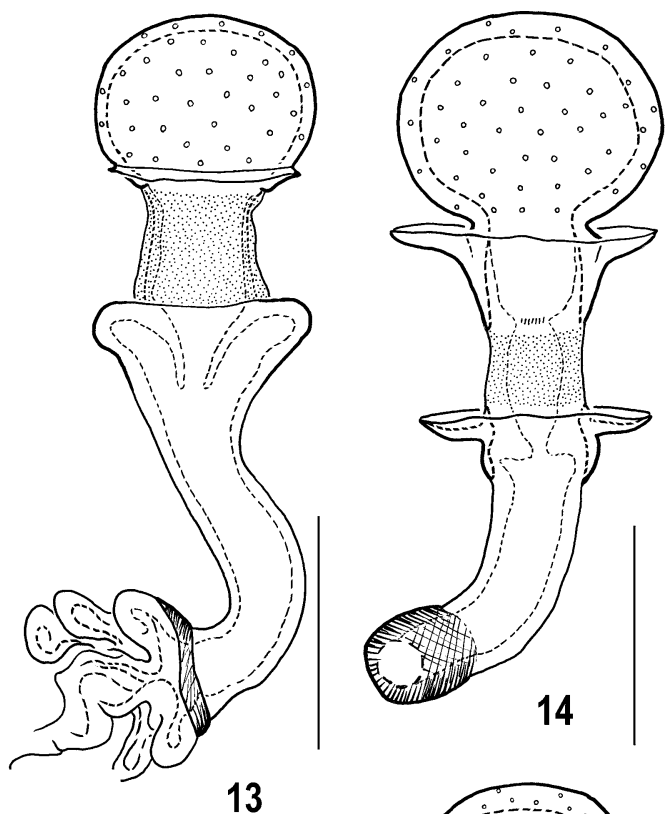

13
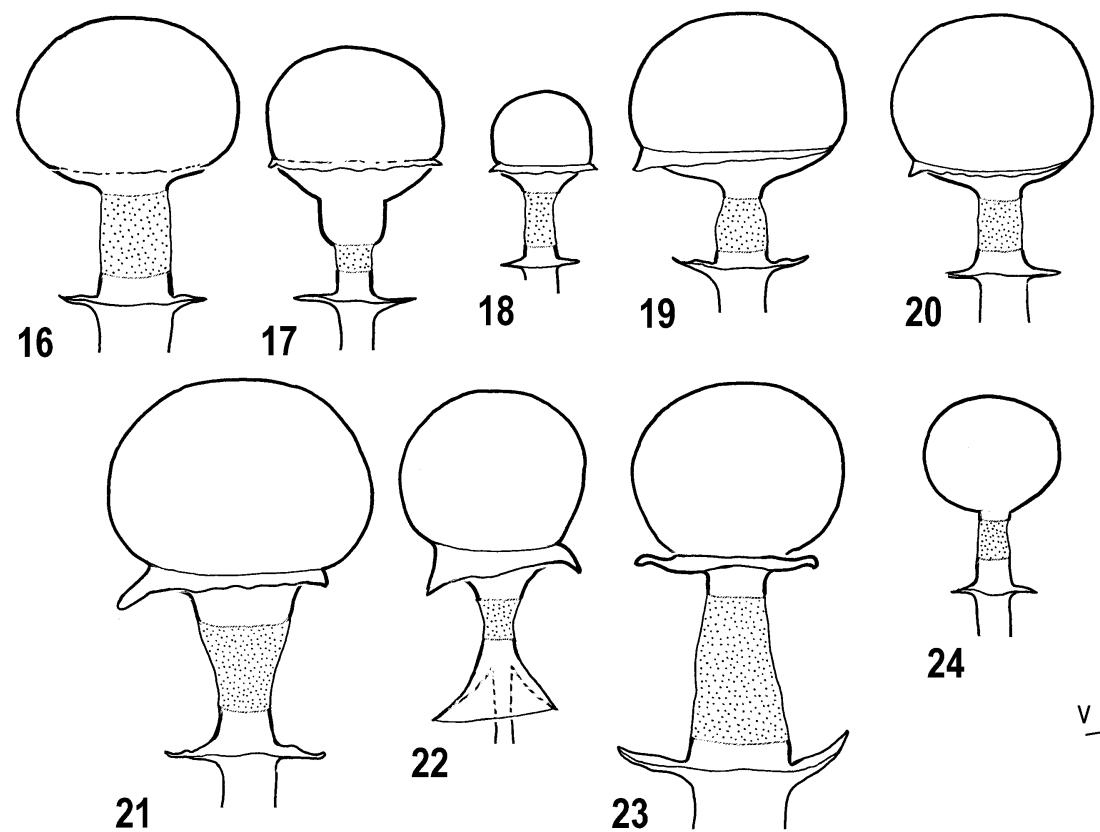

24

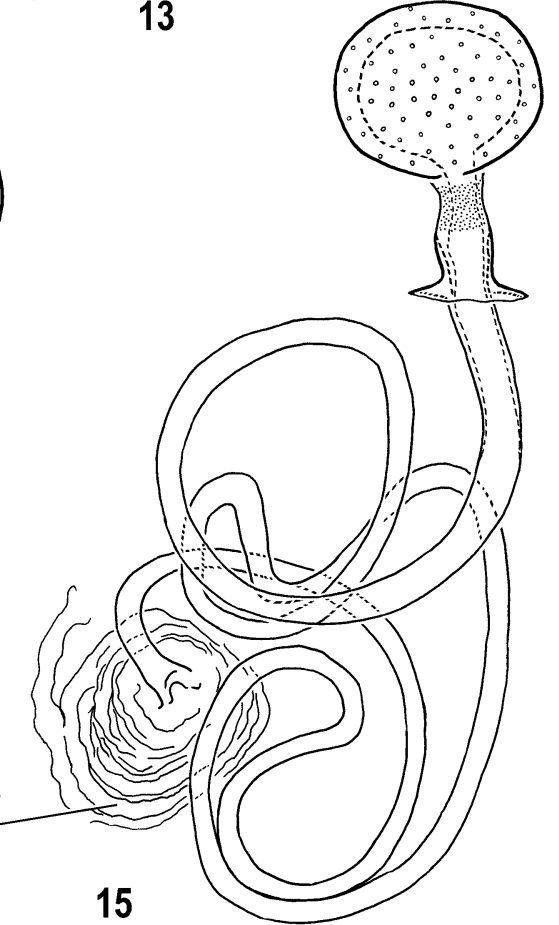

Figs 11-24. 11-15: Spermathecae in Cydninae: Cydnini: 11 - Chilocoris somalicus; 12 - Chilocoris nepalensis; 13 - Cydnus pericarti; 14 -Cydnus aterrimus (the huge membranous vaginal pouch not drawn); 15 - Parachilocoris japonicus; $\mathrm{v}-\mathrm{vagina}$. Scale bars: $0.2 \mathrm{~mm}$, except Fig. 11 (scale $0.1 \mathrm{~mm}$ ). 16-24: Idem, detail of receptacle and intermediate part in several species of Chilocoris and one species of Parachilocoris, showing some variations of the distal flange: 16 - Chilocoris somalicus; 17 - Ch. incomptus; 18 Ch. biroi; 19 - Ch. tenebricola; 20 - Ch. barbarae; 21 - Ch. piceus; 22 - Ch. ritzemai; 23 - Ch. nepalensis; 24 - Parachilocoris japonicus.

There is a considerable diversity of spermathecal structure within the tribe Geotomini, but several genera exhibit some particular common features and may be therefore grouped together into three different groups on the basis of differences exhibited by the spermathecal duct. We will not describe the spermatheca for all genera in detail; the description is presented for a single representative of each group, only giving the important differences noted for the other genera. The same is done for the "previous data" about the spermathecae: only the divergent data will be mentioned.

\subsubsection{Geotomine group I}

(Figs 25-41)

Spermathecal duct with a spherical dilationinvagination more or less developed.

Aethoscytus Lis (Figs 25, 81). Receptacle spherical, slightly flattened, sclerotized and pigmented, connected by a neck. Intermediate part long, delimited by two well 

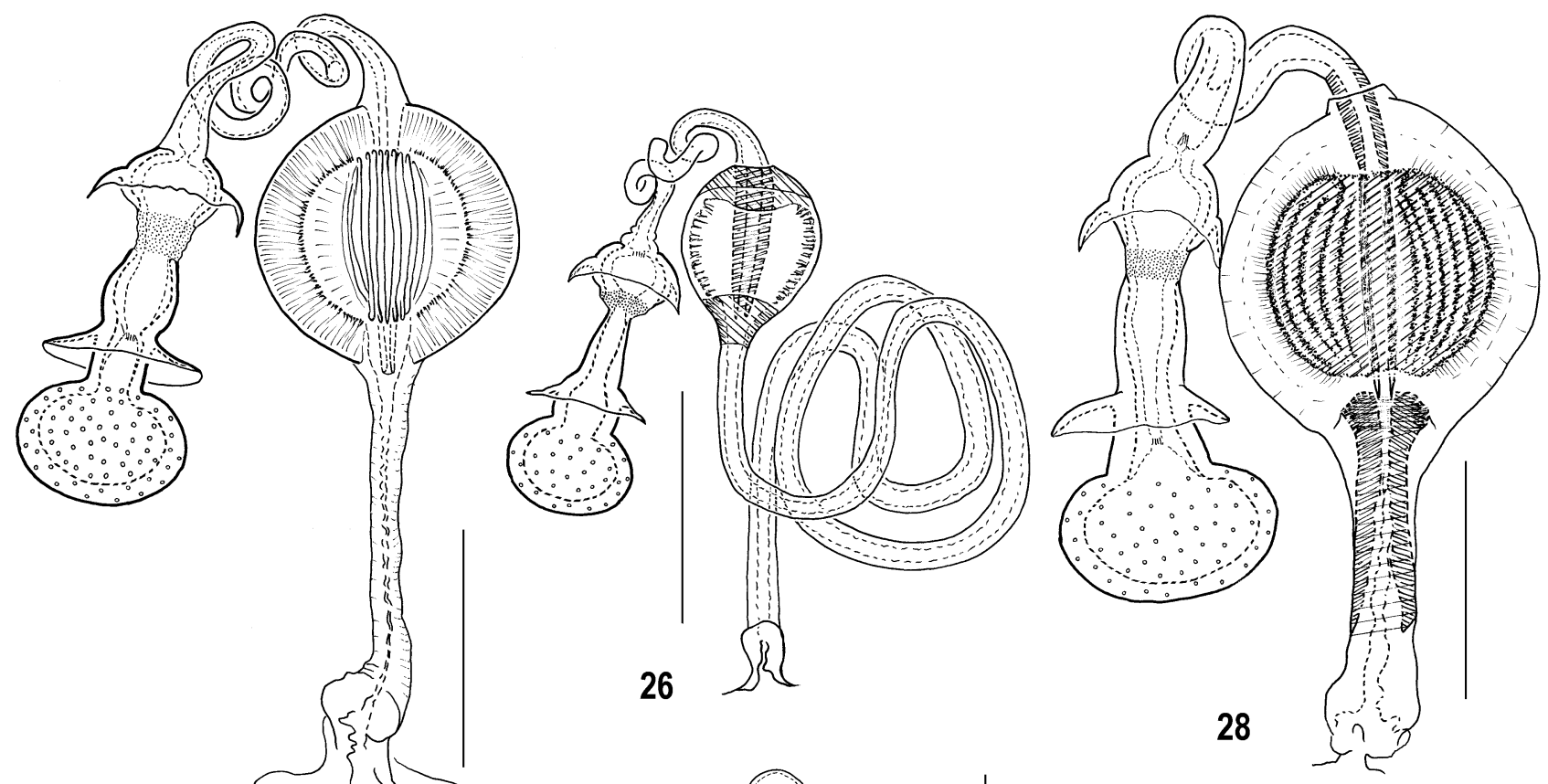

25
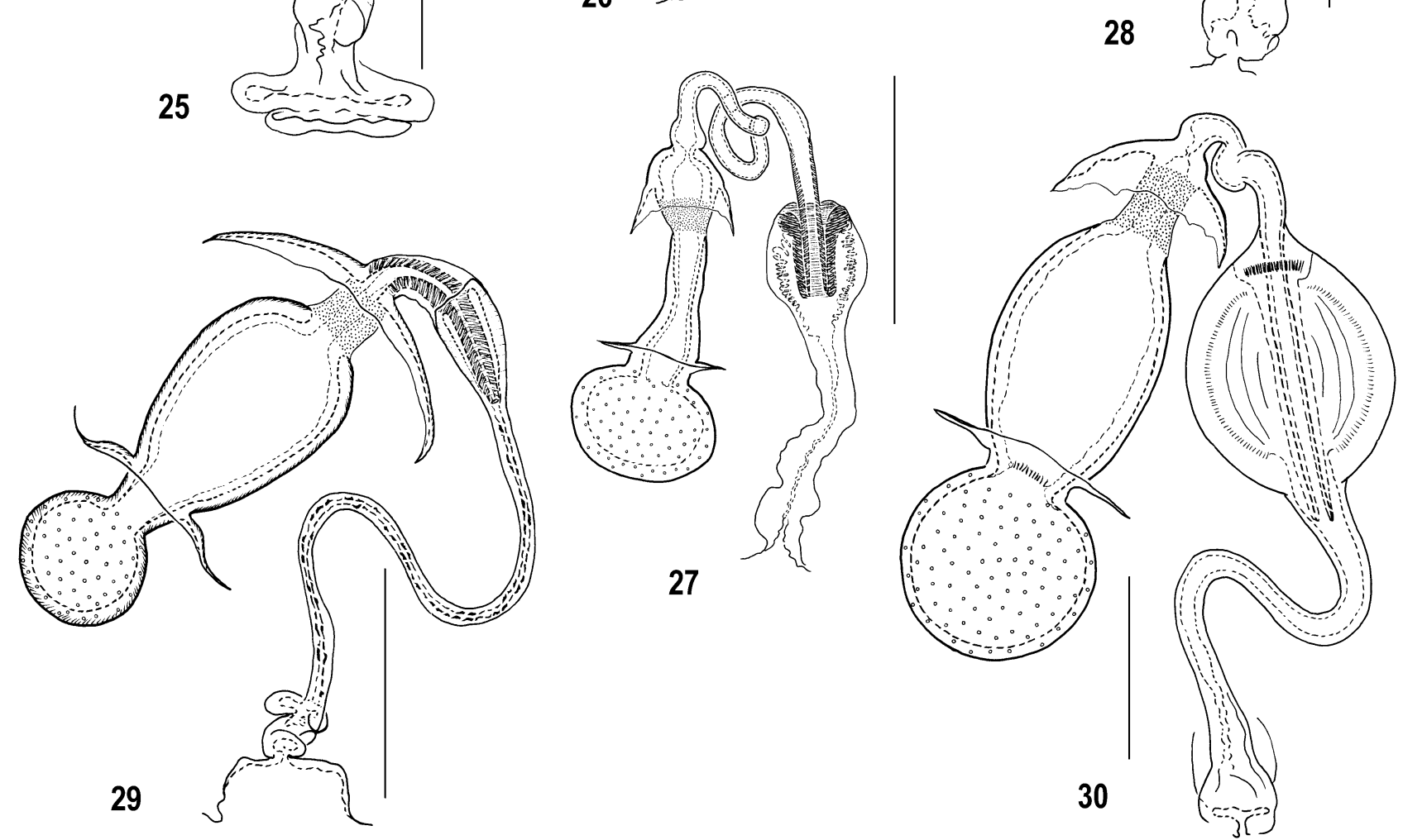

Figs 25-30. Spermathecae in Cydninae: Geotomini: 25 - Aethoscytus multisetosus; 26 - Byrsinus pseudosyriacus; 27 - Byrsinus pilosulus; 28 - Aethus lindbergi; 29 - Geocnethus boulardi; 30 - Endotylus brevicornis. Scale bars: $0.2 \mathrm{~mm}$.

developed sclerotized flanges, basally cup-like widened; flexible zone short as a constricted part in basal position; septum and fretum present. Duct with a big spherical or pear-shaped median dilation-invagination, the latter limpid with very thick wall, strongly striated; distal duct coiled; proximal duct straight and slender. Spermathecal opening through large folds of vaginal wall.

Ring sclerites present, associated with a pair of lateral vaginal pouches.

Aethus Dallas (Figs 28, 79), Dearcla Signoret. All examined species possess a big spherical dilationinvagination strongly or variously pigmented and striated; some species have thickening or pigmented parts at the level of both basal and distal poles of the dilation or along the duct; distal duct rather long and coiled, proximal one short and wide.

Ring sclerites as in Aethoscytus.

Alonips Signoret (Fig. 31), Eulonips Lis. Duct very long and coiled, bearing at about its middle a dilationinvagination of variable size depending on the species, from very small (A. apicalis) to moderate (A. taiwanicus), pigmented or not, and more or less limpid. Spermathecal opening simple. 

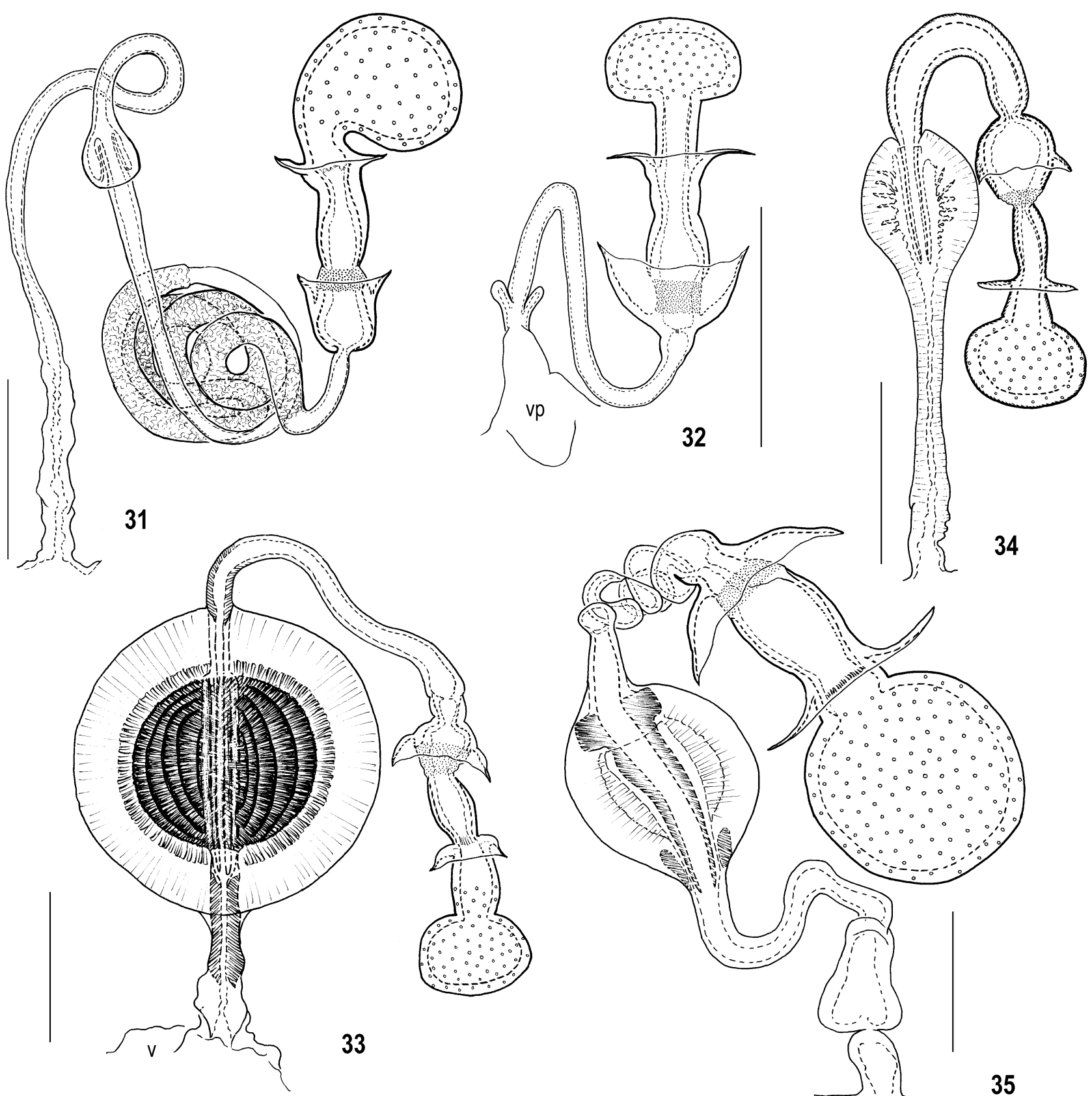

Figs 31-35. Spermathecae in Cydninae: Geotomini: 31 - Alonips apicalis; 32 - Fromundus pygmaeus; 33 - Fromundus parcimonius; 34 - Geotomus gracilipes; 35 - Lactistes vericulatus; $\mathrm{v}$ - vagina; vp - vaginal pouch. Scale bars: $0.2 \mathrm{~mm}$.

A. apicalis. This species is somewhat different in having a receptacle slightly bent and ovoid; a part of its distal coiled duct is also wider, with a cuticular intima slightly wrinkled. Kumar (1962: Fig. 58) described the same features for A. apicalis (slightly bent receptacle, long and coiled distal duct, small dilation-invagination), except for the wrinkled walled distal duct. According to Linnavuori (1993), the receptacle of A. intrusus is also "strongly" bent.

Ring sclerites (very fine) present (A. apicalis), associated with a pair of lateral vaginal pouches (shallow).

Byrsinus Fieber (Figs 26, 27, 82). Receptacle slightly hemispherical, connected by a neck. Intermediate part long and slender, except at base where it is enlarged and cup-like; flexible zone narrow; flanges well developed. Duct with various dilation-invaginations depending on the species: pear-shaped or spherical, small or big, more or less pigmented, and sometimes opaque (pallidus); distal duct relatively long and coiled (except for flavicornis); proximal duct either short (Fig. 27, pilosulus, palli$d u s$ ) or very long (Fig. 26, pseudosyriacus). Opening simple.

Ring sclerites present, associated with a pair of lateral vaginal pouches.

Cyrtomenus Amyot \& Serville. Receptacle spherical or ovoid, connected by a neck. Duct short with a spherical dilation-invagination with a strongly pigmented central core, proximal duct wide. 

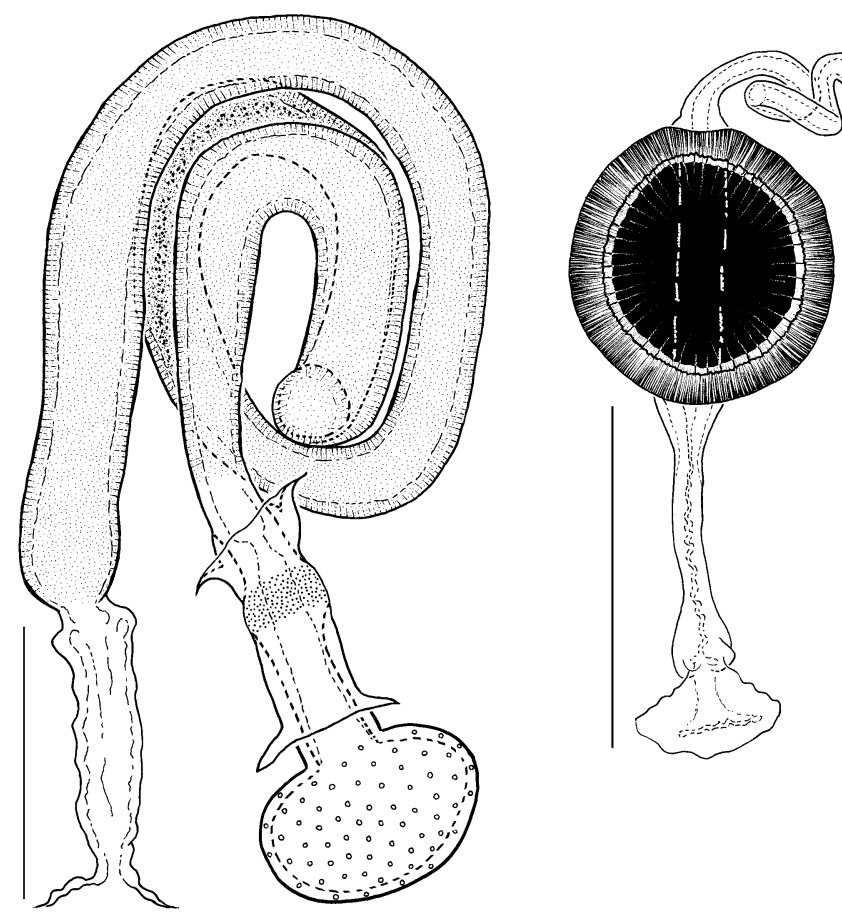

36
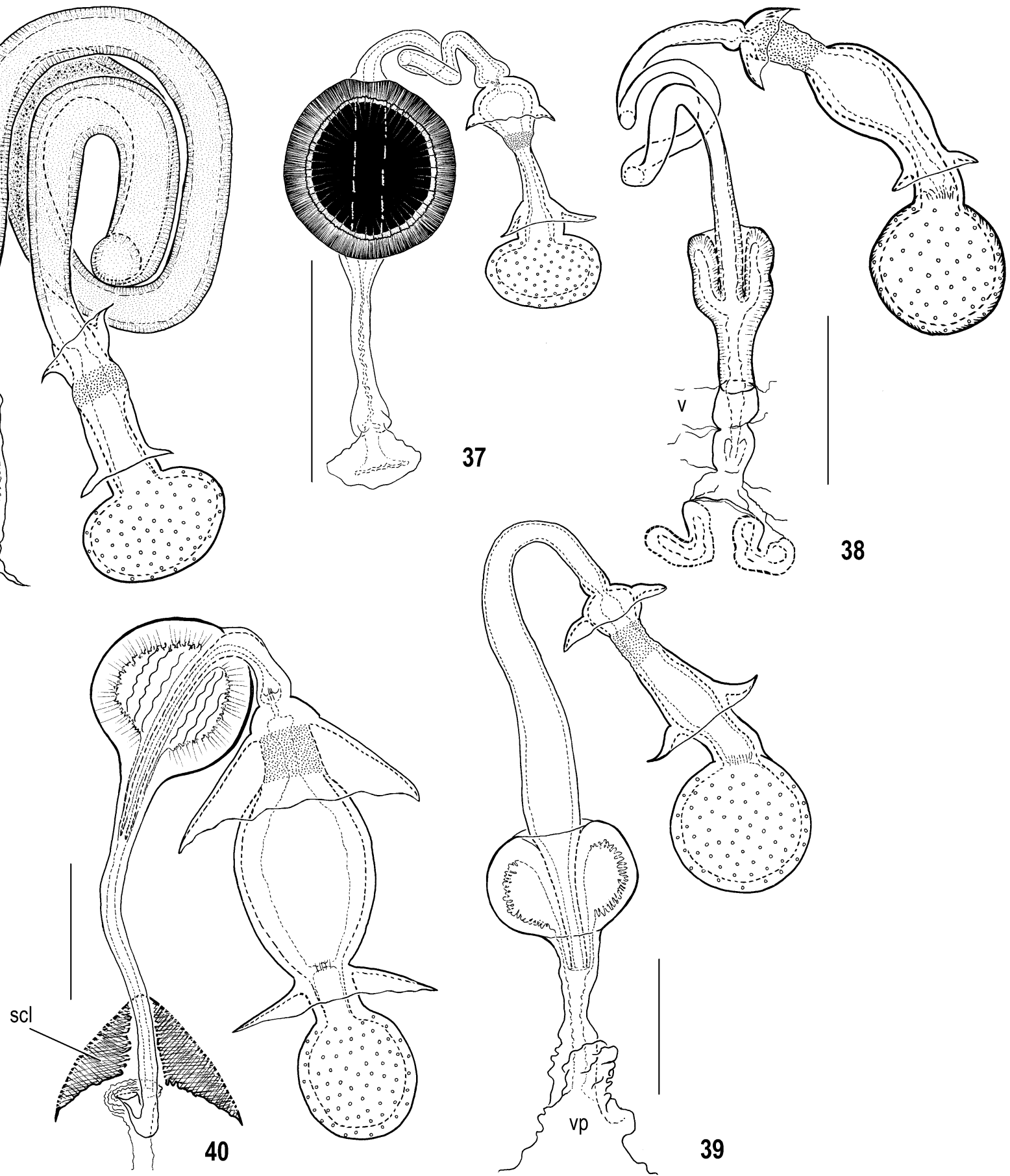

38

39

Figs 36-40. Spermathecae in Cydninae: Geotomini: 36 - Microporus nigrita; 37 - Microporus lautipennis; 38 - Macroscytus brunneus; 39 - Macroscytus reflexus; 40 - Paraethus capicola; v - vagina; vp - vaginal pouch; scl - sclerite on the vaginal wall. Scale bars: $0.2 \mathrm{~mm}$.

Dallasiellus Berg. Spermathecal duct with a very small dilation-invagination; proximal duct wide and short.

Otherwise, see the description and figure given by McDonald (1966: 55, Fig. 511) for D. discrepans. The spermatheca is the same as in D. viduus, but this author drew a pear shaped receptacle; he also indicated the presence of a pair of ring sclerites.

Endotylus Horváth (Fig. 30). Receptacle spherical connected by a very short neck. Intermediate part largely swollen from distal flange to narrow flexible zone; flanges well developed; proximal one cup-like; septum conspicuous. Duct relatively short, with spherical or pear-shaped dilation-invagination slightly pigmented. Spermathecal opening simple.

Ring sclerites present, inconspicuous, associated with a pair of not well differentiated lateral vaginal pouches.

Fromundiellus Lis, Fromundus Distant (Figs 33, 76). Receptacle spherical to hemispherical connected by a long neck. Intermediate part long; flanges well developed; flexible zone in basal position. Duct with a spherical 


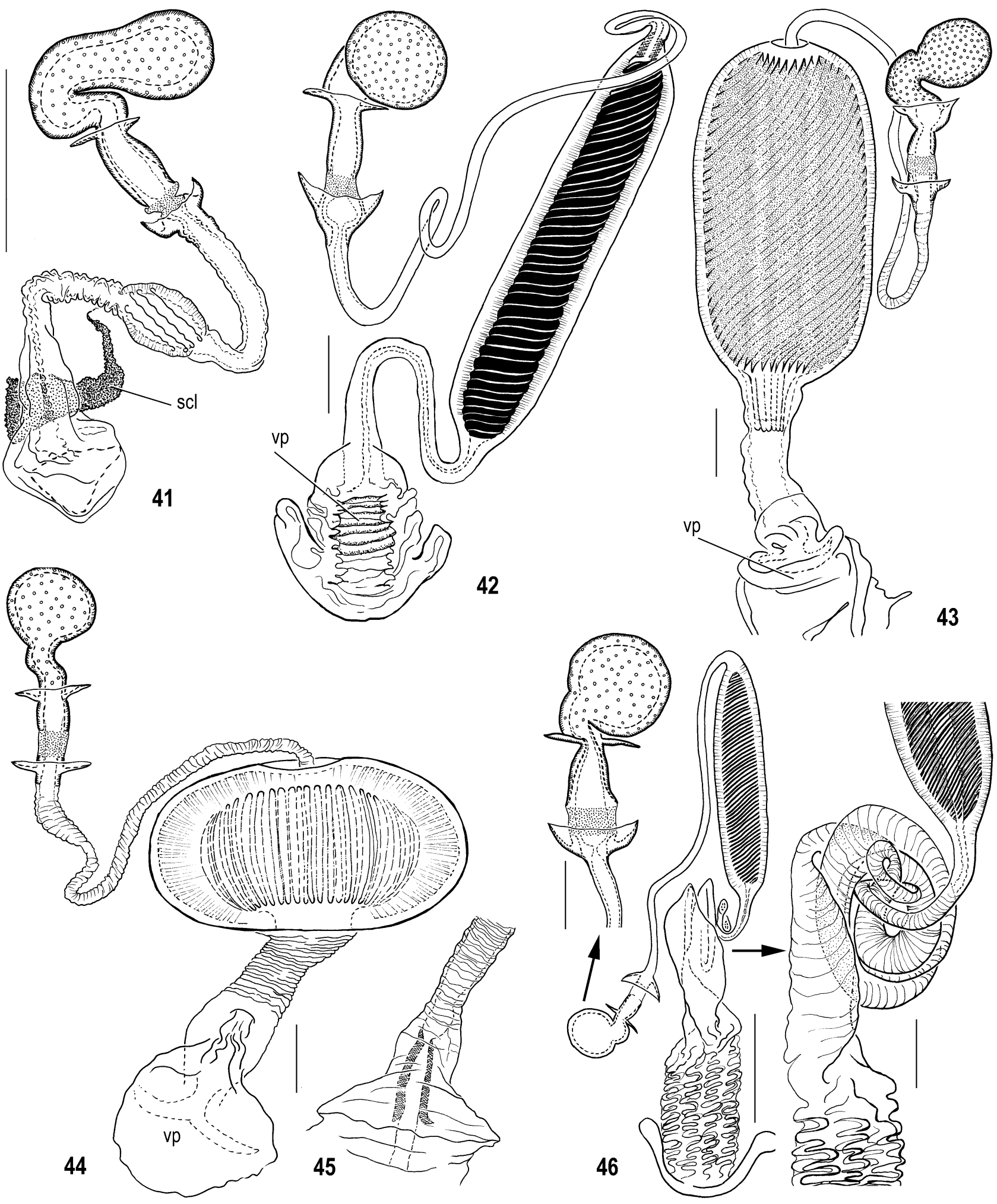

Figs 41-46. Spermathecae in Cydninae Geotomini: 41 - Gampsotes parallelus; 42 - Katakadia caliginosa; 43 - Hiverus hirtus; 44 - Adrisa atra; 45 - Teabooma princeps, base of the proximal duct and spermathecal opening into the vagina; 46 - Scoparipes stygius, general view and details: seminal receptacle and intermediate part, on the left; proximal duct, on the right; vp - vaginal pouch; scl - sclerotization in the vaginal wall. Scale bars: $0.2 \mathrm{~mm}$, except Fig. 46 (general view): $1 \mathrm{~mm}$.

dilation-invagination (except for $F$. pygmaeus) of variable size (from very small to big), more or less pigmented and opaque, with striated wall; distal duct short in
Fromundus, rather long in Fromundiellus; proximal duct short. Spermathecal opening simple.

Exception: in Fromundus pygmaeus (Fig. 32), the duct is short and devoid of dilation; at its base, it forms a short 

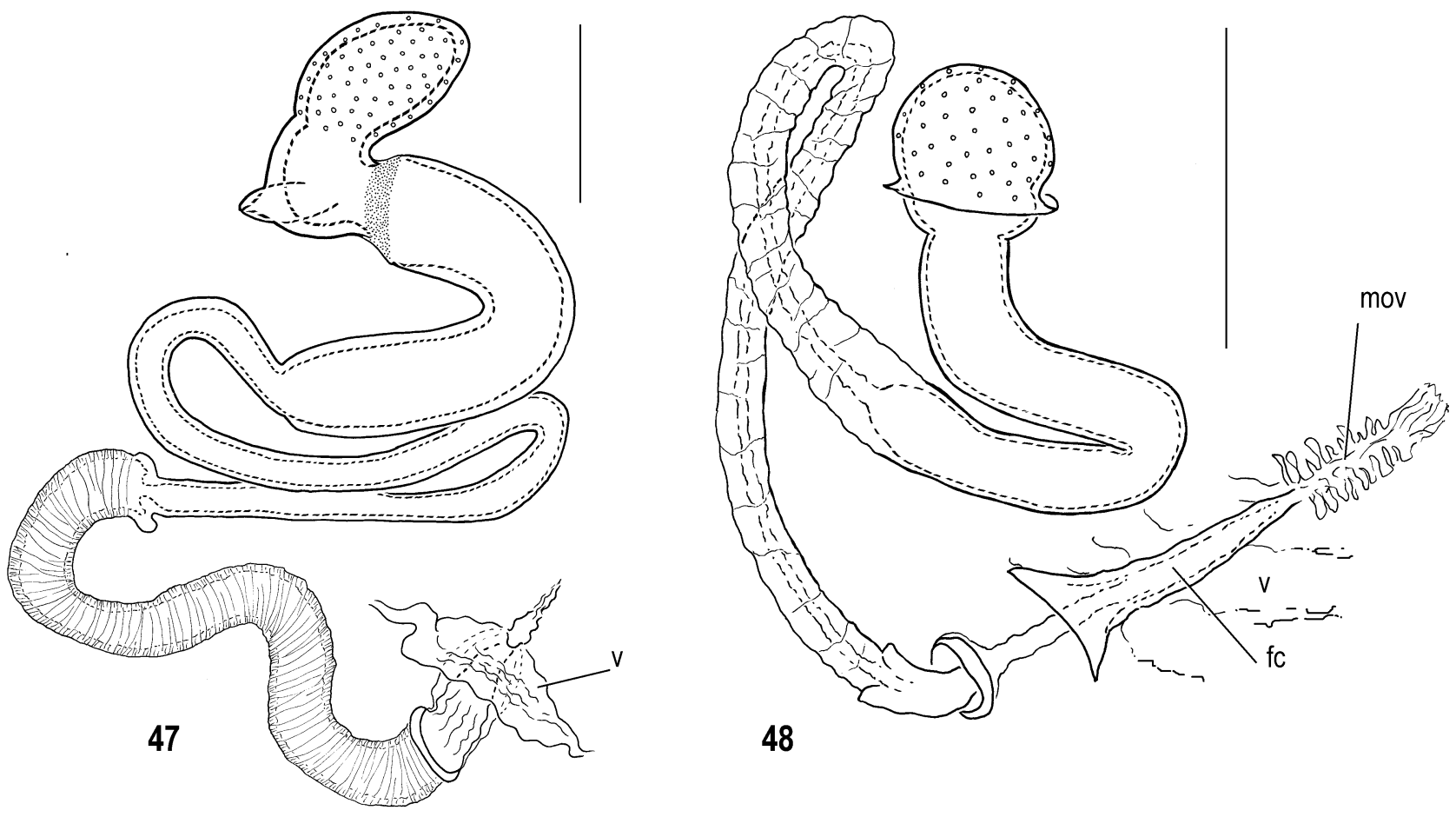

48

Figs 47, 48. Spermathecae in Garsauriinae: 47 - Garsauriella haglundi; 48 - Peltoxys thaumastellus; fc - fecundation canal; mov - median oviduct; $\mathrm{v}$ - vagina. Scale bars: $0.2 \mathrm{~mm}$.

invagination just before the opening into the vagina, through a small dorsal pouch. According to Kim \& Lee (1995: Fig. 4), the spermathecal duct forms also in Fromundus palliditarsus a small invagination inside the enlarged basal part of the duct.

Ring sclerites present, associated with a pair of lateral vaginal pouches.

Gampsotes Signoret (Fig. 41). Receptacle elongate and bent at right angle, strongly sclerotized and pigmented, thick-walled. Intermediate part long and straight; flanges of moderate size; flexible zone short in basal position; septum indistinct, fretum present. Duct unpigmented, rather short and wide, thin-walled, soft and more or less wrinkled, with a small dilation at its middle, the latter being simple without invagination and thick-walled (striated intima); proximal duct becoming progessively wider at base. Spermathecal opening simple and very wide, situated just beside a curious sclerotized structure present in vaginal wall.

Ring sclerites indistinct, probably absent; nevertheless, additional specimens should be examined in order to know if the two very small sclerotized rings found in the ventral vaginal wall are regressed ring sclerites or some small trivial sclerites.

Geocnethus Horváth (Fig. 29). Receptacle spherical connected by a neck. Intermediate part long and swollen in most studied species (see also the numerous drawings given by Linnavuori, 1993); it swells from distal flange to a narrowed basal flexible zone; flanges greatly expanded; the proximal one cup-shaped and particularly developed in several species (boulardi, ornatus, ornatellus). Duct with a dilation-invagination varying from species to species: from small to big, pear-shaped or spherical, variously pig- mented; distal duct rather short, sometimes reduced to a very small thickened and pigmented segment as in Fig. 29; proximal duct moderate. Spermathecal opening simple, through close folds and a small dorsal pouch of the vagina.

Ring sclerites present (oval and well marked) associated with a pair of lateral vaginal pouches.

Geotomus Mulsant \& Rey (Fig. 34). Receptacle hemispherical (sometimes slightly mushroom-shaped) connected by a neck. Intermediate part long and rather straight distally, cup-like enlarged at the level of the proximal flange. Duct with a pear-shaped dilation-invagination of variable size, from very small (elongatus) to moderate (perpunctatus), pigmented, unpigmented or with only some part pigmented; distal duct usually long and coiled, proximal one often wide and thick-walled. Spermathecal opening simple, into a small dorsal pouch of the vagina.

Ring sclerites present, associated with a pair of lateral vaginal pouches.

Lactistes Schiødte (Figs 35, 80). Receptacle spherical or ovoid connected by a short neck. Intermediate part wide, the two flanges well developed, the proximal one more expanded and cup-like; septum and fretum conspicuous. Duct with a pear-shaped dilation-invagination of moderate size, with strong sclerotizations at some places (particularly along the invaginated part of the duct, basally or at the top of the dilation); distal duct relatively long and coiled; proximal one shorter and straight. Spermathecal opening simple.

Ring sclerites present (but inconspicuous), as well as a pair of lateral vaginal pouches.

Note: All these characteristics seem constant within the genus (see also Linnavuori, 1993), in particular the form and the size of the dilation-invagination. 


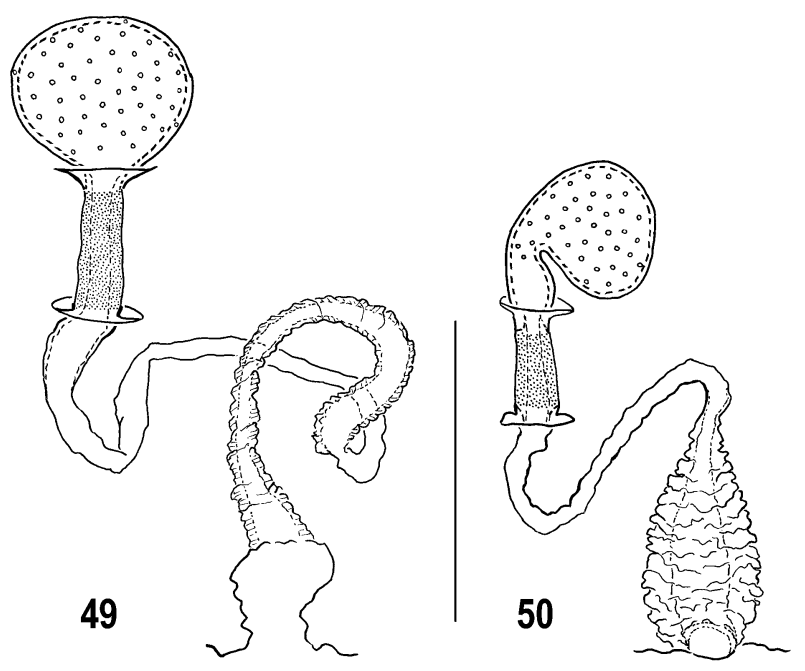

Figs 49, 50. Spermathecae of Nishocoris (Garsauriinae): 49 $N$. bicolor; $50-N$. bipunctatus. Scale bar: $0.2 \mathrm{~mm}$.

Macroscytus Fieber (Figs 38, 39). Receptacle ovoid or slightly elongated, hardly bent in most species examined. Duct with spherical dilation-invagination of different sizes (small to very big), variously pigmented; distal duct longer than proximal very short one; basal part of the latter may not be free (M. brunneus), linked to vaginal wall. Spermathecal opening simple, through some folds of vaginal wall.

Ring sclerites present, associated with a pair of lateral vaginal pouches.

Note: The widespread species M. brunneus has been examined and its spermatheca were compared in several different populations. All spermathecae are similar showing the same features (receptacle ovoid and bent, intermediate part long, spermathecal duct with a very small dilation-invagination). The previous data (Pendergrast, 1957; Linnavuori, 1993) confirm also the consistency of these features.

Melanaethus Uhler, Mesocricus Horváth, Microscytus Lis. Spermatheca as in Aethus and Aethoscytus. Receptacle spherical, slightly flattened, connected by a neck. Intermediate part long. Duct with a small or moderate dilation-invagination, spherical or pear-shaped.

Microporus Uhler (Figs 36, 37). Receptacle hemispherical, connected by a short neck. Intermediate part long and straight, proximal part cup-like in some species (see first group below); both flanges well developed. Two species groups may be recognized according to the spermathecal duct with or without dilation.

Group 1: lautipennis (Figs 37, 77), pallidipennis, vietnamicus. Duct with a spherical and pigmented dilationinvagination; distal duct slender and coiled; proximal one shorter and straight. Spermathecal opening simple.

Group 2: laticeps, nigrita (Fig. 36). Duct devoid of dilation; it appears coiled, distinctly wider than in species of group 1, and also softer, less sclerotized and smooth. In addition, the intermediate part is shorter and straight, unswollen basally.
Ring sclerites present in both groups, already indicated by Schmitz (1976) in M. pallidipennis. A pair of lateral vaginal pouches also present.

Pangaeus Stål. Receptacle ovoid. Duct with a small pear-shaped dilation; distal duct coiled and narrow; proximal duct definitely wider and rather short.

Paraethus Lis (Figs 40, 78). Receptacle spherical or ovoid connected by a neck. Intermediate part greatly swollen from distal flange to basal narrowed flexible zone; both flanges strongly developed, proximal one cuplike, expanded; septum and fretum clearly visible. Duct with pear-shaped dilation-invagination rather limpid; distal duct very short, proximal duct moderate. Spermathecal opening simple near small triangular sclerotized area in vaginal wall (capicola).

Ring sclerites and a pair of lateral vaginal pouches present.

Pseudonalips Froeschner. Duct having a big spherical pigmented dilation-invagination; distal duct long and coiled.

Raunoloma Lis. Intermediate part wide; proximal flange cup-like and greatly expanded. Dilationinvagination spherical and pigmented; strong sclerotizations at the junction between dilation and distal duct.

\subsubsection{Geotomine group II}

(Figs 44, 45)

Spermathecal duct with a large pumpkin-like dilation.

Adrisa Amyot \& Serville (Fig. 44). Receptacle spherical, sclerotized and pigmented, thick-walled, connected by a long slightly bent neck. Intermediate part long, straight, delimited by two well-developed flanges; flexible zone in basal position; a moderate fretum present. Duct entirely unsclerotized and unpigmented, swelling about its middle into a huge white pumpkin-like dilation (without invagination); dilation with a striking thick intima, striated (outer layer) and vertically fluted (inner layer), with elastic consistency; distal duct narrow, thinwalled, soft and folded (intima finely striated); proximal duct wider with same intima. Spermathecal opening into a small vaginal pouch somewhat complicated, with twists and turns.

Ring sclerites (small and well marked) present, associated with lateral vaginal pouches.

Choerocydnus White. Idem. Receptacle spherical straight, not bent. The pumpkin-like dilation includes an invagination.

Cydnotomus Lis. Idem. Duct with a very large flattened dilation-invagination (wheel-like).

Teabooma Distant. Idem. The large dilation is simple, without invaginated part of the duct; spermathecal opening into a small vaginal pouch including two internal rod-like sclerites well pigmented, placed longitudinally and running parallel to each other (Fig. 45).

\subsubsection{Geotomine group III}

(Figs 42, 43, 46)

Duct with a sausage-like dilation. 


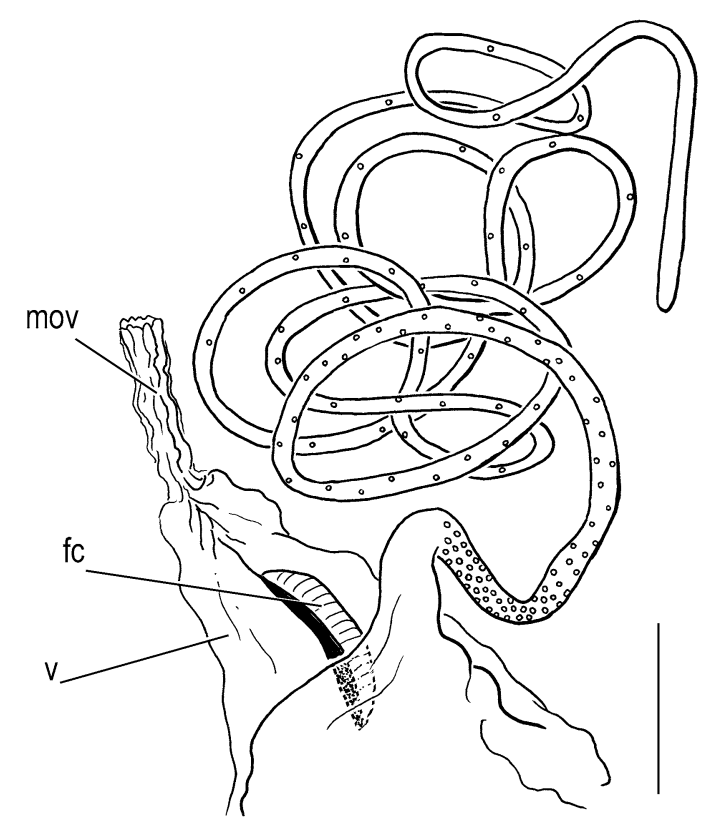

Fig. 51. Spermatheca of Amaurocoris curtus (Sehirinae, Amaurocorini); fc - fecundation canal; mov - median oviduct; v - vagina. Scale bar: $0.2 \mathrm{~mm}$.

Hiverus Amyot \& Serville (Fig. 43). Receptacle ovoid connected by a long neck strongly bent at right angle. Intermediate part long and straight; both flanges stout and likewise moderately expanded. Duct having a big barrelshaped dilation-invagination; cuticular wall of the latter slightly pigmented and half-translucent half-opaque, making outer diagonally regular grooves or stripes; distal duct long and narrow; proximal duct wide and short. Spermathecal opening through a small folded vaginal pouch.

Ring sclerites not apparent, probably absent.

Katakadia Distant (Fig. 42). Receptacle spherical connected by a strongly bent neck and reaching on one side distal flange. Intermediate part long with two well developed flanges; basal part cup-like, expanded; flexible zone in basal position. Duct with a long sausage-like dilation (simple, without invaginated part); cuticular wall of the latter very characteristic: outer layer finely striated, inner layer strongly pigmented (dark opaque with red reflections), regularly obliquely fluted. Spermathecal opening through numerous and regular large folds into a small fairly complex dorsal vaginal pouch.

Ring sclerites indistinct, but laterally on the vaginal wall a pair of huge membranous sacs is present.

Pseudoscoparipes Lis, Scoparipoides Lis. Same as Katakadia except for: receptacle strongly pigmented; proximal duct widening progressively toward the base, thick-walled, unpigmented, soft and folded; spermathecal opening through complicated folds of the vaginal wall.

Ring sclerites indistinct (Pseudoscoparipes), probably absent; same for the lateral vaginal pouches not observed.

Scoparipes Signoret (Fig. 46). Same spermathecal features as in Katakadia except for the proximal duct much longer and coiled, strongly widening toward the base. Opening into vagina unclear, difficult to interpret: a long and broad segment densely folded can be seen just as well as basal part of the spermathecal duct or as a part of the vagina.

Ring sclerites absent (not found); a pair of lateral pouches present.

\subsection{Garsauriinae Froeschner}

(Figs 47, 50)

Species examined: Blaena coarctata Froeschner, setosa Walker Garsauria aradoides Walker, laosana Lis, usambarica Schouteden - Garsauriella haglundi (Bergroth) - Nishocoris bicolor Lis, bipunctatus Lis - Peltoxys brevipennis (F.), thaumastellus Linnavuori, typicus (Distant).

Previous data: Linnavuori (1993): Garsauriella haglundi (Bergroth). Nishadana arabica (Horváth), Peltoxys thaumastellus Linnavuori.

Blaena Walker, Garsauria Walker, Garsauriella Linnavuori (Fig. 47). Receptacle ovoid, weakly pigmented, slightly bent to a very wide strongly curved neck; the latter bearing at base a reduced flange on one side only. Intermediate part well marked distally by this asymmetrical distal flange, not delimited proximally (due to absence of proximal flange); short flexible zone present posteriorly to distal flange; septum or fretum absent. Duct very wide and long, contorted, formed by two quite different segments: 1) a long segment three times folded, smooth, rigid and slightly pigmented; the first third very wide, then turning abruptly narrower along remaining two thirds; the segment ending into a small thick-walled swelling; a kind of fretum present at this level; 2) second part leading to vagina unsclerotized, unpigmented, soft; cuticular intima striated and folded; at base, a sclerotized ring around the duct present. Spermathecal opening somewhat complicated and not entirely understood; hidden under a large funnel-like vaginal fold with some structures resembling a fecundation canal.

Ring sclerites (conspicuous, subtriangular) present, not associated with lateral vaginal pouches.

Nishadana Distant. From the drawing given by Linnavuori (1993: Fig. 91d): Receptacle spherical. Intermediate part with very reduced flanges (distal flange seems absent). Duct simple, very long and coiled, without any differentiation.

Nishocoris Lis (Figs 49, 50). Receptacle hardly pigmented, thin-walled, spherical without neck (bipunctatus) or ovoid with a neck and strongly bent (bicolor). Intermediate part straight delimited by two moderate flanges and almost entirely occupied by a long flexible zone. Duct soft, thin-walled, basally widdened either as a distinct small dilation (bicolor) or as a weak widening of the ductus (bipunctatus), these widdened parts having same wrinkled intima in the two species. Spermathecal opening simple.

Ring sclerites present but inconspicuous, not associated with vaginal pouches.

Peltoxys Signoret (Fig. 48). Entire spermatheca unpigmented. Receptacle spherical, with a small asymmetrically developed flange (distal flange) around its basal part. Intermediate part as in Blaena, Garsauria and Garsauriella, delimited by the above mentioned asymmetrical distal flange and not delimited posteriorly (lacking of proximal 


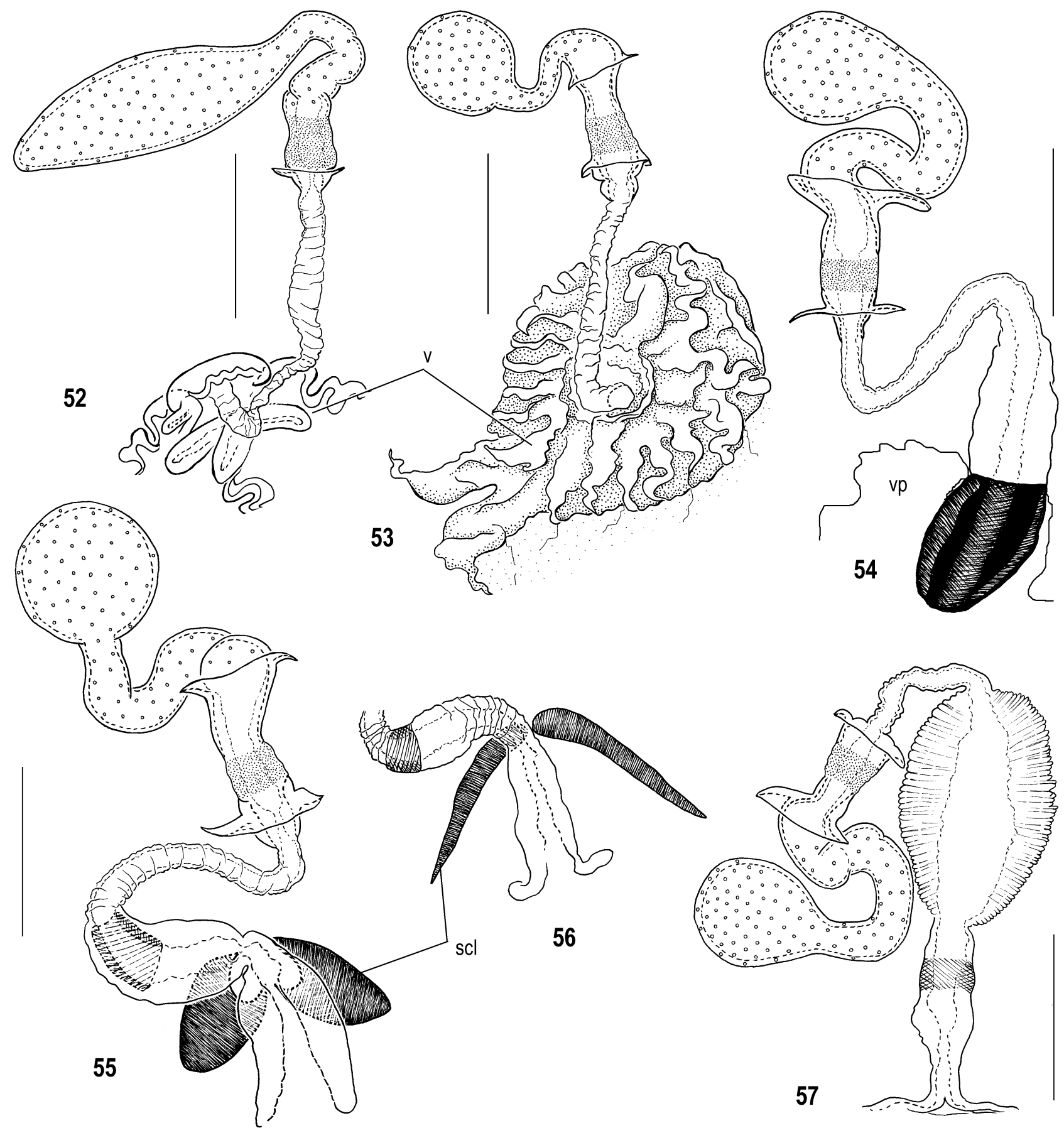

Figs 52-57. Spermathecae in Sehirinae: Sehirini: 52 - Adomerus rotundus; 53 - Adomerus congener; 54 - Adomerus biguttatus, the base of the spermathecal duct is entirely pigmented and sclerotized; 55 - Sehirus morio; 56 - Sehirus luctuosus, spermathecal opening into vagina; 57 - Canthophorus melanopterus; scl - sclerites on the vaginal wall; $\mathrm{v}$ - vagina; vp - vaginal pouch. Scale bars: $0.2 \mathrm{~mm}$.

flange); nevertheless, in Peltoxys, no flexible zone is obvious. Duct: different parts of duct similar to those described in Garsauriella. Spermathecal opening through particular vaginal structures: posteriorly to a sclerotized ring encircling the base the duct, follows a funnel-shaped duct entering into a long cuticular piece ending with a pointed tip. This vaginal structure drawn also by Linnavuori (1993: Fig. 104) might be a kind of fecundation canal.
Ring sclerites (thick and subtriangular) present, not associated with vaginal pouches.

\subsection{Sehirinae Amyot \& Serville}

(Figs 51-62)

\subsubsection{Amaurocorini Wagner}

(Fig. 51)

Species examined: Amaurocoris curtus (Brullé) - Linospa candida (Horváth), orbicularis (Jakovlev). 


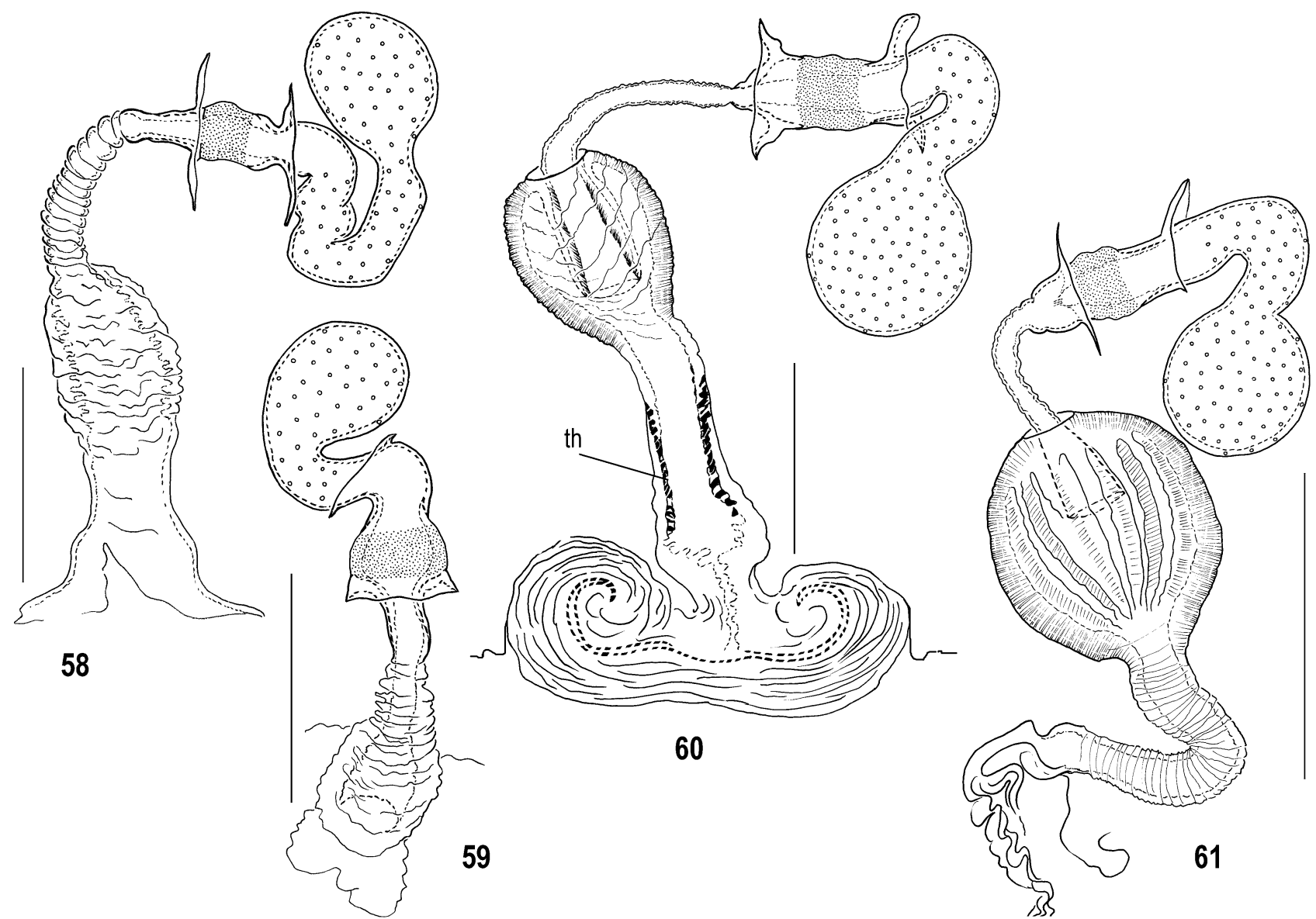

Figs 58-61. Spermathecae in Sehirinae: Sehirini: 58 - Legnotus picipes; 59 - Lalervis expansa; 60 - Tritomegas sexmaculatus; 61 - Crocistethus aeneus; th - pigmented thickening of the intima. Scale bars: $0.2 \mathrm{~mm}$.

Previous data: Ahmad \& Moizuddin (1980): Amaurocoris curtus (Brullé) (as Scutellocoris nigra Ahmad \& Moizuddin) - Linnavuori (1993): A. curtus (Brullé).

Amaurocoris Stål (Fig. 51), Linospa Signoret. Spermatheca consisting of a long, thin-walled tube of nearly uniform diameter throughout its length; in Linospa, the tube may be slighlty enlarged apically. Intermediate part absent. Cuticular wall thin and smooth without any differentiation from base to apex, covered with scattered glandular cells (ductules), the latter more dense in basal part. Spermathecal opening simple, wide, near a tubular structure slightly sclerotized and pigmented running into the vaginal dorsal wall from the base of the spermathecal tube towards the common oviduct. This structure is interpreted as a fecundation canal.

Ring sclerites absent.

Note. In Amaurocoris curtus, Ahmad \& Moizuddin (1980) noted a spermatheca devoid of flanges, pump region and apical bulb. Linnavuori (1993: Fig. 93f) reported and figured the spermathecal tube as having "a weakly sclerified" apical bulb, probably a mistake due to a specimen not cleared enough.

\subsubsection{Sehirini Amyot \& Serville}

(Figs 52-62)

Species examined: Adomerus biguttatus (L.), congener (Jakovlev), rotundus (Hsiao) - Canthophorus coeruleus
(Reuter), dubius (Scopoli), fuscipennis (Horváth), impressus (Horváth), melanopterus (Herrich-Schaeffer) - Croscistethus aeneus (Brullé), waltlianus (Fieber) - Lalervis alticola (Linnavuori), expansa (Signoret), tibialis (Stål) - Legnotus limbosus (Geoffroy), picipes (Fallén) - Ochetostethus balcanicus Wagner, brachyscytus Reuter, opacus (Scholtz), sahlbergi Wagner, tarsalis (Mulsant \& Rey) - Sehirus cypriacus Dohrn, luctuosus Mulsant \& Rey, morio (L.), parens (Mulsant \& Rey), robustus (Horváth) - Tritomegas bicolor (L.).

Previous data: Pendergrast (1957): Tritomegas bicolor (L.) (as Sehirus) - Putchkova (1959): Canthophorus dubius (Scopoli), Sehirus luctuosus Mulsant \& Rey, Tritomegas sexmaculatus (Rambur) - Polivanova (1959): Tritomegas sexmaculatus (Rambur) (as Canthophorus), bicolor (L.) (as Sehirus) - Linnavuori (1993): Ochetostethus opacus (Scholtz). Sehirus tibialis Puton - McDonald (1966): Sehirus cinctus (Palisot) - Kim \& Lee (1995): Adomerus triguttulus (Motschulsky) - Kerzhner (1976): Ochetostethus corniger Kerzhner, kiritshenkoi Medvedeva, nanus Herr.-Schaeffer, opacus Scholtz, perepelovi Kerzhner, tarsalis Mulsant \& Rey - Magnien (1998): Legnotus fumigatus (Costa), limbosus (Geoffroy), pericarti Magnien, picipes (Fallén) - Rizzotti-Vlach (2000): Ochetostethus melonii Rizzotti-Vlach - Magnien (2006): Ochetostethus balcanicus Wagner, heissi Magnien, opacus (Scholtz).

Adomerus Mulsant \& Rey (Figs 52-54). The spermatheca of the three studied species appeared to be quite different and will be described separately. Peculiar vaginal structures more or less associated with the spermathecal opening seem to occur frequently in this genus. 


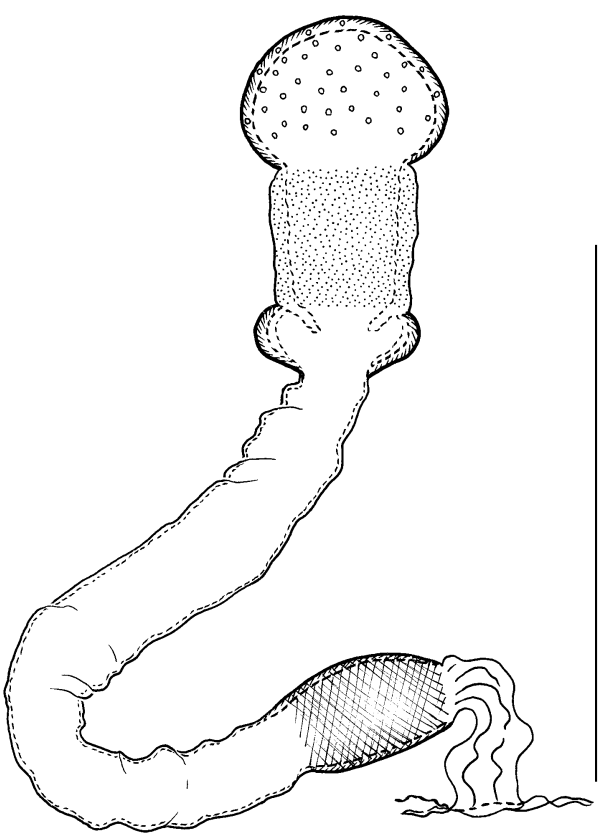

Fig. 62. Spermatheca of Ochetostethus tarsalis (Sehirinae: Sehirini). Scale bar: $0.2 \mathrm{~mm}$.

A. biguttatus (Fig. 54). Receptacle elongate, thinwalled, weakly pigmented and sclerotized; distally ovoid, basally bearing a long tubular-like contorted and strongly bent neck. Intermediate part straight, delimited by two well developed flanges, distal one relatively thick, proximal one thin and soft; flexible zone rather long; septum and fretum indistinct. Duct unpigmented, thinwalled, soft, narrow in first half of its length, then thickwalled widening progressively toward base, lumen remaining unchanged. Spermathecal opening via a strongly pigmented and sclerotized basal structure apparently formed by stout thickenings of duct cuticular wall. Just posteriorly to this sclerotized aperture, vagina differentiated into a stout multilobate dorsal pouch exhibiting a peculiar structure: a translucent intima remarquably thick, greatly sinuous internally and exhibiting numerous pigmented particles at some places.

Ring sclerites (thin and very close together) present in this species as well as in the two following species. No lateral vaginal pouches present.

A. congener (Fig. 53). Receptacle and intermediate part similar to those of $A$. biguttatus, but receptacle distally more spherical with a neck somewhat shorter, S-like curved, with flanges less developed. Duct short, unpigmented, membranous, soft. Spermathecal opening at center of a peculiar area of vaginal wall where intima is strongly folded with some pigment particles into folds; this area contrasts strongly with the very smooth cuticular intima found elsewhere in the vagina.

A. rotundus (Fig. 52). Receptacle thin-walled, elongate and oblong, connected by a twisted neck curved at right angle. Intermediate part rather short; distal flange absent, proximal one present, but reduced; flexible zone long; septum indistinct, fretum present. Duct short, unpig- mented, thin-walled, soft. Spermathecal opening into a folded asymmetrical vaginal pouch.

Note. The spermatheca of $A$. triguttulus described by Kim \& Lee (1995) is very similar to that of $A$. rotundus, but distal flange is present. In triguttulus, the authors noted also the presence of a pair of "accessory sacs" on both sides of the spermathecal duct, absent in rotundus.

Canthophorus Mulsant \& Rey (Fig. 57). Receptacle as in A. biguttatus. Intermediate part straight, delimited by two well-developed flanges, distal one slightly asymmetrical; flexible zone rather long at middle of the segment. Duct relatively short, unpigmented, with a median dilation simple (without invagination), elongate, thickwalled (with striated intima); distal duct narrow, thinwalled, soft; proximal duct wider, soft, a short sclerotized pigmented segment forming a ring in the middle. Spermathecal opening simple, without particular structure.

Ring sclerites (very thin) present. Rieger (1997) described and illustrated intraspecific variation in two species of the genus (C. dubius and C. impressus).

Croscistethus Fieber (Fig. 61), Tritomegas Amyot \& Serville (Fig. 60). Similar to Canthophorus except for the following. Intermediate part: disk-like flanges equal in size (Tritomegas), or distal flange asymmetrical (Croscistethus); flexible zone taking up the basal half of the segment. Duct: the dilation includes an invagination; the invaginated part of the duct becomes progressively wider and does not reach the basal part of the dilation; the cuticular wall of the dilation is thick and striated, forming large vertical folds; distal duct narrow, thin-walled, soft; proximal one wider, exhibiting some internal sclerotized spots strongly pigmented at some places (Tritomegas). Spermathecal opening through simple irregular folds (Croscistethus), or through a large vaginal structure roughly bilobed, this one having a cuticular wall remarkably thick, regularly winded on both sides of the opening (Tritomegas); this structure does not form two sac-like pouches as figured by Polivanova (1959), because the lumen appears in fact extremely thin in the dense roll of cuticle.

Ring sclerites present, different in the two species: thin, oval and close together (Croscistethus); thick, strongly pigmented, distant (Tritomegas).

Lalervis Signoret (Fig. 59), Legnotus Schiødte (Fig. 58). Receptacle as in previous genera, thin-walled, weakly or not pigmented or sclerotized; neck more or less elongated and twisted depending on the species. Intermediate part either straight with well-developed flanges (Legnotus) or wide (or widening towards base) with reduced flanges (Lalervis); flexible zone long; septum inconspicuous, fretum not very pronounced. Duct short, soft, with folded wall, widening basally into a dilation, more pronounced and differentiated (creased wall) in Legnotus than in Lalervis. Spermathecal opening into vagina simple through some folds of vaginal wall.

Ring sclerites present, already observed and described by Magnien (1998) in several species of Legnotus.

Ochetostethus Fieber (Fig. 62). Receptacle spherical, thin-walled, well pigmented and sclerotized, directly con- 


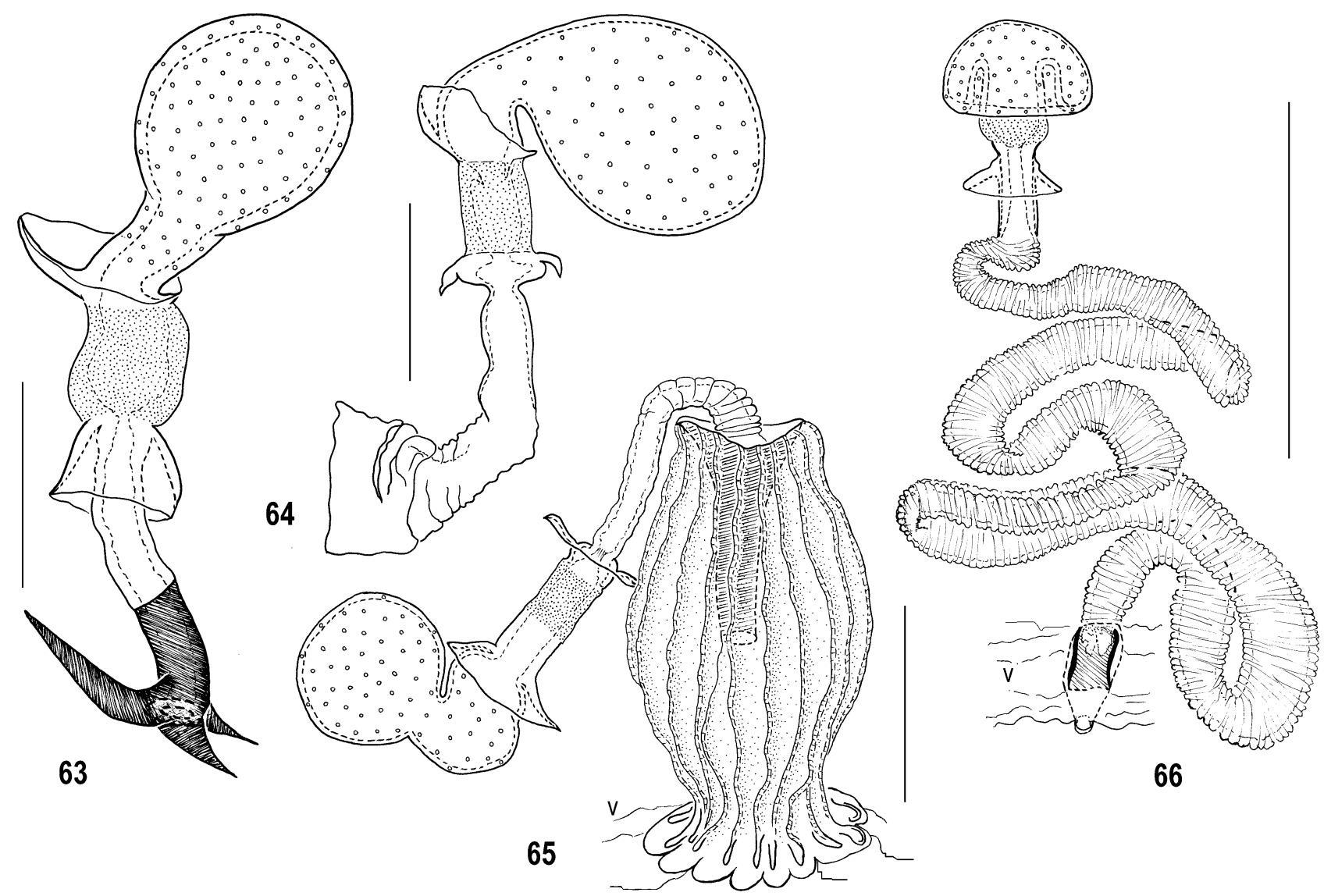

Figs 63-66. Spermathecae of some species removed from Cydnidae or still unplaced: 63 - Parastrachia japonica (Parastrachiidae); 64 - Dismegistus sanguineus (unplaced); 65 - Thyreocoris scarabaeoides (Thyreocoridae); 66 - Thaumastella aradoides (Thaumastellidae); $\mathrm{v}$ - vagina. Scale bars: $0.2 \mathrm{~mm}$.

nected to intermediate part. Intermediate part wide, devoid of flanges, consisting of a long, straight flexible zone, and a widened cup-like well pigmented basal part; septum unobtrusive, fretum well distinct. Duct simple, wide, thinwalled but rigid, devoid of any differentiation except for short basal segment sclerotized and slightly pigmented. Opening into vagina simple, through small membranous pouch.

Ring sclerites inconspicuous, probably absent.

Note. The comparative data already obtained (Kerzhner, 1976; Magnien, 2006) and the present observations show that the spermatheca is remarkably uniform within the genus; in particular, the duct is devoid of any differentiation except a basal sclerotized ring, always present.

Sehirus Amyot \& Serville (Fig. 55). Receptacle and intermediate part as in Canthophorus or very similar. Duct short, soft and folded without definite dilation or differentiation, widening slightly toward base, a short segment pigmented and sclerotized as in Canthophorus. Spermathecal opening between a pair of strongly pigmented sclerites differentiated in the vaginal wall; the form of these sclerites is distinct in the two species examined: morio (Fig. 55) and luctuosus (Fig. 56).

Ring sclerites present.

\subsection{Genera formerly included within Cydnidae: Dismegistus, Parastrachia, Thaumastella, Thyreocoris}

\section{Genus Dismegistus Amyot \& Serville}

(Fig. 64)

A still unplaced genus.

Species examined: Dismegistus sanguineus de Geer. Previous data: Leston (1956): D. binotatus (Weswood) - Dolling (1981): D. fimbriatus (Thunberg).

Description. Receptacle ovoid, thin-walled, weakly pigmented and sclerotized, connected by a short strongly bent neck. Intermediate part straight, delimited by two flanges; distal one long and thin, asymmetrically developed (on one side only); proximal one short and thick, pigmented, poorly developed; flexible zone long occupying entire length between flanges; septum and fretum present. Duct short, soft, devoid of differentiation, widening toward base. Spermathecal opening wide and simple, through some large folds.

Pair of conspicuous ring sclerites (thick and pigmented) present; presence of associated vaginal pouches (poorly differentiated) suspected.

\section{Genus Parastrachia Distant}

(Fig. 63)

Currently in Parastrachiidae Oshanin.

Species examined: Parastrachia japonensis (Scott). 
Previous data: Schaefer et al. (1988): P. japonensis (Scott).

Description. Receptacle ovoid connected by a slightly bent neck, sclerotized and pigmented, thick-walled. Intermediate part delimited by two well developed flanges, distal one asymmetrical and perpendicular to duct, proximal one extending posteriorly along duct; flexible zone occupying entire segment between flanges; septum and fretum inconspicuous. Duct very short and simple, basal part strongly sclerotized and pigmented, equipped with three buttress-like carina around vaginal opening. Spermathecal opening itself very simple in dorsal vaginal wall, strongly sclerotized and pigmented, (see description given by Schaefer et al., 1988).

Ring sclerites present as already shown by Schaefer et al. (1988); they are associated with a pair of well developed lateral vaginal pouches, similar to those found in geotomine species (Fig. 1A).

\section{Genus Thaumastella Horváth}

(Fig. 66)

Currently in Thaumastellidae Seidenstücker.

Species examined: Thaumastella aradoides Horváth

Previous data: Štys (1964): T. aradoides Horváth - Jacobs (1989): T. elisabethae Jacobs, namaquensis Schaefer \& Wilcox.

Description. Receptacle very small, slightly pigmented, subhemispherical, mushroom-shaped. Intermediate part rather short, delimited by a stout medium-sized proximal flange; distal flange absent; flexible zone in apical position, septum present posteriorly; just behind flange, a short rigid segment connects spermathecal duct. Duct very long and wide, soft and coiled; its membranous wall entirely transparent, finely creased. Spermathecal opening through small rectangular rigid structure differenciated in vaginal wall.

Ring sclerites not observed, probably absent.

Note. Our observations are in agreement with the description given by Štys (1964). Only Jacobs (1989) mentioned the mushroom-shaped structure of the receptacle in two other species of the genus, but he did not give any precise information about the spermathecal duct.

\section{Genus Thyreocoris Schrank}

(Fig. 65)

Currently in Thyreocoridae Amyot \& Serville.

Species examined: Thyreocoris scarabaeoides (L.). Previous data: Pendergrast (1957), Putchkova (1959) and Štys \& Davidová (1979): T. scarabaeoides (L.), T. fulvipennis (Dallas).

Description. Receptacle weakly sclerotized, bent at right angle, formed by a spherical distal part and a twisted basal neck. Intermediate part straight, delimited by two equally well-developed flanges; flexible zone long (about half the length of intermediate part); septum and fretum present, unobtrusive. Duct with a huge membranous basal dilation-invagination; invaginated part large, slightly sclerotized and pigmented, reaching into only a half length of the dilated part; wall of dilation very thin, transparent and regularly pleated; distal duct short, soft and folded; no proximal duct. Spermathecal opening into vagina simple and large, direct from base of dilation of spermathecal duct.

Ring sclerites not found, probably absent.

\section{THE DIFFERENT TYPES OF SPERMATHECAE RECOGNIZED WITHIN THE CYDNIDAE}

From the results presented above, one may recognize four main types of spermathecae in the Cydnidae (as currently delimited), which can be distinguished according to the number and structure of the differentiated parts: the amaurocorine, amnestine, garsauriine types, and a multifacied pentatomoid type, named here for convenience "cydnoid" type. Within the "cydnoid" type, six different spermathecal facies can be observed: the ochetostethan, cydnan, sehiran, scoparipan, adrisan and geotoman facies. We attempt here to define and to comment these morphological types, from simple to more complex. The characters defining each type and facies are summarized in Table 1. Table 2 shows how the spermathecal types and facies are distributed within the family.

In order to facilitate the comparison between the different types of spermathecae, we shall consider first the characteritic features of the pentatomoid type of spermatheca, based on the literature data (mainly Pendergrast, 1957; McDonald, 1966, 1970, 1976, 1979; Gapud, 1991) and our own unpublished investigations on Pentatomoidea and other Pentatomomorpha.

\subsection{The pentatomoid type of spermatheca}

In Pentatomoidea, a large and extremely diverse group of bugs, the spermatheca shows a great diversity, especially at the level of the spermathecal duct and to a lesser extent also at the level of the apical receptacle. As in other Pentatomomorpha, it is usually associated with parietovaginal glands (ring sclerites). The pentatomoid spermatheca can be clearly defined by its intermediate part well delimited by two flanges (Pendergrast, 1957; McDonald, 1966; Štys \& Davidová, 1979; Schaefer et al., 1988; Schaefer, 1993b; Gapud, 1991) and the other features listed below.

\subsubsection{A highly complex and characteristic intermediate part}

This segment is of great interest because it is easily recognizable and exhibits some distinctive characters: it is short, distinctly delimited by distal and proximal flanges, it comprises a flexible zone and two other particularities, namely a septum and a fretum (Fig. 69) (unpublished data).

An intermediate part with this shape is present in all families of Pentatomoidea and it does not exist either in Coreoidea or in Lygaeoidea. In those groups, the intermediate part is often very long, flanges occur rarely and the flexible zone is lacking, although judging from some drawings it seems that its occurence may be suspected in some species (Rhyparochromidae) (see in particular: Slater \& Sweet, 1977; O’Donnell, 2000).

As already shown by Carayon (1955) and Pendergrast (1957), a pentatomoid-like spermatheca with a similar intermediate part (and the same bulbous apical receptacle) 
is also present in two other pentatomomorphan groups (Pyrrhocoroidea, Aradoidea), and also in Leptopodomorpha (Saldoidea). We confirm here this finding. The Pyrrhocoroidea possess indeed the proximal flange, a flexible zone and a septum (see Pluot, 1970). The Aradidae possess also one or both flanges (exceptionally none) (see Kumar, 1967; Lee \& Pendergrast, 1983; Monteith, 1997), and a flexible zone and a septum (unpublished data). The Saldidae also have a pentatomoid-like spermatheca with an intermediate part often well delimited by a proximal flange (see Cobben, 1980, 1985, and unpublished data from J. Carayon summarized by Péricart, 1990); nevertheless, one must emphasize that in Saldidae there is no flexible zone, and no septum or fretum (unpubl. data, to be verified).

\subsubsection{The ground plan of the pentatomoid spermatheca}

According to Schaefer et al. (1988), Gapud (1991) and Schaefer (1993b), a hypothesis on the ground plan structure of the pentatomoid spermatheca can be formulated. The plesiomorphic pentatomoid spermatheca consists probably of the following elements: a globose or spherical apical receptacle; an intermediate part relatively short, well delimited by at least a proximal flange (never absent, but rare exceptions exist) and having a flexible zone and at least a septum; a duct simple, devoid of differentiated part. It is also usually associated with a pair of ring sclerites.

\subsection{Types of spermathecae within Cydnidae: Description and comments}

Both the receptacle and the intermediate part (Figs 67, $68,70-75)$, which are relatively constant compared to the spermathecal duct, are useful in establishing the main types. The structure of the spermathecal duct, very variable, cannot be used; nevertheless, it allows to define several particular facies of spermatheca. The first three types appear to be of a non-pentatomoid type as defined above. The fourth type named here for convenience "cydnoid" type is clearly pentatomoid.

\subsubsection{The amaurocorine type}

Genera included: Amaurocoris (Fig. 51), Linospa.

General structure. Spermatheca reduced to a long coiled tube devoid of any cuticular differentiation along its length; cuticular intima unsclerotized and unpigmented, surrounded by glandular cells. Spermathecal opening associated to a vaginal structure interpreted as a fecundation canal. Ring sclerites absent.

Comments. The whole tube functions as a long seminal receptacle. This type of spermatheca, extremely simple, differs radically from all other types found in Cydnidae. To our knowledge, such a basic type has not been described until now in Pentatomoidea or Pentatomomorpha. It is in fact very strange and difficult to understand and to interpret.

This simple structure could reflect a regressive evolution similarly as observed in rare pentatomoid genera: for instance Trichopepla (Pentatomidae) (cf. McDonald, 1966, 1976) and Megaris (Megarididae) (cf. McDonald, 1979). Regression seems to have occurred also in certain
Scutelleridae such as Fokkeria and Homaemus (McDonald, 1966: Figs 412, 431) in which the spermatheca tends to be elongate with an intermediate part poorly differentiated, and is also associated with a fecundation canal. Nevertheless, in the case of Amaurocoris and Linospa, the length of the spermathecal tube $(5 \mathrm{~mm}$ in Amaurocoris: as long as the total length of the insect) does not seem to be in favour of a regression.

Certainly, as noted by Štys (1962), long and tubular spermathecae with undifferentiated apical bulbous receptacle occur also in some pentatomomorphan families. They are known actually in: Alydidae (Ahmad \& Southwood, 1964; Kumar, 1965a; Vavrinová, 1988; Moulet, 1993), Coreidae Hydarini (Brailovsky, 1987), Lygaeidae Lygaeinae (Scudder, 1965; Brailovsky, 1984) or Heterogastridae (Scudder, 1962). However, in Lygaeinae, and probably in other groups, one can recognize in the spermathecal tubewhen carefully examined - the three characteristic differentiated parts (receptacle, intermediate part, duct) present in most pentatomomorphan groups, if not all.

Finally, one can also observe that the amaurocorine type is surprisingly similar to the type found in Gerromorpha (Pendergrast, 1957; Andersen, 1982): a spermathecal tube associated with a fecundation canal. But it is a clear case of convergence. It is known indeed that a fecundation canal arose by convergent evolution in several heteropteran families (see Pendergrast, 1957; Scudder, 1959; Cobben, 1970; Pluot, 1970; Andersen, 1982) and even in Coleoptera (see Pendergrast, 1957). In Pentatomoidea, the structures described as a "sclerotized groove" in Canopus (Canopidae) and several scutellerid genera by McDonald (1966) are the same structures described later by GaffourBensebbane (1991a, b, 1992) in some other Scutelleridae as "canal de fécondation".

\subsubsection{The amnestine type}

Genus included: Amnestus (Fig. 4).

General structure. Spermatheca only slightly sclerotized, consisting of only two distinctly differentiated parts: a spherical apical receptacle and a wide coiled rigid duct (Fig. 67). Typical intermediate part with flanges absent (but see comments below). Spermathecal opening somewhat complicated, surrounded by a small evagination and a weakly sclerotized ring of the vaginal wall. A membranous sac-like diverticulum present at base of the duct. Ring sclerites absent.

Comments. McDonald (1966) considered the amnestine spermatheca as "highly aberrant" and unique. The amnestine type is indeed strange: it lacks a definite intermediate part (absence of flanges) and the duct possesses a basal membranous diverticulum.

Lacking a definite intermediate part, the amnestine type does not belong to the general pentatomoid type as defined above. In the absence of flanges (or some apodemes), the intermediate part cannot be recognized with certainty. Nevertheless, two structures suggest that a kind of intermediate part might exist: a cuticular rim (like a small distal flange) at base of the receptacle, and a (possible) very narrow flexible zone just below the capsule (Fig. 67). If we interpret the coiled stout duct as part of the interme- 

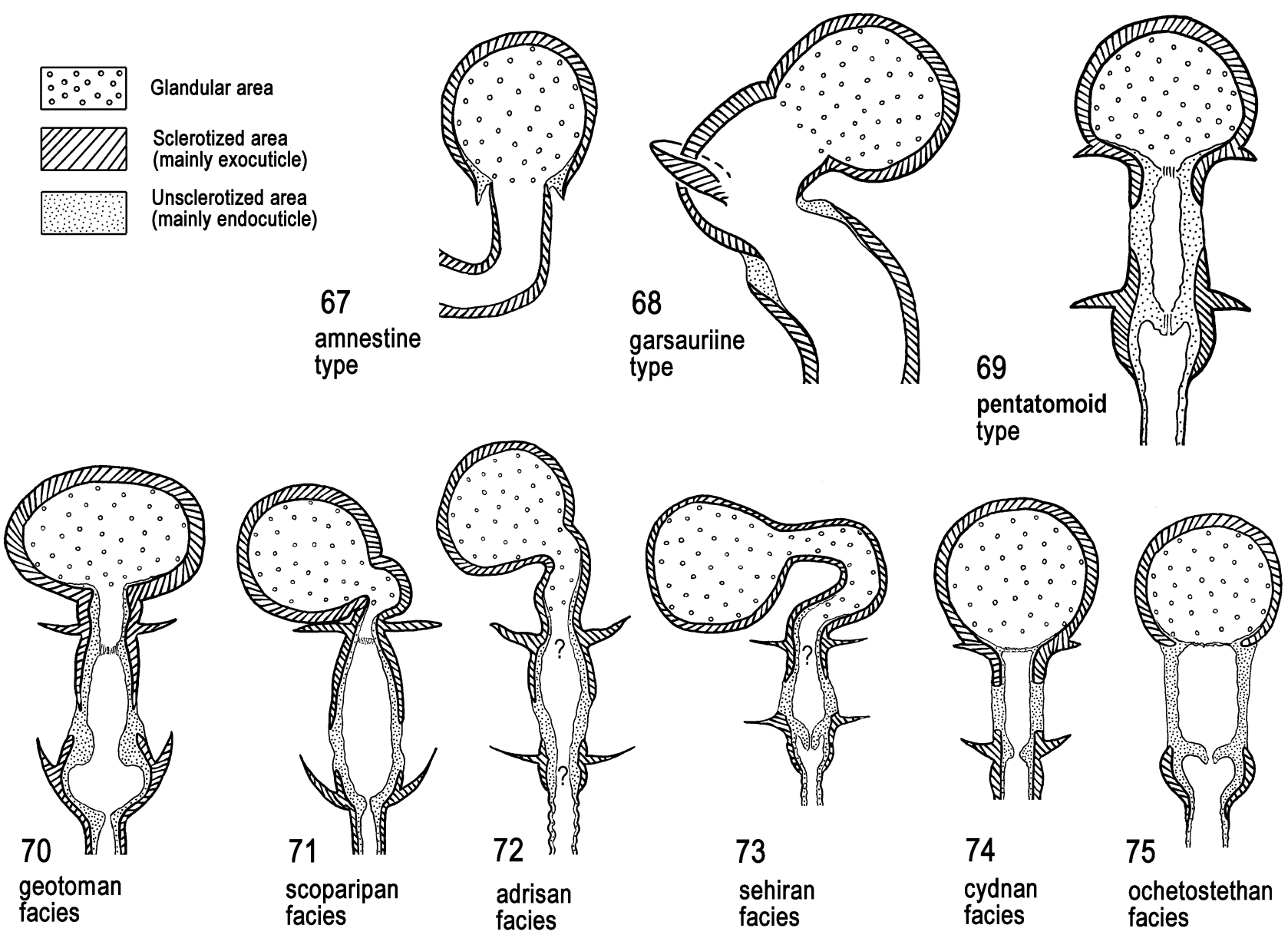

Figs 67-75. Schematic drawings of the receptacle and the intermediate part (pump apparatus) in several types (Figs 67-69) and facies (Figs 70-75) of spermathecae. In the amnestine and garsauriine types, the intermediate part is not delimited posteriorly.

diate part and the basal sclerotized ring as a kind of proximal flange, it appears that this type presents some similarities with that found in some Rhopalidae (see figures given by Pendergrast, 1957; Vavrinová, 1988; Moulet, 1993).

The coiled duct could be the "twisted duct" forming the main part of the intermediate part in many Coreoidea in which flanges are often lacking. In this case, the spermathecal duct could be missing. Strong similarities exist also with spermathecae described in some Lygaeidae Orsillinae (see for instance Slater \& Ashlock, 1980). Further comparative investigations are needed to know if it is really the same structure in these families.

The second feature, the membranous diverticulum, is uninformative. A diverticulum to the spermathecal duct may occur in Pentatomoidea as well as in other pentatomomorphan superfamilies. In Pentatomoidea, it is known in Corimelaenidae (Pendergrast, 1957; McDonald, 1966), some Scutelleridae (McDonald, 1966), Dinidoridae (Pendergrast, 1957; Linnavuori, 1982; Durai, 1987; Kocorek \& Danielczok-Demska, 2002) and Tessaratomidae (Pendergrast, 1957; Kumar, 1962, 1969b). A diverticulum (or accessory gland) occurs also sporadically in Pyrrhocoridae (Freeman, 1947; Stehlík, 1965a, b; Pluot, 1970) and in Aradidae (Kumar, 1967; Lee \& Pendergrast, 1983; Monteith, 1997).

\subsubsection{The garsauriine type}

Genera included: Blaena, Garsauria, Garsauriella (Fig. 47), Peltoxys (Fig. 48).

General structure. Spermatheca well sclerotized (except the basal part of the spermathecal duct). Apical receptacle spherical connected by a bent neck. Intermediate part not delimited posteriorly (proximal flange absent); distal flange present, restricted to one side of the receptacle; flexible zone present but very short; septum or fretum absent (Fig. 68). Duct long, coiled, differentiated into three segments differing by their diameter (at first wide, then abruptly narrower) and their cuticular wall (apically smooth and rigid becoming membranous in the basal part). Spermathecal opening associated with a particular vaginal structure interpreted as a kind of fecundation canal. Ring sclerites present, clearly distinct, not associated with vaginal pouches.

Comments. This type of spermatheca is complex and not typically pentatomoidean due to the intermediate part not delimited proximally, and curiously delimited distally by a small flange restricted to one side of the seminal capsule.

The lack of proximal flange is rare in Pentatomoidea (but see exceptions described by McDonald, 1966 in some scutellerid species). As already shown by Pendergrast (1957) and Štys (1966) among others, many Core- 
TABLE 1. Main characters observed in the four types and the six facies of spermathecae found in Cydnidae as currently delimited (+, presence; -, absence; ?, unclear, structure not distinct). Character 1: Undifferentiated spermathecal tube. Characters 2-14: Differentiated spermatheca. 2-7: Spermathecal duct. 2 - simple; 3 - bipartite; 4 - with dilation; 5 - with dilation plus invagination; 6 cuticular wall of the dilation striated or lamellar; 7 - with diverticulum. 8-12: Intermediate part. 8 - fretum; 9 - proximal flange; 10 - flexible zone; 11 - septum; 12 - distal flange. 13, 14: Seminal receptacle. 13 - not bent; 14 - bent. 15-17: Associated vaginal structures. 15 - fecundation canal; 16 - pair of ring sclerites; 17 - ring sclerites associated with lateral vaginal pouches.

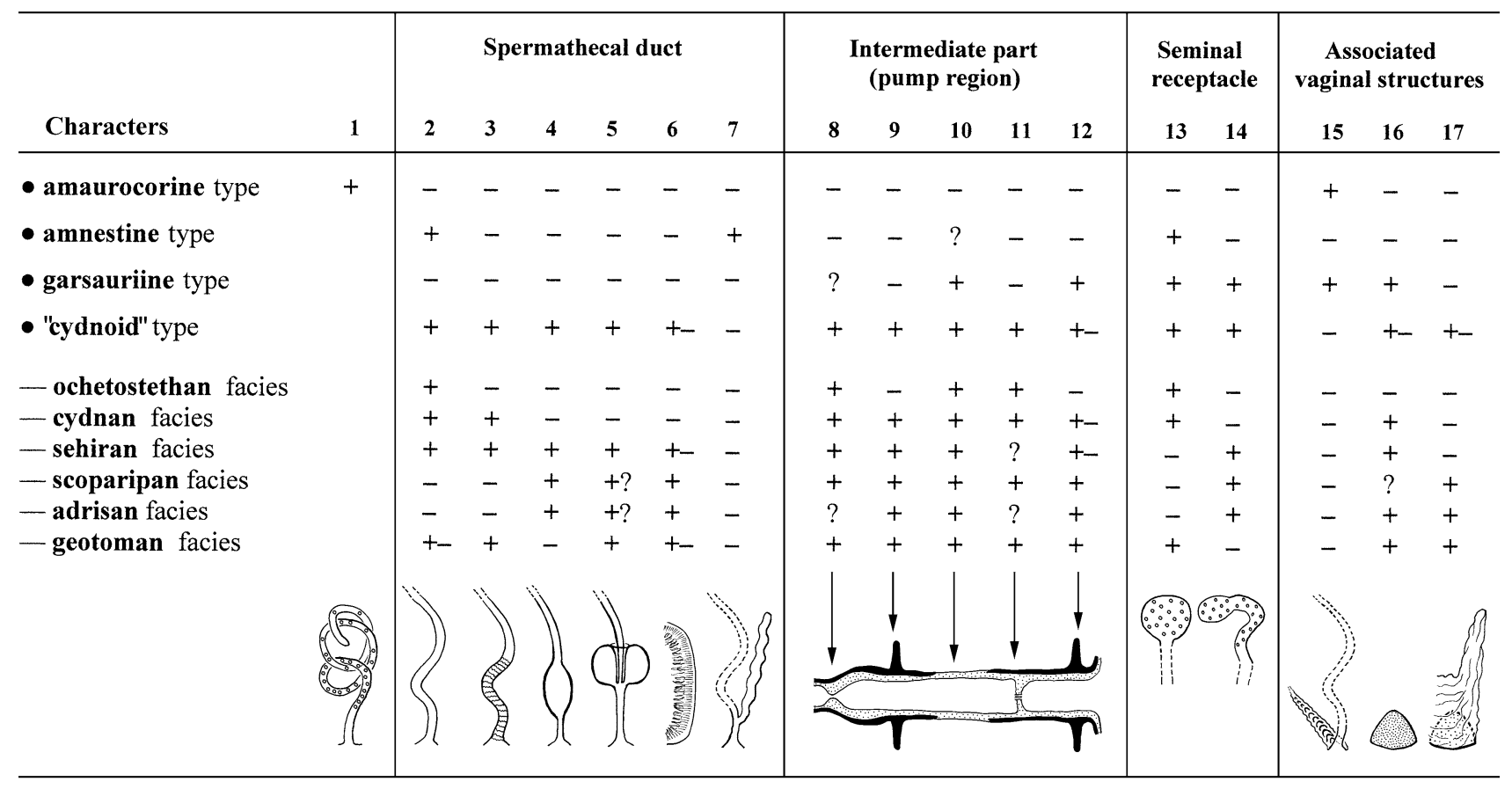

oidea and Lygaeoidea are characterized by the absence of proximal flange. This character and other features (general appearance of the wide and contorted apical duct, diameter of the duct variable, presence of a membranous basal part of the spermathecal duct) evoke certain spermathecae in Coreoidea or some Lygaeidae Orsillinae (see for instance Aschlock, 1967).

A slight swelling present between the two main parts (rigid/membranous) of the spermathecal duct could be the posterior limit of a possible intermediate part. At that place a kind of fretum exists. This swelling may act as a proximal flange for the muscle fibres. In this case, the long pigmented and rigid distal part of the duct should be regarded as the intermediate part. Comparable conditions can be observed in Coreidae (Pendergrast, 1957; Vavrinová, 1988; Lee et al., 1989; Moulet, 1993).

\subsubsection{The "cydnoid" type}

Taxa included: all Cephalocteinae, most Cydninae (Cydnini + Geotomini) and Sehirinae: Sehirini.

General structure. Spermatheca composed of three well distinct parts. Apical receptacle spherical or somewhat elongate. Intermediate part well delimited by distal and proximal flanges (rarely absent), having definite flexible zone, septum and fretum. Duct simply tubular or comprising a very variable dilated part along its length. Ring sclerites present or absent, associated or not with a pair of lateral vaginal pouches.

TABLE 2. Correspondence between the different types of spermathecae found in Cydnidae and the internal classification of the family [Froeschner (1960) and Lis (1994)]. Taxa in bold are those in which representatives possess a pentatomoid type of spermatheca ("cydnoid" type, in bold too). Light-faced taxa are those in which representatives have a non-pentatomoid spermatheca. Taxa underlined are those in which several types or facies of spermathecae coexist.

\begin{tabular}{|c|c|c|}
\hline Taxa & \multicolumn{2}{|c|}{ Morphological types and facies of spermatheca } \\
\hline Amnestinae Hart & amnestine type & \\
\hline Cephalocteinae Mulsant \& Rey & "cydnoid" type & \\
\hline Cephalocteini Mulsant \& Rey & “cydnoid" type & geotoman facies \\
\hline Scaptocorini Froeschner & "cydnoid" type & geotoman facies \\
\hline Cydninae Billberg & “cydnoid" type & \\
\hline Cydnini Billberg & "cydnoid" type & cydnan facies \\
\hline Geotomini Wagner & "cydnoid" type & geotoman facies + adrisan facies + scoparipan facies \\
\hline Garsauriinae Froeschner & garsauriine type & \\
\hline Sehirinae Amyot \& Serville & amaurocorine type + "cydnoid" type & \\
\hline Amaurocorini Wagner & amaurocorine type & \\
\hline$\underline{\text { Sehirini Amyot \& Serville }}$ & “cydnoid" type & sehiran facies + ochetostethan facies \\
\hline
\end{tabular}


Comments. The "cydnoid" type cannot be regarded as a "cydnid type" of spermatheca able to define a group of cydnid representatives. As shown above by its general structure, it is simply a pentatomoid type including a considerable range of diverse spermathecae, particularly as for the spermathecal duct. Some constant features exhibited by the receptacle and the intermediate part (Figs 70-75), and the differentiations of the duct as well, allow us to recognize six different facies (or subtypes) in cydnid spermathecae, described below from the most simple to the most complex.

\subsubsection{The ochetostethan facies}

Genus included: Ochetostethus (Fig. 62).

General structure. Apical receptacle spherical, sclerotized, without neck. Intermediate part devoid of flanges, straight with an enlarged cup-like basal part and a long flexible zone; septum and fretum present (Fig. 75). Duct simple, short, relatively wide, without particular differentiation except for a basal thickening as a pigmented segment. Spermathecal opening simple. Ring sclerites probably absent, no lateral vaginal pouches present.

Comments. This facies is probably restricted to the genus Ochetostethus. It appears very simple and unique within Cydnidae, owing to the complete lack of flange, the long flexible zone, the short and wide duct. Despite the absence of flange, the intermediate part can be recognized: the muscle fibers are obviously inserted at the base of the receptacle and around the enlarged base of the intermediate part.

\subsubsection{The cydnan facies}

Genera included: Cydnus (Figs 13, 14), Chilocoris (Figs 11, 12), Parachilocoris (Fig. 15). Probably Nishocoris (Figs 49, 50) and Nishadana.

General structure. Apical receptacle spherical, sclerotized and thick-walled, without basal neck. Intermediate part straight; distal flange often very reduced (sometimes asymmetrical or absent) located around the base of the receptacle; the proximal one moderately developed; flexible zone relatively long located at the middle of the segment; septum and fretum present (Fig. 74). Duct more or less long and coiled, rigid, without dilation or differentiation (with rare exceptions). Spermathecal opening through an evagination of the vagina, the vaginal wall being creased at this place. Ring sclerites present, not associated with vaginal pouches.

Comments. The cydnan facies appears relatively constant within Cydnini. By the aspect of its three parts, it recalls the plataspid spermatheca which is also devoid of any differentiation along the spermathecal duct (Pendergrast, 1957; Kumar, 1962, McDonald, 1970; DavidováVilímová \& Štys, 1980). The reduction or loss of the distal flange occurs rarely in other Cydnidae (Ochetostethus, Adomerus), and in Pentatomidae as well (Gapud, 1991).

Apart from the Plataspidae, a simple spermathecal duct (without differentiation) is known in only three other pentatomoid families: Acanthosomatidae (Pendergrast, 1957; Servadei, 1964), Lestoniidae (McDonald, 1970; Fischer,
2000), Urostylididae (Pendergrast, 1957; Kumar, 1971; Agarwal \& Baijal, 1982); it may also occur sporadically in Scutelleridae (McDonald, 1966; Gaffour-Bensebbane, 1991b, 1992).

The spermathecae of Nishocoris (Figs 49, 50) and Nishadana (from the Fig. 91 in Linnavuori, 1993) seem to belong to the cydnan facies despite the fact that the spermathecal duct is not rigid; in Nishocoris and apparently in Nishadana, it is soft and swells toward the base. Nishocoris possesses also a pair of ring sclerites.

\subsubsection{The sehiran facies}

Genera included: Adomerus (Figs 52-54), Canthophorus (Fig. 57), Crocistethus (Fig. 61), Exosehirus, Legnotus (Fig. 58), Lalervis (Fig. 59), Sehirus (Figs 55, 56), Tritomegas (Fig. 60).

General structure. Spermathecal intima usually thin and soft, weakly sclerotized and unpigmented, except for some places. Apical receptacle elongate or ovoid with a long twisted neck. Intermediate part rather straight, with two thin flanges more or less expanded, perpendicular and subparallel; flexible zone relatively long (almost half the length of the segment); septum indistinct, fretum present (Fig. 73). Duct relatively short, thin-walled, wrinkled (or creased), exhibiting several differentiations: simple basal swelling, sac-like dilation, dilation with a broad and partial invagination (never profound or pronounced). Spermathecal opening often complicated by various cuticular differentiations in the vaginal wall (folds and bends, sclerotization, thickening). Ring sclerites present, usually well distinct, not associated with vaginal pouches.

Comments. The sehiran facies appears rather variable, but it is constant when considering only the general features of the apical receptacle and the intermediate part (Fig. 73). Another constant feature is the cuticular wall often unsclerotized, thin and soft. The spermathecal duct and the opening into the vagina, both show a great diversity. When it occurs, the invagination within the dilation does not have exactly the same structure as in the geotoman facies; it seems as if it is still in an early stage of development, not fully accomplished. Nevertheless, the wall of the dilated part is often similarly striated.

\subsubsection{The scoparipan facies}

Genera included: Scoparipes (Fig. 46), Pseudoscoparipes, Scoparipoides, Katakadia (Fig. 42), Hiverus? (Fig. 43).

General structure. Apical receptacle spherical, strongly bent against a short basal neck. Intermediate part long, well delimited by two wide flanges, the proximal one cup-like; flexible zone short in basal position; septum and fretum present (Fig. 71). Duct with an elongate strongly pigmented sausage-like dilation; outer surface of the cuticular wall regularly fluted diagonally; distal part of the duct smooth and slender, proximal part widening towards the vagina. Spermathecal opening associated with numerous folds of the vaginal wall showing marks of pigmentation at some places. Ring sclerites indistinct or absent, nevertheless, laterally a pair of vaginal pouches is present.

Comments. The intermediate part is not very different from that of the geotoman facies. The dilation of the duct 

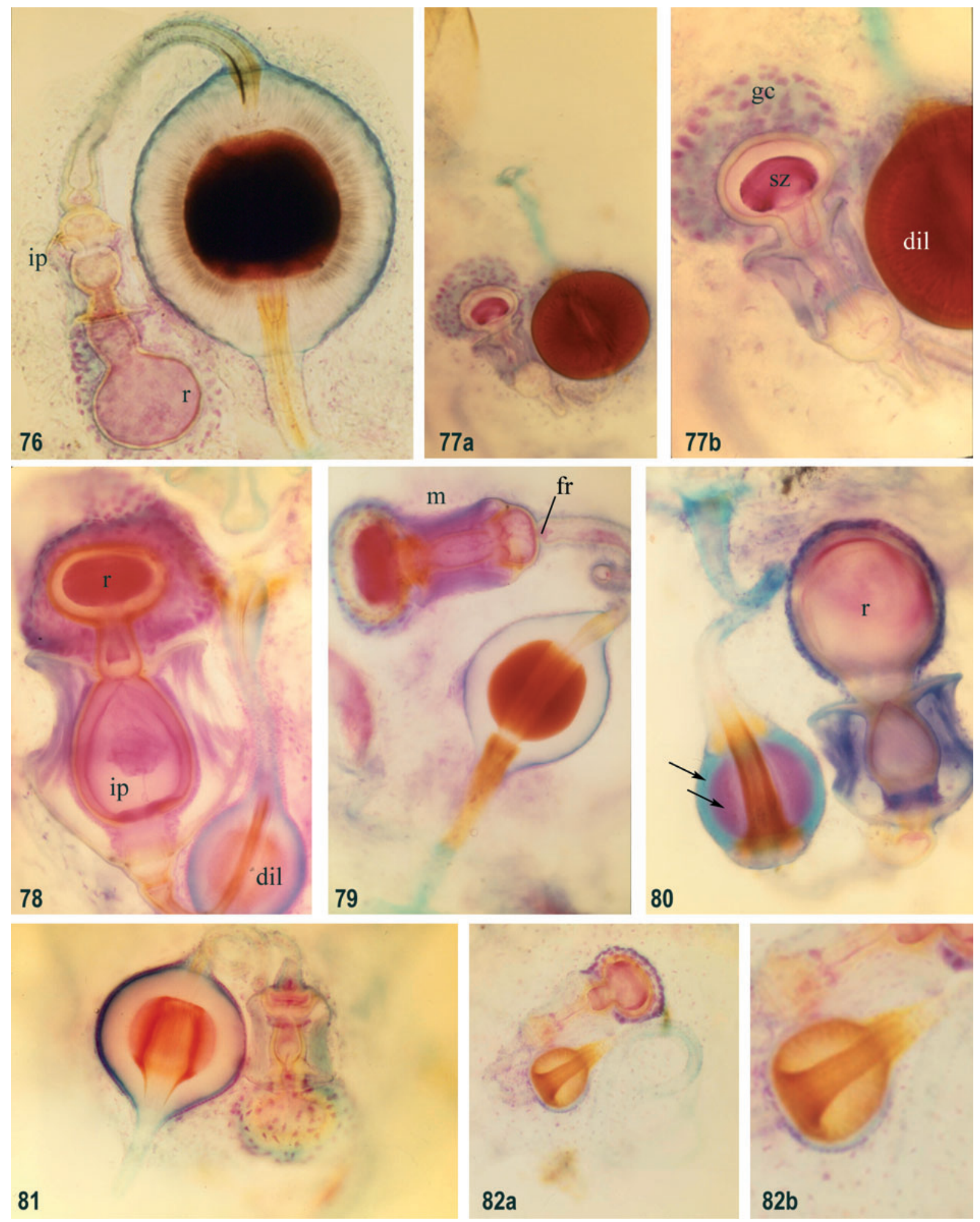

Figs 76-82. Photomicrographs of whole mount geotomine spermathecae, all having along the spermathecal duct a dilation including invagination (Carnoy; Feulgen-fast green): 76 - Fromundus parcimonius, seminal receptacle (r), intermediate part (ip) and dilation of the duct; note the thick unpigmented intima finely striated and the dark central core formed by the strongly pigmented internal edge of the intima; 77 - Microporus lautipennis, general view [a] and details [b] of the spermatheca in an inseminated female; note the large cap of glandular cells (gc) around the receptacle (r) filled with a compact mass of secretion and spermatozoa (sz); the spherical dilation (dil) is strongly pigmented and opaque; 78 - Paraethus capicola; note the swollen intermediate part (ip) and the translucent dilation relatively small (dil); 79 - Aethus lindbergi; note the muscle fibres (m) around the intermediate part, the widdened cup-like base of the segment - the fretum (fr) is distinct - and the pigmented central core of the dilation; 80 - Lactistes vericulatus; note the relatively large spherical receptacle ( $\mathrm{r}$ ), the moderate size of the transluscent dilation, the internal pigmentation and the two layers of the cuticular wall differently stained (arrows); 81 -Aethoscytus multisetosus; note the wide invagination through the translucent dilation moderately pigmented; 82 - Byrsinus pseudosyriacus, spermatheca and detail of the spermathecal dilation; note the small size of the weakly pigmented dilation. 
does not include an invagination and its shape is unusual within Pentatomoidea. Nevertheless, the cuticular wall of the dilation regularly fluted exhibits evident similarities with that observed in other facies (adrisan and geotoman facies).

With some hesitation, we have included Hiverus hirtus in this group in spite of the fact that, in this species, the dilation of the spermathecal duct includes an invagination. The other characters (shape of the receptacle and intermediate part, aspect of the outer cuticular surface of the dilation) correspond quite well with the scoparipan facies.

\subsubsection{The adrisan facies}

Genera included: Adrisa (Fig. 44), Choerocydnus, Teabooma (Fig. 45), Gampsotes (Fig. 41).

General structure. Apical receptacle spherical, bent to a basal neck. Intermediate part long, straight, delimited by two well-developed, perpendicular and subparallel flanges; flexible zone rather long in basal position; septum and fretum indistinct (Fig. 72). Duct entirely unpigmented with usually a large dorso-ventrally flattened pumpkin-like dilation, the latter with or without invagination; the cuticular wall of the dilation thick, striated and fluted; distal and proximal ducts thin, soft and folded; the proximal one distinctly wider. Spermathecal opening through a particular dorsal pouch of the vagina. Ring sclerites present, associated with two lateral well differentiated vaginal pouches.

Comments. The adrisan facies looks like the sehiran facies in some respects: a bent receptacle; a straight intermediate part not swollen basally; an unpigmented spermathecal duct. Nevertheless, the flattened shape of the huge dilation, the unsclerotized structure of the latter and the characteristic spermathecal opening are distinctive characters. On the other hand, the striated and fluted structure of the cuticular wall of the dilation are shared with the geotoman facies. A comparable (pumpkin or wheel-like) huge dilation-invagination can be found in some Canopidae (McDonald, 1979), but in that group it appears entirely sclerotized and pigmented.

Gampsotes parallelus seems to belong to the adrisan facies despite the very small dilation (simple) of the spermathecal duct. It possesses several distinctive features of this facies: a spherical receptacle bent to a basal neck, an intermediate part straight, and probably as the most significant, the same particular spermathecal opening.

\subsubsection{The geotoman facies}

Taxa included: most Cydninae: Geotomini [Aethoscytus (Fig. 25), Aethus (Fig. 28), Alonips (Fig. 31), Byrsinus (Figs 26, 27), Cyrtomenus, Dallasiellus, Dearcla, Endotylus (Fig. 30), Eulonips, Fromundus (Figs 32, 33), Geocnethus (Fig. 29), Geotomus (Fig. 34), Lactistes (Fig. 35), Macroscytus (Figs 38, 39), Melanaethus, Mesocricus, Microporus (Figs 36, 37), Microscytus, Pangaeus, Paraethus (Fig. 40), Pseudonalips, Raunoloma]. Cephalocteinae Cephalocteini and Scaptocorini [Cephalocteus (Fig. 5), Pseudostibaropus (Fig. 8), Scaptocoris (Fig. 9), Schiodtella (Fig. 6)]

General structure. Apical receptacle spherical, often slightly hemispherical, thick-walled, connected by a short neck. Intermediate part long, well delimited by two flanges, the basal part swollen, cup-like in shape; flexible zone in basal position, as a short narrower segment; septum and fretum present (Fig. 70). Duct usually with a spherical or pyriform dilation-invagination variously sized (from small to very big) and colored (pigmentation, sclerotization); wall of the dilation always thick and striated; distal and proximal duct smooth and rather rigid. Spermathecal opening within folds and bends of the surrounded vaginal wall, but without sclerotization. Ring sclerites present, always associated with a pair of lateral vaginal pouches more or less diffentiated.

Comments. This facies is very constant unless the spermathecal duct is considered. In particular the apical receptacle (not bent) and the intermediate part (long and more or less basally swollen) are characteristic for all Geotomini and Cephalocteini. Nevertheless, there are some species with an apical receptacle slightly (Macroscytus) or more distinctly (Alonips) bent.

The spermathecal duct shows marked variations at the level of the dilation (size, form, pigmentation and sclerotization). But the dilation always including an invagination is a constant feature. Only three of the examined species lack true dilation (Microporus nigrita: Fig. 36; $M$. laticeps; Fromundus pygmaeus: Fig. 32); in these species, the duct is devoid of differentiation, except basally. In the geotoman facies, the development of the invagination is fully achieved, like in the Pentatomidae. However, the very thick striated wall of the dilation-invagination in Cydnidae is very characteristic and could be regarded as an autapomorphic condition.

\subsection{Spermathecal structures in Dismegistus, Parastrachia, Thaumastella and Thyreocoris}

In this section, we compare the spermathecal structures observed in the four genera removed from the Cydnidae with that of the six facies of the "cydnoid" type. Dismegistus is still unplaced after being described as a Cydnidae Sehirinae and variously placed in the Pentatomoidea (see Dolling, 1981). Parastrachia is now included in a family of its own, the Parastrachiidae (see Schaefer et al., 1988; Sweet \& Schaefer, 2002). Thyreocoris was considered either as a cydnid (see for instance Wagner, 1963 or Dolling, 1981) or as a representative of a separate family (Štys \& Davidová, 1979; Linnavuori, 1993; Lis, 1994). The problematic genus Thaumastella was transferred from Lygaeoidea to Pentatomoidea by Štys (1964) who gave it a family rank. Later, Dolling (1981) reduced the group to a subfamily of Cydnidae, but this decision was not followed by subsequent authors (Jacobs, 1989; Schaefer, 1993; Lis, 1994; Henry, 1997).

Dismegistus (Fig. 64) and Parastrachia (Fig. 63). The two genera possess a pentatomoidean spermatheca (Leston, 1956; Dolling, 1981; Schaefer et al., 1988).

Strangely, both spermathecae show a nearly identical configuration and marked similarities: apical receptacle ovoid and bent; distal flange asymmetrical; long flexible zone taking up the length of the segment; spermathecal duct very short without any differentiation. In addition, 
both possess a pair of ring sclerites and associated vaginal pouches.

We are in accordance with Schaefer et al. (1988), considering the spermatheca of Parastrachia similar to a certain degree with some sehirine spermathecae. In particular, it possesses a strongly sclerotized structure at the base of the spermathecal duct and it shares with Ochetostethus a very long flexible zone. The character "long flexible zone" is also present in the acanthosomatid spermatheca (unpublished data).

Note. The spermathecal character used by Sweet \& Schaefer (2002) to exclude Parastrachia from the Cydnidae (namely, spermathecal duct short and slender), cannot be treated as a reliable because Cydnidae may have such a spermathecal duct as well.

Thyreocoris (Fig. 65). Both Pendergrast (1957) and Scudder (1959) though that Thyreocoris has no relationship with Cydnidae. Nevertheless, the spermatheca of Thyreocoris presents some resemblances with the sehiran facies and also at least one resemblance with the type of spermatheca found in Pentatomidae. The spermathecal characters in Thyreocoris appear intermediate between Sehirinae: Sehirini and Pentatomidae.

With the sehiran facies, it shares the following features: shape of the seminal receptacle elongate and bent, intermediate part with the flexible zone in basal position, a spermathecal dilation including a partial invagination. With the pentatomid type, it shares the same kind of dilation along the duct, i.e. a thin-walled and membranous dilation; this character is present in all spermathecae observed in Pentatomidae (Gapud, 1991). Nevertheless, the absence of the proximal duct and consequently the direct large opening into the vagina via the basal part of the dilation was never seen in other Pentatomoidea.

Thaumastella (Fig. 66). The spermatheca does not present resemblance with the cydnid spermathecae examined in this paper. Moreover, its facies is not typically pentatomoidean owing to the following features: the mushroom appearance of the receptacle due to the invaginated basal part (to our knowledge this particularity is only encountered in Pyrrhocoridae and rarely in Lygaeidae s. 1.); the intermediate part rather short with a septum in the middle and fretum absent (no narrowing of the lumen was observed at the level of the flange); the creased thin cuticular wall of the spermathecal duct. These features which may be observed in some Lygaeoidea and Pyrrhocoroidea, have not been encountered until now in Pentatomoidea. Thus, the spermatheca of Thaumastella appears as more pyrrhocoroid-like, or lygaeoid-like as suggested by Štys (1964), than pentatomoid-like. Jacobs (1989) suspected some relationships of Thaumastella with Blaena or Peltoxys, but the spermathecae do not support this idea.

\section{DISCUSSION AND CONCLUSIONS}

The present study shows that the spermatheca displays a considerable diversity within the Cydnidae, a peculiarity already noted by previous authors (Pendergrast, 1957; McDonald, 1966; Linnavuori, 1993). The spermathecal diversity may be observed when considering the construc- tion of the organ (four recognized types fundamentally different), the form (highly variable) and the degree of complexity (from very simple to highly complex). Such a diversity is not the rule in most pentatomoid families and gives rise to many questions and some conclusions.

\subsection{Potential phylogenetic importance of the cydnid spermatheca}

\subsubsection{The current Cydnidae: A polyphyletic assemblage}

As the most important conclusion, our results suggest that the Cydnidae as currently defined might be a polyphyletic group. Four types of spermathecae that are not built following the same ground-plan are present. Moreover, only one, the "cydnoid" type is pentatomoid in construction, the three other being either aberrant or non pentatomoid.

The amaurocorine type of spermatheca deviates strongly not only from the pentatomoid type but also from the pentatomomorphan forms of spermathecae; it is rather enigmatic and presently impossible to interpret. In particular, we cannot determine if such a very simple spermathecal tube is a derived state resulting from a regressive evolution, or not.

Neither the amnestine nor the garsauriine types are pentatomoid in construction, but show interesting structural similarities with the spermatheca of some Coreoidea or Lygaeoidea (further verification is needed). These findings do not support Dolling (1981) who claimed that the Garsauriinae share many characters (other than spermatheca) with Sehirinae. Apart from the spermatheca, the Amnestinae and the Garsauriinae present other additional unusual features (Froeschner, 1960). Therefore, the isolated position of the Sehirinae Amaurocorini, Garsauriinae and Amnestinae among Cydnidae must be stressed. It leads to the question: How should we treat the other groupings of intrafamilial level?

\subsubsection{The "cydnoid" type: A diversity difficult to interpret}

Even when removing the three groups possessing nonpentatomoid spermathecae (Amnestinae, Garsauriinae and Sehirinae: Amaurocorini) out of present consideration, there is still a considerable diversity in cydnid spermathecae. The "cydnoid" type of spermatheca is present in the Cephalocteinae + Cydninae + Sehirinae: Sehirini, a grouping, for convenience and more clarity, regarded in the further discussion as the "Cydnidae sensu stricto". If we consider the six spermathecal facies included in the so called "cydnoid" type, it is clear that this type cannot be regarded as a "cydnid type". It has been impossible to find any synapomorphies shared by the six different facies and to fit the spermathecae into a general and consistent pattern.

Consequently, "Cydnidae s. str." cannot be defined on the basis of the spermatheca unlike some other large pentatomoid families. In Pentatomidae, Plataspidae and Dinidoridae, in which the spermathecae have been adequately investigated, the spermatheca shows a fundamentally uniform structure throughout each family or subfamilies and is well characterized by some particular features: duct with a huge membranous dilation including invagination in Pentatomidae (Pendergrast, 1957; Servadei, 1964; Gapud, 
1991, among other); duct simple without differentiation in Plataspidae (Pendergrast, 1957; Kumar, 1962; McDonald, 1970; Davidová-Vilímová \& Štys, 1980; Kim \& Lee, 1993); duct wide or expanded with or without similarly wide diverticulum in Dinidoridae (Pendergrast, 1957; Durai, 1987; Kocorek \& Danielczok-Demska, 2002). Thus, each family is well defined firstly by its spermathecal duct. It is also true, but to a certain extent and only when subfamilies are considered, for the Tessaratomidae (Pendergrast, 1957; Kumar, 1969a, b; Kumar \& Ghauri, 1970).

Only one large pentatomoid family, the Scutelleridae, possess a high spermathecal diversity. It is interesting to note that the spermathecal duct in "Cydnidae s. str." shares with that of Scutelleridae a comparable diversity and same anagenetic changes including comparable steps toward increased complexity (see Pendergrast, 1957; Servadei, 1964; Kumar, 1965b; McDonald, 1966; McDonald \& Cassis, 1984; Gaffour-Bensebbane, 1991b, 1994). Invagination of the spermathecal duct within the dilation does not exist however in the Scutelleridae, except in Chrysocoris stallii (Wolff) as shown by Kumar (1962).

In "Cydnidae s. str.", the diversity concerns also particularly the spermathecal duct. It is observed in all lineages, and even within a single genus (see below to realize the real difficulties to find generic characters). This diversity is remarkable and may reflect paraphyletic nature of this assemblage. But more interesting is the view that the "Cydnidae s. str." may have a recent origin and might be a lineage still intensely diversifying. The considerable diversity in the group strongly supports this idea. The spermatheca appears to be an organ presenting a number of potentialities expressed or not, depending on the species. Nevertheless, this is in contradiction with the widespread opinion that the group is an ancient one (e.g., Cobben, 1968; Schaefer, 1981, 1988; Schuh \& Slater, 1995).

\subsubsection{The "cydnoid" type: Spermathecal character states difficult to evaluate}

Again, we consider here only the "cydnoid" type and the six different spermathecal facies present in the "Cydnidae s. str." (Cydninae + Cephalocteinae + Sehirinae: Sehirini). Several authors have already discussed the spermathecal characters in the Pentatomoidea (Štys, 1964; Štys \& Davidová, 1979; Gapud, 1991; Schaefer, $1993 b)$. Their polarity is extremely difficult to evaluate and must be considered with caution. In fact, spermathecal structures require a much wider survey within Pentatomoidea to determine what groups they can define, to estimate the plesiomorphic/apomorphic conditions and to determine possible convergencies. Several spermathecal characters are probably affected by considerable homoplasy. The flanges and the spermathecal duct evidently evolved convergently in various clades, and reversals into a simple condition is probable. The same concerns many differentiations of the spermathecal duct. On the other hand, the intermediate part, the ring sclerites and the vaginal pouches seem to provide more constant features.
The presumed plesiomorphic condition is when the spermathecal duct is simple, not dilated. Such spermatheca occurs within the Pentatomoidea and widely outside the superfamily. Unfortunately, we do not know if the simple spermathecae observed in Cydnini or in some Sehirini (cydnan and ochetostethan facies) are reversals or not.

A dilation along the spermathecal duct is also common in many families of Pentatomomorpha, but a dilation with an invaginated part of the duct is restricted to some Pentatomoidea: i.e., Pentatomidae (Gapud, 1991), Thyreocoridae (Štys \& Davidová, 1979; present paper), Cyrtocoridae (Rolston \& McDonald, 1979; Gapud, 1991), Aphylidae (McDonald, 1970); in these four families the wall of the huge dilation is thin and membranous. In "Cydnidae s. str.", exists also a dilation which includes an invagination (sehiran, scoparipan, adrisan, and geotoman facies); it is never thin and membranous and exhibits some potential autapomorphic particularities.

The spermathecal duct of the Cydninae Geotomini and Cephalocteinae presents indeed a character which may be considered unique within Pentatomoidea, not having been found outside the Cydnidae, i.e., a striated thick-walled dilation including (in most cases) an invaginated part of the duct. Such a dilation - though less differentiated may occur also within the Sehirinae.

\subsubsection{Presumed synapomorphies linking "Cydnidae s. str." and other Pentatomoidea}

Regarding the structure of the spermatheca and that of the vagina, it appears that the "Cydnidae s. str." (i.e. Cydninae + Cephalocteinae + Sehirinae: Sehirini) or parts of them (tribe or subfamily) share probable synapomorphies with several pentatomoid families.

In many instances the cydnid spermatheca ressembles the scutellerid spermatheca in the shape and structure. More precisely, the very particular features of the cuticular lining exhibiting internal striation or "gills" in the thick-walled dilation of the spermathecal duct, characteristic of most "Cydnidae s. str.", is also observed in some Scutelleridae and could be considered as a synapomorphic character. In Canopidae the spermathecal duct posseses also a striated thick-walled dilation (which includes invagination) and the same internal "gills".

Another synapomorphy seems to link the cydnid and scutellerid families: the presence of paired ring sclerites associated with vaginal pouches (the latter being more differentiated in Scutelleridae than in Cydnidae). The presence of huge lateral vaginal pouches in other small pentatomoid families should be noted here: Canopidae and Corimelaenidae also possess, like Cydninae Geotomini and Cephalocteinae, a well developed vagina and a pair of lateral vaginal pouches (usually associated with ring sclerites). These vaginal features seem to be shared also by the Urostylididae, Dismegistus and Parastrachia. Further studies are needed in order to know if these vaginal pouches are homologous structures in these taxa and if they are really associated with the ring sclerites and the spermatheca as in Cydnidae and Scutelleridae. 


\subsection{Taxonomic importance of the spermatheca in Cydnidae}

Spermathecal characters in "Cydnidae s. str." (Cydninae + Cephalocteinae + Sehirinae: Sehirini) are of great taxonomic value at specific, generic and supra-generic levels, and they have some significance for the classification of the group.

At the species level, the spermathecal duct, particularly its swelling, and some structures around the spermathecal opening may bring the most useful characters. Differences were found practically in every case in which several species of a genus had been examined. On the other hand, we did not observe intraspecific variation, when numerous female specimens from different populations (Macroscytus brunneus) were examined. In Cydninae and Sehirinae, the dilation of the duct (structure, dimensions, general form, pigmentation) is usually sufficient for separating the species. In Sehirinae: Sehirini, the sclerotization around or near the spermathecal opening shows a great diversity and seems to be very useful.

Some characteristics of the spermathecal duct are probably useful also at the generic level. Nevertheless, despite (or because) the great diversity of the structure of the duct within most of the accepted genera, we were unable to find satisfactory generic characters, especially in the tribe Geotomini. Within several genera (Aethus, Byrsinus, Fromundus, Geotomus, Macroscytus) the dilationinvagination varies extensively from very small to very big. Conversely, other genera (Chilocoris, Microporus, Fromundus, Adomerus) as currently delimited seem to be heterogeneous regarding the spermathecal duct; these differences might suggest that either the systematic placement of some species needs re-assessment or that certain genera should be divided into subgenera. Nevertheless, certain differences in the spermathecal duct seem to be reliable in defining some natural species groups, e.g., Sehirus are characterized by a simple dilation of the duct, whereas Tritomegas and Crocistethus are characterized by a dilation plus invagination. The structures, often complicated, associated with the spermathecal opening seem suitable to provide some generic characters.

At the suprageneric level, several characters can be regarded as probable synapomorphies linking several genera. See, for instance, the two following cases in Geotomini: (1) in the group formed by genera Geocnethus, Paraethus, Endotylus, Raunoloma the intermediate part swells greatly, the proximal flange tends to develop also greatly, whereas the receptacle seems reduced, (2) genera Alonips, Eulonips, Pseudonalips possess a very long and coiled distal duct, uncommon in Geotomini. Some other features such as: presence or absence of dilation along the spermathecal duct, presence or absence of invaginated part of the spermathecal duct within the dilation, presence or absence of paired ring sclerites associated or not with vaginal pouches, are also excellent additional characters.

\subsection{Spermatheca and cydnid classification}

A correspondence between the groupings based on spermathecal structures (types and facies) and the taxonomic groups currently recognized in Cydnidae is more or less obvious (Table 2) inasmuch as most taxonomic groups are characterized by only one type (except Sehirinae with two types).

The three non-pentatomoid types of spermatheca correspond to small groups limited to a single genus (amnestine type) or a few genera (amaurocorine and garsauriine types); as for the "cydnoid" type of spermatheca, it corresponds to the major part of cydnid species.

When regarding only the "cydnoid" type of spermathecae and its six different facies, the situation seems to be rather confusing and only some general remarks can be made.

Spermathecae having a geotoman facies (spermatheca + ring sclerites + a pair of vaginal pouches) are observed without any notable variation in two subfamilies: the Cephalocteinae (Cephalocteini, Scaptocorini) and the Cydnidae Geotomini (major part). On the other hand, within the Geotomini, two other spermathecal facies can be observed (scoparipan and adrisan facies); thus the largest tribe of Cydnidae (i.e. Geotomini) appears in need of restructuring, even though the three spermathecal facies possess some similarities (including same vaginal structures: paired ring sclerites associated with vaginal pouches). Till the tribe is redefined and reconstructed it should be named as the "Geotomini s. lato".

In the same way, the Sehirini appears somewhat heterogeneous with two facies of spermathecae, the sehiran and the ochetostethan facies being rather different. Finally, a single tribe, the Cydnidae Cydnini appears homogeneous with only one facies of spermatheca (cydnan facies).

When looking at the current systematic position of the studied taxa it appears clear that only two genera of Garsauriinae (Nishocoris and Nishadana) do not fit into the subfamily scheme. These two genera were until not long ago placed in the subfamily Cydninae within the tribe Cydnini (Linnavuori, 1993; Lis, 1994, 1999), but recently both were transferred to Garsauriinae on the basis of the metathoracic wing venation (i.e. vannus I absent) (Lis \& Heyna, 2001). Nevertheless, the present results may suggest the absence of the vannus $I$ in the two mentioned genera as a secondary loss. Moreover, the venation of mesothoracic wings in Nishocoris and Nishadana (Lis, unpubl.) are typical of Cydninae as defined by Lis (2002). Because also the abdominal trichobothrial pattern in Nishocoris and Nishadana is typical of the Cydninae (not Garsauriinae) (Lis \& Hohol-Kilinkiewicz, 2001, 2002; Lis, unpubl.), the systematic position of these two genera should obviously be reconsidered; we therefore transfer them back from Garsauriinae to Cydninae: Cydnini (the spermathecal characters - see Figs 47, 48, and Fig. 91d in Linnavuori, 1993 - allow to put them within the cydnan facies).

The major subdivisions of the Cydnidae should therefore be re-examined. On the basis of the spermatheca and the associated structures (ring sclerites, lateral pouches) one could recognize four main groups of possible equal taxonomic rank: (1) the Cydninae Cydnini with the cydnan spermathecal facies; (2) the Cydninae Geotomini + Cepha- 
locteini with the geotoman, adrisan, and scoparipan spermathecal facies; thus this group falls into three subgroups (geotoman, adrisan, scoparipan); the very particular structure of the dilation-invagination (with striated wall) clearly supports this grouping; (3) the Sehirinae, except Ochetostethus, with the sehiran spermathecal facies; (4) the Ochetostethus group with the quite different ochetosthetan facies.

In conclusion the spermatheca (and associated vaginal structures) proved to be an organ highly informative among Pentatomoidea, useful in recognizing mono-, paraor polyphyletic groups and giving indications on the position of certain taxa. While Dismegistus, Parastrachia, and Thyreocoris appear clearly as pentatomoid genera on the basis of their spermatheca, it is not the case of Thaumastella which possess spermathecal features more lygaeoid or pyrrhocoroid than pentatomoid.

The spermatheca allows us to consider the Cydnidae in a new light. Nevertheless, even restricted to "Cydnidae s. str." (i.e.: Cydninae + Cephalocteinae + Sehirinae: Sehirini), the only species group having a pentatomoid spermatheca, the remark made by Froeschner (1960) and retained by Lis (1994): "a clear cut definition of the Cydnidae is not easy to formulate", is still appropriate. We conclude that it is impossible to characterize the Cydnidae on the basis of the spermatheca.

In certain respect the very high diversity of the cydnid spermatheca, with plesio- and apomorphic character states (and extreme simplification or complication) occuring in different groups, evokes the heterobathmy (of W. Hennig) i.e. the mosaic evolution (of E. Mayr); the cydnid group could be a good example of this phenomenon.

The results of the present study allow us to discuss some questions concerning internal classification and potential relationships within pentatomoid families, although the evolution of this organ in the superfamily is far from clear. It is now necessary to study it properly within other Pentatomoidea in various families. Some unpublished data although incomplete are promising.

Being aware that changes in the classification of the "Cydnidae s. str." suggested by present results on the spermatheca should be supported by studies on some other characters, we decided not to establish any new suprageneric taxon within the family till the entire "Cydnidae s. lato" is phylogenetically studied (Lis, under preparation). Nevertheless, as a final result we propose to: (1) move Nishadana and Nishocoris from Garsauriinae back to Cydninae: Cydnini; (2) remove the tribe Amaurocorini from Sehirinae and to upgrade it to a separate subfamily Amaurocorinae stat. nov. Moreover, we regard both the Geotomini and the Sehirini as not monophyletic and we indicate that by appending them sensu lato (Geotomini s. 1., Sehirini s. 1.).

ACKNOWLEDGMENTS. We are very grateful to P. Stys (Praha), C. Dupuis (Paris) and C.W. Schaefer (Storrs) for their comments on the manuscript, their precious suggestions and their linguistic corrections. Special thanks are due to P. Štys for his kind assistance in rereading the paper.

\section{REFERENCES}

ADAms T.S. 2001: Morphology of the internal reproductive system of the male and female of two spotted stink bug, Perillus bioculatus (F.) (Heteroptera: Pentatomidae) and the transfer of products during mating. Invert. Reprod. Devel. 39: $45-53$.

Agarwal S.B. \& Baijal H.N. 1982: External genitalia of Urostyis pallida Dall. (Pentatomidae: Urostylinae) and phylogenetic significance in family Pentatomidae. J. Entomol. Res. 6: 166-171.

Ahmad I. \& Moizuddin M. 1980: A new tribe, a new genus and two new species of Cydnidae (Heteroptera: Pentatomoidea) from Pakistan with phylogenetic considerations. Trans. Shikoku Entomol. Soc. 15: 1-9.

Ahmad I. \& Southwood T.R.E. 1964: The morphology of the Alydid abdomen with special reference to the genitalia and its bearing on classification (Heteroptera). Tijdschr. Entomol. 107: 365-378.

ANDERSEN N.M. 1982: The Semiaquatic Bugs (Hemiptera, Gerromorpha): Phylogeny, Adaptations, Biogeography, and Classification. Entomonograph 13. Scandinavian Science Press, Klampenborg, 455 pp.

Aschlock P.D. 1967: A generic classification of the Orsillinae of the World (Hemiptera - Heteroptera: Lygaeidae). Univ. Calif. Publ. Entomol. 48: 1-82.

BerLese A. 1899: Fenomeni che accompagnano la fecondazione in taluni insetti (Memoria 2). Riv. Patol. Veget. 7[1898]: $1-18$.

Bonhag P.F. \& Wick J.R. 1953: The functional antomy of the male and female reproductive systems of the milkweed bug, Oncopeltus fasciatus (Dallas) (Heteroptera: Lygaeidae). $J$. Morphol. 93: 177-283.

BrailovsKy H. 1984: Revisión del género Latochrimnus Brailovsky (Hemiptera - Heteroptera - Lygaeidae - Lygaeinae). An. Inst. Biol. Univ. Nat. Autón. Méx. (Zool.) 55: 111-128.

Brailovsky H. 1987: La tribu Hydarini Stål, en el continente americano con descripción de dos nuevos géneros, una nueva especie y una nueva subspecie (Hemiptera - Heteroptera) (Coreidae). An. Inst. Biol. Univ. Nat. Autón. Méx. (Zool.) 58: 623-650.

CARAYON J. 1955: Quelques caractères anatomiques des Hémiptères Aradidés. Rev. Fr. Entomol. 22: 169-180.

CARAYON J. 1964: La spermathèque et les voies génitales femelles des Lygaeidés Oxycareninae (Heteroptera). Rev. Fr. Entomol. 31: 196-218.

Cobben R.H. 1968: Evolutionary Trends in Heteroptera. Part. I. Eggs, Architecture of the Shell, Gross Embryology and Eclosion. Mededeling $\mathrm{n}^{\circ} 151$ of the Laboratory of Entomolgy of the agricultural University, Wageningen, $475 \mathrm{pp}$.

COBBEN R.H. 1970: Morphology and taxonomy of intertidal dwarfbugs (Heteroptera: Omaniidae fam. nov.). Tijdschr. Entomol. 113: 61-90.

CobBen R.H. 1980: The Saldidae of the Hawaiian archipelago (Hemiptera: Heteroptera). Pacif. Insects 22: 1-34.

CoBben R.H. 1985: Additions to the Eurasian saldid fauna with a description of fourteen new species (Heteroptera, Saldidae). Tijdschr. Entomol. 128: 215-270.

Czaja J. \& Lis J.A. 2002: Four new species of the Afrotropical genus Coleocydnus J.A. Lis (Hemiptera: Heteroptera: Cydnidae). Pol. Pis. Entomol. 71: 273-292.

Czaja J. \& Lis J.A. 2003: Coleocydnus inexpectatus, a new Afrotropical species of burrower bugs (Hemiptera: Heteroptera: Cydnidae). Pol. Pis. Entomol. 72: 197-202. 
Davidová-Vilímová J. \& ŠTYs P. 1980: Taxonomy and phylogeny of West Palearctic Plataspidae (Heteroptera). Stud. CSAV 4: 1-155.

Dolling W.R. 1981: A rationalized classification of the Burrower Bugs (Cydnidae). Syst. Entomol. 6: 61-76.

DupuIs C. 1955: Les genitalia des Hémiptères Hétéroptères (Genitalia externes des deux sexes; Voies ectodermiques femelles). Revue de la morphologie. Lexique de la nomenclature. Index bibliographique analytique. Mém. Mus. Nat. Hist. Nat. (A), Zool. (N.S.) 6: 183-278.

Dupuis C. 1963: Progrès récents de l'étude des genitalia des Hétéroptères (Etude bibliographique critique). $2^{\mathrm{e}}$ thèse Doct. Sc., Paris, (Arch. Orig. Centre Doc. CNRS n 386). Polycopié, $100 \mathrm{pp}$.

DupuIS C. 1970: 28. Heteroptera. In Tuxen S.L. (ed.): Taxonomist's Glossary of Genitalia in Insect. Munksgaard, Copenhagen, pp. 190-208.

DURAI P.S.S. 1987: A revision of the Dinidoridae of the World (Heteroptera: Pentatomoidea). Orient. Insects 21: 163-360.

FISCHER C. 2000: The disc-like organ of the Lestoniidae (Heteroptera: Pentatomoidea), with remarks on lestoniid relationships. Insect Syst. Evol. 31: 201-208.

Freeman P. 1947: A revision of the genus Dysdercus Boisduval (Hemiptera, Pyrrhocoridae), excluding the American species. Trans. R. Entomol. Soc. Lond. 98: 373-424.

Froeschner R.C. 1960: Cydnidae of the Western Hemisphere. Proc. U. S. Nat. Mus. 111: 337-680.

Gaffour-Bensebbane C. 1991a: Morphologie des voies génitales ectodermiques des femelles d'Eurygaster austriaca (Schrank, 1776). Bull. Soc. Entomol. Fr. 95[1990]: 209-228.

GafFour-BensebBane C. 1991b: Importance des pièces génitales ectodermiques femelles dans la distinction des espèces d'Eurygaster (Laporte, 1832). I - Les espèces paléarctiques (Heteroptera, Scutelleridae). Nouv. Rev. Entomol. (N.S.) 8: 287-305.

GafFour-Bensebbane C. 1992: Importance des pièces génitales ectodermiques femelles dans la distinction des espèces d'Eurygaster (Laporte, 1832). II - Les espèces néarctiques (Heteroptera, Scutelleridae). Nouv. Rev. Entomol. (N.S.) 9: 29-46.

GafFour-Bensebbane C. 1993: Les corrélations morphofonctionnelles des organes copulateurs femelles et mâles chez les Scutelleridae (Heteroptera, Pentatomoidea). Bull. Soc. Entomol. Fr. 98: 313-321.

GafFour-BensebBane C. 1994: Les variations morphologiques de l'appareil génital ectodermique des femelles de Scutelleridae (Heteroptera, Pentatomoidea). 1. Les pièces internes. Nouv. Rev. Entomol. (N.S.) 11: 267-281.

GAPUD V.P. 1991: A generic revision of the subfamily Asopinae, with consideration of its phylogenetic position in the family Pentatomidae and superfamily Pentatomoidea (Hemiptera Heteroptera). Philipp. Entomol. 8: 865-961.

Heming-van Battum K. \& Heming B.S. 1986: Structure, function and evolution of the reproductive system in females of Hebrus pusillus and $\mathrm{H}$. rufipes (Hemiptera, Gerromorpha, Hebridae). J. Morphol. 190: 121-167.

Henry T.J. 1997: Phylogenetic analysis of family groups within the infraorder Pentatomomorpha (Hemiptera: Heteroptera). Ann. Entomol. Soc. Am. 90: 275-301.

JACOBS D.H. 1989: A new species of Thaumastella with notes on the morphology, biology and distribution of the two southern African species (Heteroptera: Thaumastellidae). J. Entomol. Soc. Sth Afr. 52: 301-316.

KERHZNER I.M. 1976: [New and little known Heteroptera from Mongolia and adjacent regions of the USSR. III. Insects of Mongolia.] 4: 30-86 [in Russian].
Kim H.R. \& LeE C.E. 1993: The spermathecae of the Plataspidae from Korea (Heteroptera, Hemiptera). Nature \& Life (Korea) 23: $115-120$.

KIM H.R. \& LeE C.E. 1995: Comparative morphology of the spermathecae and the phylogenetic relationships of Korean Cydnidae (Hemiptera, Heteroptera). Russ. Entomol. J. 3[1994]: 41-48.

Kocorek A. \& Danielczok-Demska T. 2002: Comparative morphology of the spermatheca within the family Dinidoridae. Eur. J. Entomol. 99: 91-98.

KUMAR R. 1962: Morpho-taxonomical studies on the genitalia and salivary glands of some Pentatomoidea. Entomol. Tidskr. 83: 44-88.

KUMAR R. 1965a: Aspect of the morphology of Coreoidea and their value in its higher classification. Proc. R. Soc. Queensl. 76: 27-91.

KUMAR R. 1965b: Contribution to the morphology and relationships of Pentatomoidea (Hemiptera: Heteroptera). Part I. Family Scutelleridae. J. Entomol. Soc. Queensl. 4: 41-55.

KUMAR R. 1967: Morphology of the reproductive and alimentary systems of the Aradoidea (Hemiptera), with comments on relationships within the superfamily. Ann. Entomol. Soc. Am. 60: $17-25$.

Kumar R. 1969a: Morphology and relationships of the Pentatomoidea (Heteroptera). III. Natalicolinae and some Tessaratomidae of uncertain position. Ann. Entomol. Soc. Am. 62: 681-695.

Kumar R. 1969b: Morphology and relationships of the Pentatomoidea (Heteroptera). IV. Oncomerinae (Tessaratomidae). Austr. J. Zool. 17: 553-606.

Kumar R. 1971: Morphology and relationships of the Pentatomoidea (Heteroptera). 5: Urostylidae. Am. Midl. Nat. 85: 63-73.

Kumar R \& GHauri M.S.K. 1970: Morphology and relationships of the Pentatomoidea (Heteroptera). 2. World genera of Tessaratomini. Dtsch. Entomol. Z. 17: 1-32.

Lee C.E. \& Pendergrast J.G. 1983: The spermathecae of New Zealand Aradidae (Hemiptera: Heteroptera). J. Nat. Hist. 17: $113-122$.

LeE K.Y., LeE C.E. \& PARK H.C. 1989: A comparative study on the spermathecae of the Coreidae from Korea (Heteroptera, Hemiptera). Nature \& Life (Korea) 19: 7-14.

Leston D. 1956: The Ethiopian Pentatomoidea (Hemiptera). XXII. On Dismegistus Amyot and Serville (Cydnidae). Proc. R. Entomol. Soc. Lond. (A) 31: 87-94.

LinNAVUORI R.E. 1982: Pentatomidae and Acanthosomidae of Nigeria and the Ivory Coast, with remarks on species of the adjacent countries in West and Central Africa. Acta Zool. Fenn. 163: 1-176.

LinNavuori R.E. 1993: Cydnidae of West, Central and NorthEast Africa (Heteroptera). Acta Zool. Fenn. 192: 1-148.

Lis J.A. 1994: A Revision of Oriental Burrower Bugs (Heteroptera: Cydnidae). Upper Silesian Museum, Department of Natural History, Bytom, 349 pp.

Lis J.A. 1999: Burrower bugs of the Old World - a catalogue (Hemiptera: Heteroptera: Cydnidae). Genus (Wroclaw) 10: $165-249$.

Lis J.A. 2002: The mesothoracic wing and its phylogenetic significance in Cydnidae (Hemiptera: Heteroptera). Pol. Pis. Entomol. 71: 43-71.

Lis J.A. \& Heyna J. 2001: Metathoracic wings venation in Cydnidae (Hemiptera: Heteroptera) and its bearing on the classification of the family. Ann. Zool. (Warszawa) 51: 429-465.

Lis J.A. \& Hohol-Kilinkiewicz A. 2001: Abdominal trichobothrial pattern and its taxonomic and phylogenetic signifi- 
cance in Cydnidae (Hemiptera: Heteroptera) - II. Amnestinae and Garsauriinae. Ann. Zool. (Warszawa) 51: 467-471.

Lis J.A. \& Hohol-KilinKiewicz A. 2002: Abdominal trichobothrial pattern and its taxonomic and phylogenetic significance in Cydnidae (Hemiptera: Heteroptera). IV. Cydninae. Pol. Pis. Entomol. 71: 133-143.

Magnien P. 1998: Contribution à l'étude du genre Legnotus Schiødte et description d'une nouvelle espèce de Turquie (Heteroptera, Cydnidae). Bull. Soc. Entomol. Fr. 103: 463-473.

Magnien P. 2006: A new species from the Near East for the genus Ochetostethus Fieber 1860 (Heteroptera, Cydnidae). In Rabitsch W. (ed.): Hug the Bug - for love of the true bugs. Festschrift zum 70. Geburstag von Ernst Heiss. Denisia 19: 513-516.

MaLouf N.S.R. 1933: Studies on the internal anatomy of the stink bug Nezara viridula. Bull. Soc. Entomol. Egypte 17: 96-119.

McDonald F.J.D. 1966: The genitalia of North American Pentatomoidea (Hemiptera: Heteroptera). Quaest. Entomol. 2: $7-150$.

McDonald F.J.D. 1970: The morphology of Lestonia haustorifera China (Heteroptera: Lestonidae). J. Nat. Hist. 4: 413-417.

McDonald F.J.D. 1976: Revision of the genus Trichopepla (Hemiptera: Pentatomidae) in N. America. J. N. Y. Entomol. Soc. 84: 9-22.

McDonald F.J.D. 1979: A new species of Megaris and the status of the Megarididae McAtee \& Malloch and Canopidae Amyot \& Serville (Hemiptera: Pentatomoidea). J. N. Y. Entomol. Soc. 87: 42-84.

McDonald F.J.D \& Cassis G. 1984: Revision of the Australian Scutelleridae Leach (Hemiptera). Austr. J. Zool. 32: 537-572.

Moizuddin M. \& Ahmad I. 1990: A revision of Cydnidae (Hemiptera: Pentatomomorpha: Pentatomoidea) from Indo-Pakistan area with a cladistic analysis of the included genera. Orient. Insects 24: 305-354.

Monteith G.B. 1997: Revision of the Australian flat bugs of the subfamily Mezirinae (Insecta: Hemiptera: Aradidae). Mem. Queensl. Mus. 41: 1-169.

Moulet P. 1993: Structures méconnues dans la spermathèque d'Hétéroptères Coreoidea paléarctiques. Ann. Soc. Entomol. Fr. (N.S.) 29: 159-172.

O'DonNell J.E. 2000: Notes on the phylogenetic relationships of Neotropical Antillocorini, with description of three new species (Heteroptera: Rhyparochromidae: Rhyparochrominae). J. N. Y. Entomol. Soc. 108: 114-129.

Pendergrast J.G. 1957: Studies on the reproductive organs of the Heteroptera with consideration of their bearing on classification. Trans. R. Entomol. Soc. Lond. 109: 1-63.

PérICART J. 1990: Hémiptères Saldidae et Leptopodidae d'Europe occidentale et du Maghreb. Faune de France 77. Fédération française des Sociétés de Sciences naturelles, Paris, 238 pp.

PLuOT D. 1970: La spermathèque et les voies génitales femelles des Pyrrhocoridés (Hemiptera). Ann. Soc. Entomol. Fr. (N.S.) 6: $777-807$.

Polivanova E.N. 1959: [Importance des caractères anatomiques pour la systématique et la détermination des corrélations phylogénétiques chez les Hétéroptères, Pentatomoidea]. Trudy Inst. Morph. Zhivotn. Severtsova 27: 201-220 [in Russian].

Putchkova L.V. 1959: [Traits généraux de la structure des œufs et de l'appareil génital femelle des Hétéroptères à scutellum]. Praci Inst. Zool. Acad. Ukrain. 15: 117-125 [in Ukrainian, Russian abstr.].
RamamuRTY P.S. 1969: Histological studies of the internal organs of reproduction in Nezara viridula Fabr. (Pentatomidae - Heteroptera, Insecta). Zool. Anz. 183: 119-139.

RamamurTy P.S. \& MeDHI W.P. 1970: The internal reproductive organs of Cydnus indicus Westw. A histological study (Cydnidae, Heteroptera, Insecta). La Cellule 68: 97-106.

RIEGER C. 1997: Ergänzungen zur Faunistik und Systematik einiger Wanzen in Baden-Württemberg (Insecta, Heteroptera) II. Carolinea 55: 43-48.

Rizzotti Vlach M. 2000: Una nuova specie di Ochetostethus della Sardegna e note sulla distribuzione del genere in Italia (Heteroptera, Cydnidae). Nouv. Rev. Entomol. (N.S.) 17: 69-76.

Rolston L.H. \& McDonald F.J.D. 1979: Keys and diagnoses for the families of Western Hemisphere Pentatomoidea, subfamilies of Pentatomidae and tribes of Pentatominae (Hemiptera). J. N. Y. Entomol. Soc. 87: 189-207.

SCHAEFER C.W. 1981: The sound-producing structures of some primitive Pentatomoidea (Hemiptera: Heteroptera). J. N. Y. Entomol. Soc. 88: 230-235.

SCHAefer C.W. 1988: The food plands of some "primitive" Pentatomoidea (Hemiptera: Heteroptera). Phytophaga 2: 19-45.

Schaefer C.W. 1993a: The Pentatomomorpha (Hemiptera: Heteroptera): an annotated outline of its systematic history. Eur. J. Entomol. 90: 105-122.

SCHAEFER C.W. 1993b: Notes on the morphology and family relationships of Lestoniidae (Hemiptera: Heteroptera). Proc. Entomol. Soc. Wash. 95: 453-456.

Schaefer C.W., Dolling W.R. \& Tachikawa S. 1988: The shieldbug genus Parastrachia and its position within the Pentatomoidea (Insecta: Hemiptera). Zool. J. Linn. Soc. 93: 283-311.

Schmitz G. 1976: La faune terrestre de l'île de Sainte-Hélène. 3. Fam. Cydnidae. Ann. Mus. R. Afr. Centr. (Zool.) n ${ }^{\circ}$ 215: 353-367.

Schun R.T. \& Slater J.A. 1995: True Bugs of the World (Hemiptera: Heteroptera), Classification and Natural History. Cornell University Press, Ithaca and London, $336 \mathrm{pp}$.

SCUDDER G.G.E. 1959: The female genitalia of the Heteroptera: morphology and bearing on classification. Trans. R. Entomol. Soc. Lond. 111: 405-467.

ScudDER G.G.E. 1962: New Heterogastrinae (Hemiptera) with a key to the genera of the World. Opusc. Entomol. 27: 117-127.

SCUDDER G.G.E. 1965: Neacoryphus Scudder, a new genus of Lygaeinae (Hemiptera, Lygaeidae). Proc. Entomol. Soc. Br. Columb. 62: 34-37.

Servadei A. 1964: Il valore tassonomico delle spermateche degli Emitteri Eterotteri (fam. Pentatomidae \& Acanthosomatidae). Atti Acad. Naz. Ital. Entomol. 11: 58-86.

Slater J.A. 1950: An investigation of the female genitalia as taxonomic characters in the Miridae (Hemiptera). Iowa State Coll. J. Sci. 25: 1-81.

Slater J.A. \& Ashlock P.D. 1980: On the genus Camptocoris Puton with descriptions of two new species from South Africa (Hemiptera: Lygaeidae). J. Entomol. Soc. Sth Afr. 43: 53-63.

Slater J.A. \& CARAYON J. 1963: Ethiopian Lygaeidae IV: a new predatory Lygaeid from Africa with a discussion of its biology and morphology (Hemiptera: Heteroptera). Proc. $R$. Entomol. Soc. Lond. (A) 38: 1-11.

Slater J.A. \& Sweet M.E. 1977: The genus Plinthisus Stephens in the australian Region (Hemiptera, Lygaeidae). Entomol. Scand. 8: 109-154.

StehLí J.L. 1965a: Mission zoologique de l'I.R.S.A.C. en Afrique orientale (P. Basilewsky - N. Leleup, 1957). Pyrrhocoridae (Het.). Acta Mus. Morav. 50: 211-252. 
Stehlík J.L. 1965b: Pyrrhocoridae and Largidae collected by E.S. Brown on Solomon Islands (Heteroptera). Acta Mus. Morav. 50: 253-292.

ŠTYS P. 1962: Morphology of the abdomen and female ectodermal genitalia of the trichophorous Heteroptera and bearing on their classification. Trans. 11th Int. Congr. Entomol Vienna 1[1961]: 37-43.

ŠTYS P. 1964: Thaumastellidae - a new family of Pentatomoid Heteroptera. Acta Soc. Entomol. Cechoslov. 61: 238-253.

ŠTYS P. 1966: Morphology of the wings, abdomen and genitalia of Phaenacantha australiae Kirk. (Heteroptera, Colobatristidae) and notes on the phylogeny of the family. Acta Entomol. Bohemoslov. 63: 266-280.
ŠTYs P. \& DAVidovÁ J. 1979: Taxonomy of Thyreocoris (Heteroptera, Thyreocoridae). Annot. Zool. Bot. 134: 1-40.

Sweet M.H. \& Schaefer C.W. 2002: Parastrachiinae (Hemiptera: Cydnidae) raised to family level. Ann. Entomol. Soc. Am. 95: $441-448$.

VAVRINOVÁ I. 1988: Spermathecae of Central European species of the families Rhopalidae, Alydidae and Coreidae (Heteroptera: Coreoidea). Cas. Morav. Mus. Brne 73: 203-215.

WAGNER E. 1963: Untersuchungen über den taxonomischen Wert des Baues der Genitalien bei den Cydnidae (Hem. Het.). Acta Entomol. Mus. Nat. Pragae 35: 73-115.

Received December 14, 2006; revised and accepted December 12, 2007 